\title{
Die Wirkung von NTA auf das Wachstum des Phytoplanktons unter besonderer Berücksichtigung des Eisens als Mikroelement
}

\author{
Von HANSRUDOLF BÜRGI \\ Eidg. Technische Hochschule Zürich \\ Institut für Gewässerschutz und Wassertechnologie ${ }^{1}$
}

Manuskript eingegangen am 15. April 1974

\begin{abstract}
The Effects of NTA on the Growth of Phytoplankton with Particular Consideration Given to Iron as a Microelement
\end{abstract}

While NTA or iron may stimulate phytoplankton photosynthesis on a short-term basis in the mesotrophic Lake of Lucerne, they impede this process in the eutrophic Greifensee. After a few days, however, this reaction tapers off. It is therefore highly unlikely that iron enters into play as a growth-limiting factor; the iron which inevitably gets into lakes through wastewater treatment plant effluents as a result of tertiary treatment (precipitation with $\mathrm{Fe}^{3+}$ ) will not have a long-term stimulating effect on plankton production. Both iron - through adsorption - and NTA through chelation - reduce the supply of free ions of various metals, especially copper. Since, on the one hand, these free ions are needed for plankton growth and, on the other, have a toxic effect even in small quantities $(\mu \mathrm{g} / \mathrm{l})$, the medium can, through addition of iron or NTA, be disintoxicated or the trace metals limited, with corresponding increase or curtailment of algal production. The different patterns for the two lakes examined can be explained by the influence of the natural organic materials, found in each particular lake, on the free ions.

\section{INHAITSVERZEICHNIS}

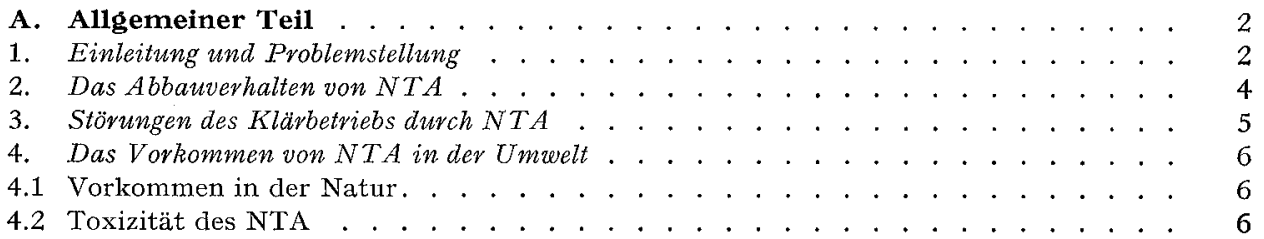

1) Die Arbeit wurde an der Eidg. Anstalt für Wasserversorgung, Abwasserreinigung und Gewässerschutz (EAWAG), Dübendorf, ausgeführt. 
4.3 Die Wirkung des NTA in natürlichen Gewässern . . . . . . . . . . . . . . . . 7

5. Die biologische Wirkung anderer (künstlicher und natürlicher) Komplexbildner. . . . . . 7

6. Die Rolle des Eisens und andever Spurenmetalle in natürichen Gewässern (Vorkommen, Lösungsbedingungen, Eisenkreislauf im eutrophen See, physiologische Wirkung und Toxizität).

B. Material und Methoden . . . . . . . . . . . . . . . . . . . . . . . . . . 12

1. Probestellen .......................... 12

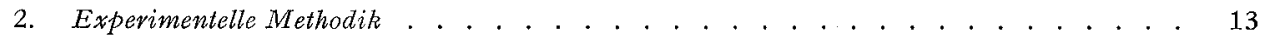

3. Analytische Methoden zur Wasseruntersuchung . . . . . . . . . . . . . . . . . . 15

4. Sedimentanalyse. . . . . . . . . . . . . . . . . . . . . . . 16

5. Biologische Methoden. . . . . . . . . . . . . . . . . . . . . . . . . . . . . 16

G. Experimente und Resultate . . . . . . . . . . . . . . . . . . . . . . . . 17

1.Versuchsdisposition . . . . . . . . . . . . . . . . . . . . . . . 17

2. Resultate Vierwaldstättersee . . . . . . . . . . . . . . . . . . . . . . . . . . 17

2.1 Physikalische Daten . . . . . . . . . . . . . . . . . . . . . . . . . . . . . 19

2.2 Chemische Daten . . . . . . . . . . . . . . . . . . . . . . . . . . . . . . 20

2.3 Sedimentuntersuchung. . . . . . . . . . . . . . . . . . . . . . . . . . . . 21

2.4 Biologische Daten . . . . . . . . . . . . . . . . . . . . . . . . . . . . . 22

2.5 Düngexperimente (Vierwaldstättersee) . . . . . . . . . . . . . . . . . . . . . 28

2.6 Die Wirkung der einzelnen Zusätze auf die Entwicklung des gesamten Phytoplanktons 30

2.7 Die Wirkung der Zusätze auf die Entwicklung der einzelnen Phytoplanktonarten . . 32

3. Resultate Greifensee . . . . . . . . . . . . . . . . . . . . . . . . . . . . . 34

3.1 Physikalische Daten . . . . . . . . . . . . . . . . . . . . . . . . . . . . . . . . . 34

3.2 Chemische Daten . . . . . . . . . . . . . . . . . . . . . . . . . . . . . . 36

3.3 Eisenkreislauf im Greifensee (Stelle "Profil») . . . . . . . . . . . . . . . . . . 37

3.4 Sedimentuntersuchung. . . . . . . . . . . . . . . . . . . . . . . . . . . . 39

3.5 Biologische Daten . . . . . . . . . . . . . . . . . . . . . . . . . . . . . . 40

3.6 Düngexperimente (Greifensee) . . . . . . . . . . . . . . . . . . . . . . . . . 46

3.7 Dic Wirkung der Zusätze auf die Entwicklung der einzelnen Phytoplanktonarten . . 54

D. Diskussion . . . . . . . . . . . . . . . . . . . . . . . . . . . 54

1. Methodik. . . . . . . . . . . . . . . . . . . . . . 54

1.1 Versuchseinrichtung . . . . . . . . . . . . . . . . . . . . 54

1.2 NTA-Analytik . . . . . . . . . . . . . . . . . . . . . . . 56

2. Resultate und Experimente . . . . . . . . . . . . . . . . . . . . . . 57

3. Schlussfolgerungen....................... . . . 60

E. Zusammenfassung . . . . . . . . . . . . . . . . . . . . . . . . . . 61

Litcraturverzeichnis . . . . . . . . . . . . . . . . . . 64

\section{A. Allgemeiner Teil}

\section{Einleitung und Problemstellung}

Der vermehrte Gebrauch von phosphorhaltigen Substanzen hat in den letzten Jahrzehnten die Phosphatbelastung der Binnengewässer Europas wesentlich erhöht. Wie in zahlreichen Anreicherungsexperimenten und anderen Untersuchungen nachgewiesen wurde, ist in vielen Seen Phosphor der wachstumsbegrenzende Nährstoff für das Phytoplankton [4, 40-42, 71, 73, 141, 145]. Die grosse Phosphatlast in den 
Abwässern gilt deshalb als Hauptursache für die (beschleunigte) Eutrophierung der Gewässer.

Da 35-65\% des Abwasserphosphats aus Detergentien stammen [97], sind schon einige Versuche unternommen worden, die kondensierten Phosphate durch andere Stoffe zu ersetzen. Neben der relativ teuren Zitronensäure bietet sich NTA (Nitrilotriacetat) als phosphatfreier Ersatzstoff in den Waschmitteln an.

$$
\begin{gathered}
\mathrm{CH}_{2}-\mathrm{COONa} \\
\mathrm{N}-\mathrm{CH}_{2}-\mathrm{COONa} \\
\mathrm{CH}_{2}-\mathrm{COONa}
\end{gathered}
$$

Viele Nationen, darunter die USA und Kanada, erachten es als notwendig, die Phosphatgehalte der Waschmittel zu reduzieren, um vor allem eine schnellwirksame Reduktion der Phosphattrophierung zu erreichen. Schweden hat in Verträgen mit der Waschmittelindustrie den gewichtsmässigen Anteil der Waschmittelphosplate auf $7,5 \%$ gesenkt, Kanada reglementiert den Phosphatgehalt gesetzlich auf 2,2\%. In den USA besteht zurzeit (1974) noch kein nationales Gesetz, einzig 5 Staaten und 47 Gemeinden reglementieren den Phosphatanteil der Waschmittel. U̇ber die Verwendung von Ersatzprodukten existieren in keinem Land Vorschriften. Alle phosphatfreien Produkte, die weniger schädlich sind als Phosphor, sind erlaubt.

Waschmittel auf NTA-Basis werden schon seit 1968 verkauft. In Schweden repräsentieren sie 15-20\% des Marktes. In den andern europäischen Ländern sind sie bedeutungslos. In Kanada enthalten $49 \%$ aller Waschmittelprodukte NTA (gewichtsmässig entspricht das etwa $8 \%$ der verkauften Wasch-, Spül- und Reinigungsmittel). Die Regierungen Schwedens und der USA fördern den NTA-Verkauf nicht. In einem Government-Report wurde 1971 vor einem vermehrten Ersatz der Waschmittelphosphate durch NTA gewarnt [50]. Anlass zu diesem Report gaben Experimente mit Mäusen und Ratten, bei denen die Injektion hoher Dosen NTA zusammen mit Kadmium und Quecksilber zu Geburtsschäden führte. Obwohl im Report festgehalten wird, dass keine Beweise bestehen, wonach die bisherige Verwendung von NTA zu irgendwelchen biologischen Schäden geführt habe, ist in den USA das NTA als möglicher Ersatzstoff für die synthetischen Phosphate zumindest vorläufig vom Markt verdrängt.

Aus waschtechnischen Gründen zieht die Waschmittelindustrie das Pentanatrium-triphosphat dem NTA vor. Als Sequestriermittel und als Komplexbildner ist es dem NTA überlegen: Einerseits kann NTA eine Kalkausfällung beim Waschprozess nicht völlig verhindern, anderseits ist NTA ein zu starker Komplexbildner. Durch seine Fähigkeit, Metalle zu chelieren, soll NTA die Korrosion der Waschmaschinen begünstigen. Es kann auch Gewebe entfärben, die mit Metallkomplexfarben imprägniert sind [12].

Aus der Sicht des Gewässerschutzes könnte NTA ein befriedigender Ersatz für die Phosphate sein, denn NTA ist, im Gegensatz zum Phosphor, kein primärer Nährstoff des Phytoplanktons. Sein Abbauverhalten ist bekannt (siehe Kapitel 2). Hingegen ist noch nicht abgeklärt, inwiefern NTA als Komplexbildner aktiv in den Stoffhaushalt eines Sees einzugreifen vermag. Das Phytoplankton ist auf ein Minimum an Spurenelementen angewiesen. Ob die Algen indessen Metallionen oder ihre 
Komplexe vorziehen, ist nur zum Teil bekannt. Jedenfalls könnte NTA die Löslichkeitsgleichgewichte der im Wasser befindlichen Metalle entscheidend verändern und dadurch nach dem Liebigschen Minimumskonzept im Sinne von MitscherLich [87] das Pflanzenwachstum in jenen Fällen beeinflussen, wo ein Spurenelement wachstumsbegrenzend oder -kontrollierend wirkt. Dies könnte z.B. im Falle des Eisens zutreffen. Dieses Metall ist in sauerstoffreichen, karbonathaltigen Gewässern nur in der Grössenordnung von $0,1 \mu g 1^{-1}$ echt gelöst [124]. Ein vermehrter Eiseneintrag ins Seewasser als Folge der NTA-Verwendung oder als Folge der Phosphatfällung durch Eisensalze in Kläranlagen könnte die Produktionsbiologie des Planktons wesentlich verändern. NTA ist durchaus nicht der einzige Komplexbildner, der die kondensierten Phosphate ersetzen könnte. Ungeachtet dessen, ob sich NTA in den Waschmitteln als Ersatzstoff durchsetzen wird oder nicht, sind die Resultate der vorliegenden Arbeit - unter Berücksichtigung der betreffenden chemischen Affinitäten - auch für andere Ersatzprodukte interpretierbar.

Das Ziel dieser Arbeit ist es, die Wirkung von NTA- und Eisenzugaben auf die Phytoplankton-Biomasse unter möglichst natürlichen Bedingungen zu erfassen. Sie soll damit Aufschluss geben, ob geplante Abwassersanierungsmassnahmen, wie etwa die Einführung der dritten Reinigungsstufe in allen Kläranlagen im Einzugsgebiet der Seen, eventuell negative Folgen haben könnten.

\section{Das Abbauverhalten von NTA}

Die schweizerische «Verordnung über die Abbaubarkeit von Wasch-, Spül- und Reinigungsmitteln» vom 19.Juni 1972 sieht vor, dass organische Bestandteile biologisch abbaubar sein müssen [117]. Publikationen zahlreicher Laboratorien stimmen überein, dass NTA bei den im Abwasser zu erwartenden Konzentrationen (kleiner als $50 \mathrm{mg}^{-1}$ ) aerob abgebaut wird [15, 17, 62, 75, 100, 107, 122, 137, 142]. Die Abbauprodukte sind $\mathrm{CO}_{2}, \mathrm{H}_{2} \mathrm{O}$ und $\mathrm{NH}_{3}$ oder $\mathrm{NO}_{3}$. Eine gute Belüftung begünstigt den Abbau, denn die vollständige Mineralisierung verlangt pro $1000 \mathrm{mg}$ NTA $1090 \mathrm{mg}$ $\mathrm{O}_{2}$ bzw. $753 \mathrm{mg}$, wenn die Nitrifizierung nur bis zur Ammoniumstufe geht [64]. Unter total anaeroben Verhältnissen findet auch über längere Zeit hinweg kein Abbau statt [55]. Allerdings gestattet $\mathrm{NO}_{3}$ als Elektronenakzeptor gewissen Bakterien auch ohne gelösten Sauerstoff eine Verwertung des NTA als C-Quelle [32]. Die enzymatische Zersetzung beginnt erst nach einer 1- bis 2wöchigen Adaptationszeit. Die Wirkung der mechanischen Reinigungsstufe ist vernachlässigbar, denn die Adsorption des NTA an Schlammflocken, wie sie von Bouveng et al. [15] beschrieben wurde, konnte von Shumate at al. [122] und GudERnatsch [52] nicht bestätigt werden. Die Bedingungen für einen weitgehend vollständigen Abbau lassen sich - als Ergebnis verschiedener Abbautests - in folgender Weise formulieren:

Eine Belebtschlammanlage mit einer adaptierten Mikroorganismen-Population ist in der Lage, innerhalb von 3 Stunden Verweilzeit etwa $10 \mathrm{mg}$ NTA/1 zu 90\% und mehr abzubauen, vorausgesetzt, dass Sauerstoff- und Temperaturverhältnisse optimal sind und die Anlage nicht durch organische Stoffe überlastet ist (Konkurrenzreaktionen) $[28,64,107,122,137,142]$. Bei fluktuierendem NTA-Zufluss sinkt die Abbaurate zeitweise unter $80 \%$ [122].

Beim Tropfkörpersystem erscheinen bei einer Anfangskonzentration von 4 bis 20 mg NTA/l rund $10 \%$ als Restgehalt im Abfluss [17, 62]. 
In Seen und Flïssen geht der enzymatische Abbau weiter, aber die Bedingungen für einen vollständigen Abbau (genügend Sauerstoff und Temperaturen über $10^{\circ} \mathrm{C}$ ) sind nicht überall gewährleistet $[28,37,55,122,142]$. Der Abbau anderer organischer Verbindungen wird durch NTA nicht gestört. Selbst hohe Dosen von NTA 250 bis $500 \mathrm{mg} / \mathrm{l}$ ) wirkten auf Bakterien der Gattung Pseudomonas, Algen der Gattung Scenedesmus bzw. Chlorella sowie Protozoen der Gattung Colpoda nicht toxisch, so dass die Selbstreinigung der Gewässer bei den zu erwartenden NTA-Konzentrationen nicht beeinträchtigt wird $[20,102]$. Es scheint, dass die Kapazität des NTA-Abbaus durch Reaktionen innerhalb der Zellmembran bestimmt wird [122]. Innerhalb gewisser Grenzen verläuft der Abbau zeitlich linear im Sinne einer Reaktion 0. Ordnung [142].

\section{Störungen des Klärbetriebs durch NTA}

In absehbarer Zeit dürte die bis anhin empfohlene dritte Reinigungsstufe in den Kläranlagen im Einzugsgebiet der Schweizer Seen gesetzlich verankert werden, d.h. simultan oder succedan mit der biologischen Stufe muss eine Phosphatelimination durchgeführt werden [30].

Als Fällungsmittel dienen heute vor allem $\mathrm{Fe}^{3+-}$ Chlorid und Aluminiumsulfat. Die Phosphatfällung wäre auch nach einem endgültigen Ersatz der Waschmittelphosphate durch NTA notwendig, denn die Elimination der Waschmittelphosphate stellt keine Alternative zur dritten Reinigungsstufe dar. Beide Massnahmen ergänzen sich:

- Mit dem Ersatz der Polyphosphate in den Waschmitteln wird die Phosphatlast überall verringert, allerdings nur um den Betrag, den die Waschmittelphosphate heute ausmachen.

- Mit der dritten Reinigungsstufe kann zwar eine 90prozentige Elimination des Gesamtphosphors im Abwasser erreicht werden, aber der Ausbau der Gewässerschutzanlagen benötigt Zeit. Als erwünschter Nebeneffekt der dritten Reinigungsstufe hat sich die adsorptive Mitfällung von Schwermetallen und organischen Stoffen erwiesen.

Das NTA kann durch Chelierung der Abwasserschwermetalle und der Fällungsmittel den Klärbetrieb beeinflussen. Die Wirkung ist aber nur dann spürbar (Fällung von $\mathrm{Cu}$ und teilweise von $\mathrm{Pb}$ gehemmt), wenn keine an NTA adaptierte Bakterienflora vorhanden ist [93]. DUTHIE konnte zeigen, dass NTA auch dann abgebaut wird, wenn es als Komplex mit $\mathrm{Ca}, \mathrm{Cd}, \mathrm{Co}, \mathrm{Hg}, \mathrm{Mn}, \mathrm{Ni}, \mathrm{Pb}$ und $\mathrm{Zn}$ einer adaptierten Belebtschlammanlage zugeführt wird [26]. Gudernatsch und CHaU hingegen finden den Abbau der $\mathrm{Cu}$ - und Ni-Komplexe gehemmt [19, 52], während übereinstimmend mit Swisher et al. [137] der Fe-NTA-Komplex vollständig abgebaut wird. Um eine Verschleppung von $\mathrm{Ni}$ und $\mathrm{Cu}$ in natürliche Gewässer zu vermeiden, müsste daher ihre einwandfreie Abscheidung am Entstehungsort mit der Einführung des NTA parallelgehen.

Die Phosphatfällung wird durch realistische Mengen NTA (1-10 mg/l) bei der Verwendung von Aluminiumsulfat nur gering gestört [15]. Grössere Wirkung zeigt das NTA bei der Phosphatfällung mit Eisensalzen. Um in einer Anlage mit $25 \mathrm{mg}$ NTA/l im Zufluss von einer gleichbleibenden P-Ausgangskonzentration gleiche Restphosphatlast zu erreichen, braucht GUDERNATSCH [52] 30-50\% mehr Fällungs- 
mittel. Da die Ausgangskonzentration nach erfolgtem Ersatz der Waschmittelphosphate durch NTA wesentlich geringer wäre und die Versuchsanlage Gudernatschs nicht den Klärverfahren schweizerischer Abwasserreinigungsanlagen entspricht, müssen diese Zahlen aber mit Vorsicht interpretiert werden, besonders wenn man den von Gudernatsch selbst beobachteten völligen Abbau des Fe-NTA-Komplexes in Betracht zieht.

\section{Das Vorkommen von NTA in der Umrelt}

\subsection{Vorkommen in der Natur}

Nach einem vollständigen Ersatz der Waschmittelphosphate durch NTA müssten rund 3000 4000 t NTA pro Jahr abgebaut werden. Beim heutigen Stand der Gewässerschutzmassnahmen in der Schweiz werden im Landesdurchschnitt etwa $45 \%$ der Siedlungsabwässer in Kläranlagen gereinigt [29]. Da der NTA-Abbau in einer gut gewarteten zweistufigen Kläranlage etwa $90 \%$ beträgt, würden jährlich rund 1600 bis 2200 t NTA bleiben, die in Vorflutern, Faulgruben, häuslichen Kleinklärgruben usw. abgebaut werden müssten. Da die Voraussetzungen für einen vollständigen Abbau nicht immer gewährleistet sind, könnten sich, örtlich und zeitlich begrenzt, grössere Mengen NTA akkumulieren [25]. Stabilere $\mathrm{Cu-} \mathrm{und} \mathrm{Ni-Komplexe} \mathrm{des} \mathrm{NTA} \mathrm{könnten}$ sich auch im sauerstoffhaltigen Seewasser längere Zeit akkumulieren [33]. Bei Kontakt mit Sediment kann das NTA Schwermetalle lösen [51, 123]. Mit mathematischen Modellen kann errechnet werden, dass schon $0,1 \mathrm{mg}$ NTA/1 zu deutlichen Rücklösungen von Kupfer aus dem Sediment führen muss [88]. In - allerdings meteorologisch gestörten - Feldexperimenten erhielten $\mathrm{CHAU}$ et al. erhöhte Eisenund Zinkwerte und weniger deutlich auch erhöhte $\mathrm{Ni}$ - und $\mathrm{Cu}-\mathrm{Konzentrationen} \mathrm{durch}$ Rücklösung aus dem Sediment, wenn 0,5-10 mg/l NTA zugefügt wurden [19].

Wenn man zur Trinkwasserversorgung auf NTA-führendes Wasser angewiesen ist, muss es entsprechend aufbereitet werden; Aktivkohlefilter beispielsweise lassen NTA passieren. Von 279 analysierten Trinkwasserproben in den USA enthielten freilich bloss 6 Proben messbare (25 $125 \mu \mathrm{g} / \mathrm{l})$ NTA-Konzentrationen [5]. In Kanada enthielten von 50 Proben nur 4 einen NTA-Gehalt über $25 \mu \mathrm{g} / 1$, die höchste Konzentration lag in dieser Meßserie bei $55 \mu \mathrm{g} / \mathrm{l}$. Da die Analysen im Winter gemacht wurden, stellen die Zahlen Maximalwerte dar, weil tiefe Temperaturen den NTA-Abbau verlangsamen [75].

\subsection{Toxizität des NTA}

Akute Toxizität: Die akute Toxizität des NTA ist niedrig. Viele Invertebraten und eine Reihe von Fischen, Amphibien und Säugern, aber auch Algen und Pilze wurden getestet. Die Konzentration, bei der 50\% der Organismen überleben, liegt durchwegs zwischens $100 \mathrm{mg} / \mathrm{l}$ und mehr als $10 \mathrm{~g} / \mathrm{l}$ bei aquatischen Organismen bzw. 1000-2000 mg/kg Körpergewicht für Rhesusaffen und $5000 \mathrm{mg} / \mathrm{kg}$ beim Hund, wenn das NTA oral verabreicht wird $[5,31,65,75,102,140]$. Todesursache war bei vielen Tieren der veränderte $\mathrm{pH}-$ Wert, nicht das NTA an sich $[39,75]$.

Chronische Toxizität: Die chronische Toxizität beginnt bei bedeutend tieferen NTA-Konzentrationen, aber immer noch über 300 ppm in der Nahrung bzw. $20 \mathrm{mg} / \mathrm{l}$ Trinkwasser [75]. EPSTEIN befürchtete, dass NTA durch seine Abbauprodukte (sekundäre Amine) stark karzinogene Nitrosoverbindungen bilden könnte und damit 
chronisch toxisch würde [33]. Experimentell konnten WARREN und MALEC nachweisen, dass die Zwischenprodukte des NTA-Abbaus ihrerseits zufriedenstellend abgebaut werden und nicht akkumulieren [147]. Die Abbaustudien wurden mit Flusswasser aus dem Detroit River und Meramec River betrieben. Leider fehlen Langzeitexperimente über die chronische Toxizität [140].

Toxizität der Metallchelate des NTA: Die Schwermetalle, die stabile Komplexe mit NTA bilden, sind in der Ionenform bedeutend giftiger als im chelierten Zustand $[31,75,127]$. Subkutan injiziertes NTA steigert bei Ratten die Toxizität von gleichzeitig eingespritzten Schwermetallionen; oral verabreicht haben diese Schwermetalle $(\mathrm{Cd}, \mathrm{Hg})$ hingegen mit und ohne zusätzlicher oraler Aufnahme von NTA schwächere oder gleiche Wirkung $[75,112]$. Für die menschliche Sicherheit sind aber nur letztere Ergebnisse von Bedeutung. Studien mit ${ }^{14} \mathrm{C}$-markiertem NTA an Ratten zeigten, dass weniger als 1\% des zugefügten NTA im Körper abgebaut wurde und als markiertes $\mathrm{CO}_{2}$ in Erscheinung trat, der Rest wurde quantitativ mit Urin und Exkrementen ausgeschieden [85].

\subsection{Die Wirkung des NTA in natürlichen Gewässern}

Die zahlreich durchgeführten Toxizitätstests weisen auf das zentrale, durch die erwähnte Publizität in Nordamerika allerdings künstlich hochgespielte NTAProblem hin: Die Sicherheit des Menschen [5]. Bis heute blieben aber die ökologischen Aspekte einer Zufuhr von NTA (oder anderen Fremdstoffen) in natürliche Gewässer stark vernachlässigt. Zwar wurden einige Arbeiten publiziert, in denen In-vitroDüngexperimente mit Algenkulturen beschrieben wurden, wobei auch häufig See- oder Meerwasser als Kulturlösung verwendet wurde; aber auch hier wurden neben kinetischen Kriterien gerade die ökologischen Wechselwirkungen eines natürlichen Biotops unberücksichtigt gelassen $[20,34,38,91,109]$. Die Resultate vieler Autoren widersprechen sich, sowohl Hemmung als auch Förderung des Algenwachstums wird beobachtet. In Küstengebieten kann NTA durch seine Abbauprodukte eutrophierend wirken, weil hier oft Stickstoff wachstumslimitierend ist [34].

\section{Die biologische Wirkung andever (künstlicher und natürlicher) Komplexbildner}

Künstliche Komplexbildner: Während die endgültige Einführung von NTA in Waschmitteln noch im ungewissen bleibt, verwendet man schon seit vielen Jahren ÄDTA (Äthylendiamin-tetraacetat) als Stabilisator in (allerdings geringen) Mengen von 1 bis 2\% in den Waschmitteln. ÄDTA hat dort im weiteren die Aufgabe, durch Komplexbildung Metalle im Schmutz herauszulösen. ÄDTA hat vergleichbare Eigenschaften wie NTA; so kann es in höheren Konzentrationen Metalle aus dem Seesediment lösen und ihre Anionen freisetzen. Der Abbau des ÄDTA verläuft schnell, und es unterliegt zudem einem Photozerfall [131], daher wird kaum je in der Natur eine Akkumulierung dieses Komplexbildners auftreten. In Experimenten mit Algen und anderen Pflanzen bewirkt ÄDTA eine deutliche Stimulierung des Wachstums; es scheint für die Kultur gewisser Algenarten geradezu unentbehrlich [68, 69, 109, 148]. Der wachstumsfördernde Effekt kann durch zwei Hypothesen erklärt werden:

1. Spurenmetalle (z.B. Eisen) werden in einen Zustand gebracht, in dem sie von der Algenzelle besser verwertet werden.

2. ÄDTA entgiftet das Milieu der Algenkulturen durch Herabsetzen des Angebots 
an freien Ionen von $\mathrm{Cu}$ und anderen Metallen; schon die aus Salzen und dest. Wasser hergestellten Nährlösungen enthalten genügend $\mathrm{Cu}$, um für einzelne Algen giftig zu wirken. STumm nennt in einem Referat NTA und ÄDTA «quacksalberische Heilmittel», weil sie sowohl für die Herabsetzung des Angebots an Metallen - mit resultierender Toxizitätsverminderung - als auch zur Erhöhung des Angebots an Metallen empfohlen werden. Beide Auffassungen wurden experimentell belegt $[22,67,89,129]$. Ein Rechnungsmodell zeigt, dass in der Natur $10^{-5} M$ ÄDTA das Eisen $\left(10^{-6} \mathrm{M}\right)$ nicht am Ausfallen als $\mathrm{Fe}(\mathrm{OH})_{3}$ hindern kann, wenn $\mathrm{Ca}^{2+}$ mit einer Konzentration von $10^{-3} M$, entsprechend etwa den natürlich vorkommenden Mengen, bei einem $\mathrm{pH}$ von 7 bis 8 vorliegt [134]. Die Hypothese 1 ist damit in der Natur nur bedingt anwendbar; möglicherweise stabilisiert ÄDTA eine Kolloiddispersion mit Teilchengrössen unter $100 \AA$ Durchmesser, aber es cheliert Eisen nur zu einem geringen Teil.

Verschiedene Komplexbildner zeigen eine unterschiedliche Wirkungsweise. BARBER et al. konnte mit ÄDTA das Algenwachstum steigern, während er mit Glycin und Nocardamin, einem Komplexbildner, der dank seiner sterischen Struktur spezifisch $\mathrm{Fe}^{3+}$ cheliert, die Photosynthese verringerte (zit. in STumm [134]).

Natürliche Komplexbildner: Organische Stoffe natürlicher Gewässer setzen sich in erster Linie aus exkretierten Stoffwechselprodukten der Algen zusammen: Aminosäuren, Fettsäuren, Kohlehydraten, Toxinen u.a. [36, 45, 78, 94]. Je nach Art des Einzugsgebiets des Gewässers kommen ferner auch mehr oder weniger Fulvinsäuren und Huminsäuren vor. SHAPIRO nennt diese organischen Stoffe zusammenfassend «gelbe Säuren» [121]. Viele der zuerst genannten Verbindungen kommen dissoziiert im Gewässer vor. Wieweit die organischen Stoffe in der Lage sind, Kationen zu chelieren, ist nur zum Teil bekannt [27, 66]. Ebenso ist ungewiss, ob einzelne Kationen durch spezifische Affinitäten bevorzugt werden. Die Vielzahl möglicher organischer Verbindungen lässt eher den Schluss zu, dass die Konzentration der Kationen eine wichtigere Rolle spielt als die Affinitäten. Die Konzentration der organischen Stoffe variiert nach OHLE von 0,1 in oligotrophen bis $3 \mathrm{mg} / \mathrm{l}$ in eutrophen Seen [95]. Im Greifensee, einem hocheutrophen Gewässer, konnten im Sommer 1971 zwischen 5 und $6 \mathrm{mg} / \mathrm{l}$ totaler organischer C (TOC) im filtrierten Wasser gemessen werden. Die biologische Wirkung der organischen Stoffe ist vergleichbar mit der Wirkungsweise künstlicher Komplexbildner. Eine Beobachtung von BARBER und RYTHER veranschaulicht das: Wenn bei der Zirkulation vor Peru marines, nährstoffund spurenmetallreiches Tiefenwasser aufsteigt, läuft die Planktonproduktion zunächst langsam an und wird erst beschleunigt mit der Ausscheidung von organischen Exkretionsprodukten oder durch Zugabe von ÄDTA [8].

Einige Algen sind fähig, organische Stoffe direkt im Zellstoffwechsel auszunützen und sich davon teilweise zu ernähren $[35,36,45,103]$, dadurch können Produltionssteigerungen zustande kommen.

6. Die Rolle des Eisens und anderer Spurenmetalle in natürlichen Gewässern (Vorkommen, Lösungsbedingungen, Eisenkreislauf im eutrophen See, physiologische Wirkung und Toxizität)

Trotz riesigen Vorkommen auf der Erde findet man im Wasser des Ozeans und der meisten Seen nur Spuren von Eisen [59]. Auch in einem hocheutrophen See enthält sauerstoffhaltiges, karbonatreiches Wasser kaum mehr als $0,1 \mathrm{mg} / \mathrm{Fe}$. 
Davon ist wiederum nur ein geringer, variierender Teil membranfiltrierbar. Von der Gesamteisenkonzentration des Filtrats ist schliesslich nur eine Spur echt gelöst.

Viele Differenzen zwischen analytisch gemessenen Eisenwerten und den theoretischen Berechnungen (scheinbare Übersättigung) rühren nur daher, dass gewisse analytische Methoden filtrierbare, partikuläre Eisenverbindungen aufschliessen und als gelöste Ionen miterfassen. Aber auch die Löslichkeitsberechnung kann zu Fehlern führen, wenn die zwei- und dreiwertigen Eisenhydroxokomplexe vernachlässigt werden (Stumm und LeE [135]). Die Lösung und Fällung des Eisens im Wasser steht in engem Zusammenhang mit Reduktions- und Oxidationsprozessen.

In karbonathaltigen Gewässern stammt die lösliche Komponente fast ausschliesslich vom zweiwertigen Eisen [124]. Zweiwertiges Eisen ist in der Gegenwart von Sauerstoff unbeständig. Die Oxidation $\mathrm{zu}$ schwerlöslichem $\mathrm{Fe}(\mathrm{OH})_{3}$ vollzieht sich äusserst leicht. Aus diesem exergonischen Prozess bezieht eine ganze Organismengruppe ("Eisenbakterien») die Energie zur Chemosynthese. Um absinkendes Ferrihydroxid in sauerstofflosem Wasser wieder zu lösen, ist ein Reduktionsmittel notwendig. Reduzierende Agentien, z.B. Schwefelwasserstoff, können bei der Faulung absinkender, organischer Substanzen entstehen. Das Eisen wird nach der Reduktion entweder lösliches Eisenbikarbonat oder unlösliches Eisensulfid bilden. Das Gleichgewicht zwischen Eisenbikarbonat und Eisensulfid ist stark pH-abhängig. Je höher der $\mathrm{pH}$-Wert und die $\mathrm{H}_{2} \mathrm{~S}$-Konzentration ist, desto mehr ist das Gleichgewicht auf die Seite des Eisensulfids verschoben. Unter $\mathrm{pH} 7$ wird bei einer $\mathrm{H}_{2} \mathrm{~S}$-Konzentration von $2 \mathrm{mg} / \mathrm{l}$ praktisch nur Bikarbonat gebildet [96].

Ferrihydroxid bestimmt die Löslichkeit des dreiwertigen Eisens. Es kann als folgende Verbindungen auftreten: Amorphes $\mathrm{Fe}^{3+}-\mathrm{Hydroxid}$, Eisenoxidhydroxid und Eisenoxid. $\mathrm{Fe}^{3+}-\mathrm{Hydroxid}$ steht in der soliden Phase mit undissoziiert verteiltem, molekularem (nicht echt gelöstem) $\mathrm{Fe}(\mathrm{OH})_{3}$ im Gleichgewicht [74]. Im neutralen pH-Bereich ist die Löslichkeit nicht abhängig von der Hydroxid-Ionenkonzentration, und auch Phosphat hat keinen Einfluss auf die Löslichkeit des $\mathrm{Fe}(\mathrm{OH})_{\mathbf{3}}$, solange die Konzentration des anorganischen Phosphats $10^{-4} M / 1$ nicht übersteigt.

Dreiwertiges Eisen hat eine starke Neigung, Hydroxokomplexe zu bilden. Diese Komplexe gehen leicht Polymerisationsreaktionen ein, wobei die elektrische Ladung der entstehenden Kolloide vom pH abhängt. So entstehen im sauren Bereich positiv geladene, im alkalischen Bereich negativ geladene Partikeln [135]. Grössere Mengen negativ geladener organischer Schutzkolloide (z.B. Stärke, Proteine) können die Koagulation und damit das Ausfallen des Eisenhydroxids verhindern. Organisches Material (z.B. Huminsäuren und Ligninderivate) kommt oft gleichzeitig mit hohen Eisenkonzentrationen vor. Dieses gemeinsame Auftreten kann durch Komplexbildung verursacht sein. Eisenkomplexe sind denn auch die Ursache für die gelbe Farbe dieses Wassers [121, 134].

Der Eisenkreislauf im eutrophen See: Der Eisenkreislauf in einem oligotrophen See ist offen; der hier vorhandene Sauerstoff im Tiefenwasser verhindert eine Rücklösung des sedimentierten Eisens. Der Eisenkreislauf in einem eutrophen Gewässer ist dagegen teilweise geschlossen.

Die physiologische Wirkung des Eisens und anderer Spurenmetalle: Eisen ist Bestandteil der Cytochrom-Moleküle und des Ferredoxins und spielt damit eine zentrale Rolle im Energiestoffwechsel der Pflanzenzelle; es ist daher prinzipiell 


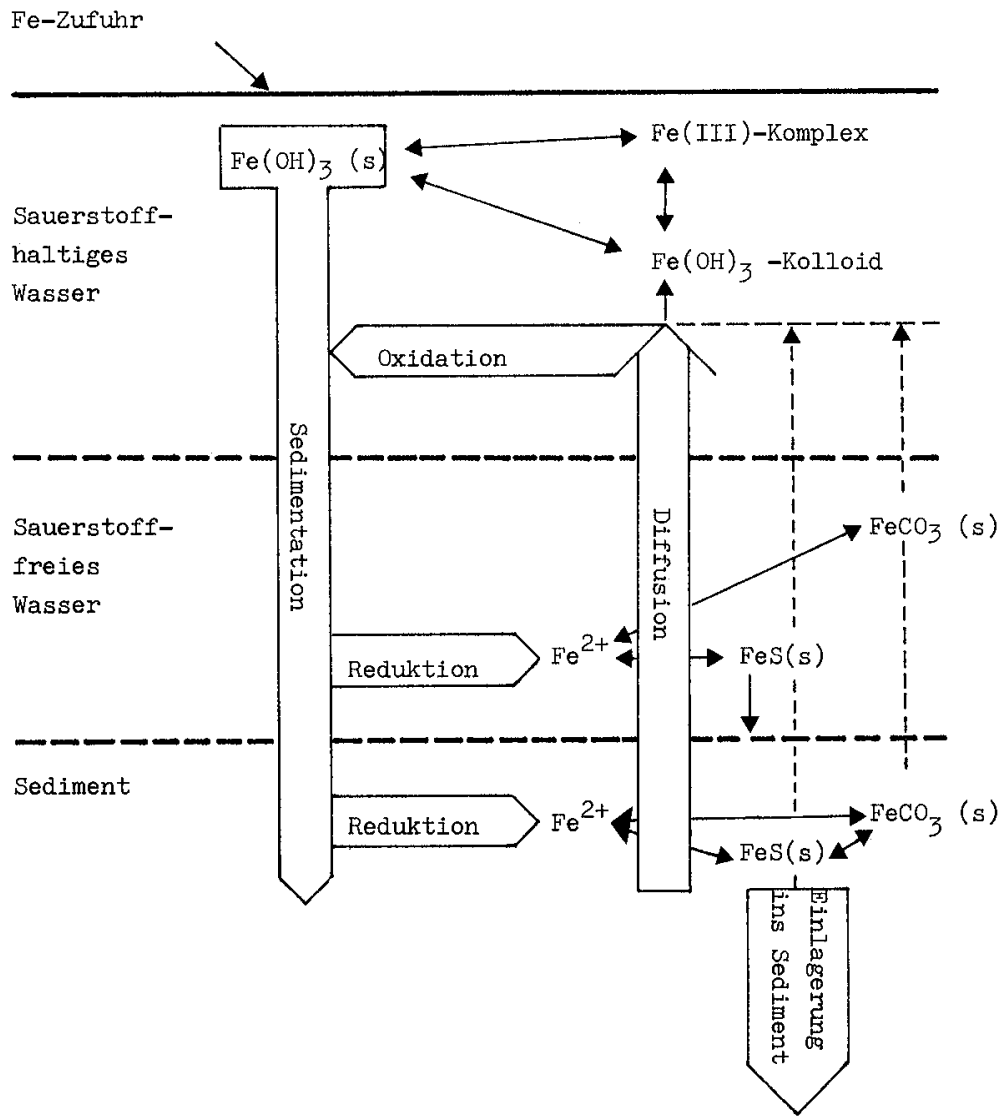

Abb. 1. Der Eisenkreislauf eines eutrophen Sees nach Sтumm [135].

Fig. 1. Iron cycle in a eutrophic lake according to Srumm [135].

denkbar, dass es - bei Mangel - das Wachstum limitieren kann. Bei höheren Pflanzen bewirkt ein Eisendefizit die Mangelkrankheit «Eisenchlorose»; die Blätter sind nicht chlorophyllgrün, sondern gelblich [86]. In vielen Nährstofftests bewirkte eine erhöhte Eisenzugabe eine Steigerung der Primärproduktion [58, 82, 119]. Wird Meerwasser als Kulturmedium verwendet, so kann die Steigerung der Photosyntheserate nach Eisenzugabe besonders deutlich verfolgt werden. In erster Linie sind es Diatomeen und Chlorophyceen, die auf ein zusätzliches Eisenangebot positiv reagieren $[6,46,83]$. $\mathrm{Da}$ im offenen Ozean neben Eisen auch Phosphor in Konzentrationen unter $10 \mu \mathrm{g} / 1$ vorliegt $[13,84]$, bringt eine Phosphatdüngung ebenso eine Steigerung der Assimilationsrate, allerdings mit einer Verzögerung von einigen Tagen gegenüber der Eisendüngung.

Wenn nun sowohl Eisen- wie Phosphatdüngung bei den gleichen Algenarten zu einer Steigerung der Photosyntheserate führt, muss gefolgert werden, dass keines der beiden Elemente das Wachstum begrenzt, oder aber, dass die Düngung des einen Stoffes (Eisen) zu besserer Resorption des andern (Phosphat) führt.

Eine mögliche Erklärung ist im Experiment von MENZEL et al. zu finden, in wel- 
chem Eisenzusätze eine unmittelbare Produktionssteigerung verursachten, während bei Phosphatzusatz die vergleichbare Wachstumszunahme um einige Tage verzögert war. Der Zusatz von Aluminium schliesslich ergab, wenn auch etwas weniger deutlich, die gleiche Reaktion wie durch Eisen. Da Aluminium kein Nährstoff ist, muss eine indirekte Wirkung angenommen werden. Eisen(III)- und Aluminium(III)Oxide und -Hydroxide sind starke Adsorbentien und wirken als Ionentauscher [21, 72]. Je nach dem pH-Wert adsorbieren sie Kationen (alkalisch) oder Anionen (sauer) [139]. Organische Stoffe können durch Dispergierung diese Austauschkapazitäten vergrössern [134].

Versuche mit Algenkulturen in geschlossenen Flaschen sind für die Erforschung der optimalen Spurenmetallkonzentration ungeeignet [16]. Die geringen Metallspuren, welche vielleicht in der Natur genügen würden, werden in den Batch-Experimenten rasch aufgebraucht oder an der Gefässwand adsorbiert [22, 131]. Mit einer vermehrten Zugabe ist es sodann noch möglich, für gewisse Spurenelemente eine scheinbar limitierende Funktion nachzuweisen. Anderseits gibt es im Plankton Spezialisten, welche P, N oder Fe speichern und monatelang in Nährlösungen wachsen, welche diese Elemente nicht enthalten $[48,106]$. Die Frage, in welchem Zustand die Spurenmetalle für den Organismus besser verfügbar sind, ob partikulär, gelöst oder cheliert, wird von verschiedenen Autoren verschieden beantwortet $[46,63,82$, 106, 131, 138]. Dank modernen Analysengeräten, mit denen geringste Mengen von Metallen quantitativ einwandfrei erfassbar sind, ist die Information über Effekte der Spurenelemente in letzter Zeit wesentlich besser geworden. GoLDMAN [48] fand in $82 \%$ von insgesamt 278 Seen Kaliforniens, Neuseelands, Afrikas und Alaskas, dass irgendein Spurenelement (mitunter auch Eisen) das Planktonwachstum begrenzte.

Die Zellinhalte der Blaualge Microcystis führen in der Natur genügend Eisen und Mangan, um maximales Wachstum zu garantieren. Die kritischen Konzentrationen wurden in ÄDTA-haltigen Medien von GERLoFF und Skoog [43] ermittelt; sie liegen für Mn bei 4 ppm und für Eisen bei $100 \mathrm{ppm}$. Nach Aussage dieser Autoren ist es unwahrscheinlich, dass eines der beiden Elemente limitierend wirkt. Das Vorherrschen von Kieselalgen im Frühling und Herbst korreliert auffällig mit dem Gehalt an Eisen (Guseva, zit. in Lund [77], Raskina [105]). Obwohl die thermische Umschichtung ebenso eine Erklärung dieses Verhaltens geben kann, wird die Dominanz der Diatomeen auf partikuläres Eisen zurückgeführt, das, als Substrat auf der Zellwand liegend, die Nährstoffe (Phosphat, Silikat?) durch Adsorption konzentriert [154]. Unter Laborbedingungen können auch die Spurenmetalle Co, $\mathrm{Zn}, \mathrm{Cu}, \mathrm{B}$ usw. in Mangelsituationen das Wachstum beeinflussen [10, 60, 151]. Der oft sehr eng begrenzte Bereich zwischen der tolerierten und der benötigten Spurenmetallkonzentration variiert von Art zu Art. In der Grössenordnung liegen die Toleranzbereiche beisammen, doch sind extreme Bedürfnisse verschiedener Organismen bekannt. Obwohl unsere Kenntnisse hier noch sehr lückenhaft sind, darf doch angenommen werden, dass bestimmte gegebene Spurenmetallkonzentrationen für einzelne Arten bereits toxisch wirken, während sie für andere Spezies gerade erst optimales Wachstum ermöglichen. Die toxische Konzentration bewegt sich oft in der Grössenordnung von einigen $\mathrm{ppb}$; dies gilt nicht nur für Kupfer und Zink, sondern auch für Mangan. Guseva [53] fand schon $0,2 \mathrm{mg} / \mathrm{l}$ Mangan, eine Konzentration, wie sie in natürlichen Gewässern sehr oft auftritt, für Blaualgen hemmend. 
Die Toxizität des Eisens: $\mathrm{Fe}^{2+}$ ist ein starkes Reduktionsmittel; während es für die Eisenorganismen die Lebensgrundlage bildet, wirkt es möglicherweise für bestimmte Algen giftig [150]. DRoop [24] fand experimentell eine fördernde Wirkung des Natriumsulfids auf die Kieselalge Skeletonema costatum und argumentierte, dass der Grund in der Verminderung der toxischen Gleichgewichtsreaktion $\mathrm{Fe}^{2+} \mathrm{zu} \mathrm{Fe}^{3+}$ liege. Die Letaldosis von Eisen liegt für Fische über $1,5 \mathrm{mg} / \mathrm{F} \mathrm{Fe}^{\mathbf{3}}$, allerdings ohne nähere Präzisierung [111]. Sporadische Abwasserwellen mit 1,4-1,7 mg/l Fe führten im Niederrhein nicht zu Fischsterben [11]. Neben der schädigenden Wirkung des $\mathrm{Fe}^{2+-I o n s}$ übt die Säurewirkung des Eisenoxidhydrats und im bewegten Wasser auch die mechanische Reibung desselben einen schädigenden Einfluss auf Organismen aus [146].

Toxizitätstests in Braunwässern, wo hohe Eisengehalte als Humate mitgeführt werden, sind nicht relevant für schweizerische Gewässer. Die einseitige Artenzusammensetzung im Vorfluter mit Braunkohlegruben-Abwasser basiert vermutlich auf dem niederen pH-Wert und nicht auf den höheren Eisenkonzentrationen, denn. nur etwa 3\% aller Algenarten sind ausgesprochen acidophil [44]. In der Schweiz sind höhere Eisenkonzentrationen nur in Seen mit anoxischem Hypolimnion zu erwarten. Diese Konzentrationen kommen aber nur während der Zirkulation mit Algen und Tieren in Kontakt. In diesem Falle kann es durch Oxidation des $\mathrm{Fe}^{2} \mathrm{zu} \mathrm{Fe} \mathrm{Fe}^{\mathbf{3}+}$ neben derjenigen von $\mathrm{H}_{2} \mathrm{~S}$ und $\mathrm{NH}_{3}$ für kurze Zeit zu einem zusätzlichen Sauerstoffschwund beitragen.

\section{B. Material und Methoden}

\section{Probestellen}

Vierwaldstättersee: Die Versuche wurden 400 m nördlich des Hydrobiologischen Labors in Kastanienbaum durchgeführt (Abb. 2). Die Tiefe beträgt an der Probenahmestelle 12-16 m. Aus Sicherheitsgründen konnte nicht weiter vom Ufer abgerückt werden (Schiffahrtslinien). Dies brachte den Nachteil mit sich, dass die chemischen Parameter mitunter von den Vergleichswerten anderer Probestellen in
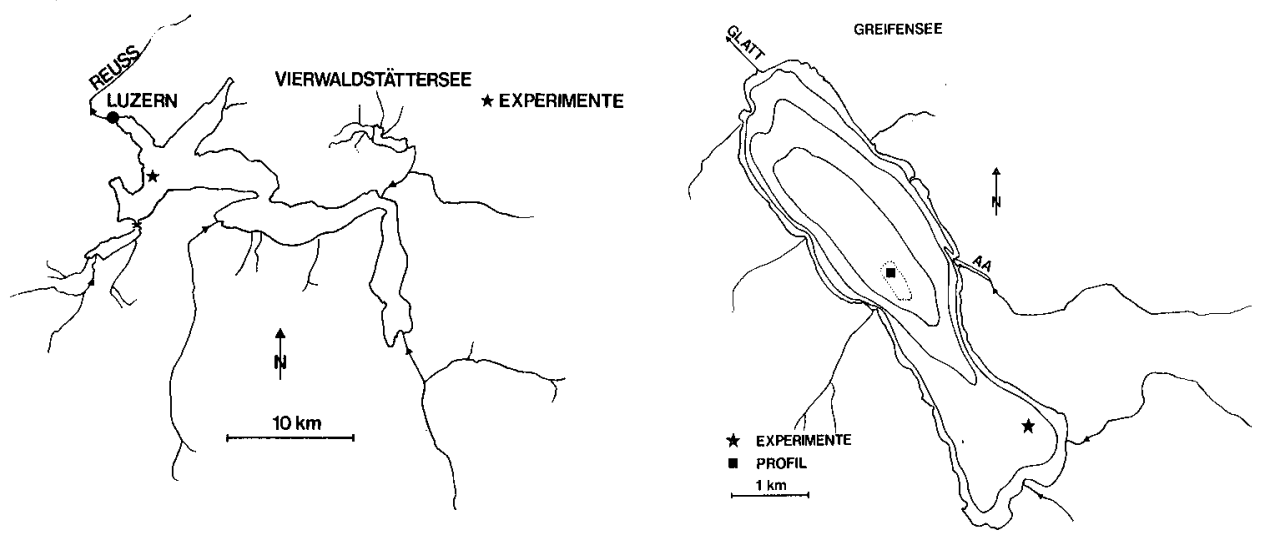

Abb. 2. Skizzen der beiden Probestellen.

Fig. 2. Sketches of the two sampling sites. 
der Seemitte abwichen. Die Artenzusammensetzung des Phytoplanktons hingegen wurde höchstens durch das gelegentliche Auftreten einzelner Tychoplankter beeinflusst.

Greifensee: Der Greifensee wurde als Beispiel eines stark eutrophen Gewässers ausgewählt. Die Probestelle lag hier im östlichen Seeteil vor Uster-Riedikon etwa $600 \mathrm{~m}$ vom Ufer entfernt. An der tiefsten Stelle des Sees (Abb. 2) wurden Vergleichsproben (Profil von 0 bis $30 \mathrm{~m}$ ) genommen. Die chemische Analyse zeigte gute Übereinstimmung beider Probestellen.

\section{Experimentelle Methodik}

Die Versuchseinrichtung bestand aus 4 Kultureinheiten, die im See in einer Linie fest verankert wurden. Jede Kultureinheit (im folgenden auch Testzelle genannt) bestand im wesentlichen aus einem transparenten Polyäthylenschlauch «Webulen» (Firma Weiss-Buob, CH-9427 Wolfhalden), von $10 \mathrm{~m}$ Länge, $1 \mathrm{~m}$ Durchmesser und $0,15 \mathrm{~mm}$ Wanddicke, und 7 Paar konzentrischen, eloxierten Aluminiumringen, die den Schlauch aufspannten und für konstantes Kulturvolumen (etwa 7000l) sorgten (Abb.3). Getragen wurde die Einrichtung durch Nylonkordeln, die auf der Aussenseite des Schlauches die Ringe über horizontal abstehende Aluminiumprofile verbanden. Die Wellenbewegung wurde durch diese Profile gedämpft, und sie übertrug sich nur
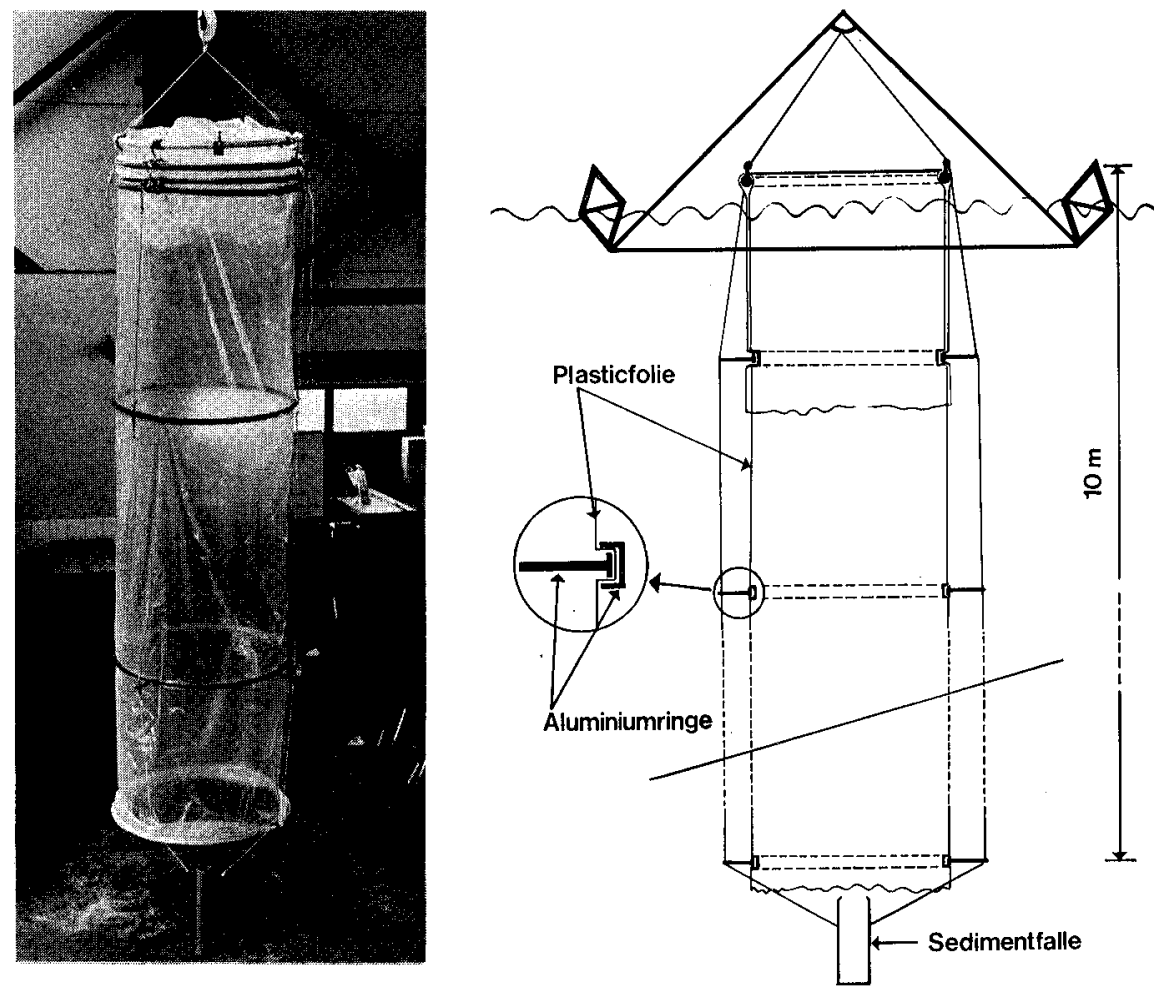

Abb. 3. Teilweise geraffte Testzcllen nach der Montage (links) und schematisch (rechts).

Fig. 3. Sampling unit partially joined together (left) and represented schematically (right). 
schwach auf die Plastikfolie. Es konnte daher selbst nach stark bewegtem See keine Beschädigung der Testzellen beobachtet werden. Das obere, offene Ende der Testzelle ragte rund $0,5 \mathrm{~m}$ über die Wasseroberfläche hinaus und war durch eine dreifache Plastikhaut geschützt.

Unter jeder Testzelle wurde eine PVC-Sedimentfalle (modifiziert nach BLOESCH [14]) angebracht. Die Montage der Testzellen erfolgte in der Versuchshalle der EAWAG unter möglichst sauberen Verhältnissen; Fussböden wurden dazu mit fabrikneuem Plastik abgedeckt. Vor dem Einhängen in den See wurde der geraffte Schlauch im Seewasser gespült. Über der Wasseroberfläche am verankerten Tetraedergestänge hängend, wurde nun Ring für Ring in den See gelassen und auf diese Weise ein geschichtetes Wasservolumen «herausgestochen». Grosser Wert wurde auf eine solide Verankerung gelegt. Total 6 Schwergewichtsanker im Gesamtgewicht von etwa $300 \mathrm{~kg}$ verhinderten auch bei starkem Wind jede Abdrift im See. Systematische Kontrollen ergaben, dass in sämtlichen Experimenten die Plastikfolien der Testzellen vollständig intakt geblieben waren. Für jedes Experiment wurden die Versuchseinrichtungen mit neuem Folienschlauch versehen. Im Innern der Kultureinheiten wurde eine Rühreinrichtung montiert, bestehend aus je drei wellengetriebenen Plexiglasrührtellern. Die Rühreinrichtung wurde aber nur in den ersten zwei Experimenten benützt, dann wurde darauf verzichtet, weil es sich herausgestellt hatte, dass dadurch der Austausch des Kulturwassers mit der Umgebung durch das untere offene Ende der Testzelle stark gefördert wurde. Die Eigenschaften, insbesondere Vor- und Nachteile der Versuchseinrichtung, werden unter D 1.1 diskutiert (S. 54).

Reagenzienzugabe und Probenahme: Die Konzentration der zu testenden Reagenzien wurde so eingestellt, dass ein einmaliges Einbringen der Lösung mit einem Schlauch auf die ganze Länge der Testzelle die gewünschte Verdünnung ergab. Der verwendete PVC-Schlauch mit $1 \mathrm{~cm}$ Innendurchmesser wurde leer in die Mitte der Testzelle eingehängt, die Düngstofflösung luftblasenfrei eingefüllt und der Schlauch nach oben gezogen. Unter dem Gewicht der überstehenden Flüssigkeitssäule strömte die Lösung durch seitliche Öffnungen am unteren Ende des Schlauches aus. Die Probenahme erfolgte mit einem weiteren PVC-Schlauch mit einer Pumpe aus drei Tiefen $(1 \mathrm{~m}, 2 \mathrm{~m}$ und $4 \mathrm{~m}$ ) oder als Mischprobe von 0 bis $8 \mathrm{~m}$ Tiefe. Die Proben für die Sauerstoffbestimmung wurden mit einer Friedingerschen Schöpfflasche genommen und nach WinkLer [152] fixiert. Die Proben für die quantitative Erfassung des Phytoplanktons wurden nach UTERmöHL [144] fixiert. Die Zugabe des ${ }^{\mathbf{1 4}} \mathrm{C}$-markierten $\mathrm{NaHCO}_{3}$ zur Messung der Primärproduktion nach Steemann-Nielsen [130] erfolgte in situ in $120 \mathrm{ml}$ messende, sterile Glasflaschen. Die Proben für die Pigmentanalysen und die chemische Analytik wurden in $1000 \mathrm{ml}$ messende Glasflaschen gefüllt. Unmittelbar nach der Probenahme wurde ein Teil davon durch MilliporeMembranfilter $(0,45 \mu)$ für die Chemieanalysen bzw. durch Whatman-GF/CGlasfaserfilter für die Chlorophyllbestimmung filtriert. Die Proben für die Spurenmetallanalyse wurden in Polystyrol-Röhrchen DIX 95 von $10 \mathrm{ml}$ (Firma Milian Instruments SA Genève) eingefüllt und mit verdünnter $\mathrm{HNO}_{3}$-Lösung fixiert.

Das Sediment wurde in den Sedimentfallen (PVC-Tubus von $50 \mathrm{~cm}$ Länge und $7 \mathrm{~cm}$ Durchmesser, vgl. Abb. 3) während des ganzen Experiments aufgefangen, am Schluss durch Zentrifugieren vom überstehenden Wasser getrennt, getrocknet und im Achatmörser zerrieben. 


\section{Analytische Methoden zur Wasseruntersuchung}

Temperatur und Leitfähigkeit: Beide Parameter wurden mit dem Oxytester nach АмвüHL [2] in situ gemessen.

Strahlungsmessung und Sichttiefe: Die Strahlungsmessung erfolgte mit dem Unterwasserphotometer der Firma Ph. Schenk, Wien, nach SaUberer [110] in folgenden Spektralbereichen:

Filterbezeichnung

Messbereich

Mittlerer opt. Schwerpunkt

$$
\text { BG } 12 \quad \text { VG } 9
$$

$320-520 \mathrm{~nm} \quad 440-660 \mathrm{~nm}$

$\mathrm{RG} 2$

$600-740 \mathrm{~nm}$

$417 \mathrm{~nm} \quad 525 \mathrm{~nm}$
RG 5

$652 \mathrm{~nm} \quad 695 \mathrm{~nm}$

Die Sichttiefe wurde mit der Sichtscheibe nach Secchi gemessen.

Sauerstoff

Säureverbrauch

$\mathrm{pH}-$ Wert

Anorganischer

Gesamtkohlenstoff

Nitrat-N

Nitrit-N

Partikulärer N

Gesamt-N

Ammonium-N

Phosphat-P

Gesamt-P

TOC

(Totaler organischer

Kohlenstoff)

Gesamthärte

Spurenmetalle

(Fe, Mn, Cu, Cr, Zn, Cd, Pb)
Nach DEV massanalytisch [23].

Potentiometrische Titration mit $0,1 \mathrm{~N} \mathrm{HCl}$ auf $\mathrm{pH}$ 4,5.

Potentiometrisch (Glaselektrode) mit PHM 26 von Radiometer, Kopenhagen.

nach HaRvey und Rodhe [57] aus pH und Säureverbrauch berechnet.

Salicylatmethode nach MüxLER und WIDEMANN [90]. Nach Strickland und Parsons [133].

Nach Stadelmann [128].

Nach Schmid [115] mittels Dampfdestillation.

Nach Schmid [115] mittels Dampfdestillation.

Molybdänblau-Methode nach AmвüHL und Schmid [3].

Nach Schmid und AmbüHL [114].

Gasanalytisch mit dem Prototyp und Analysenteil

UNOR 5 der Firma Maihak, Hamburg, nach AxT [7].

Komplexometrische Titration mit ÄDTA nach Patton und Reeder [99].

Graphitrohrküvette HGA 70 zum AtomabsorptionsSpektrometer Modell 305 der Firma Perkin-Elmer (Bodenseewerk Überlingen) nach WELZ und WIEDEKING [149].

\section{Eisenanalyse}

Allgemeines: Das im Seewasser feststellbare totale Eisen setzt sich zusammen aus echt gelösten Eisenionen, undissoziierten molekularen, kolloidalen und grobdispersen Eisenverbindungen, organischen Eisenkomplexen und dem inkorporierten oder adsorbierten Eisen des Planktons.

Die Bestimmung der echt gelösten Eisenionen, deren Konzentration besonders interessiert, stösst auf Schwierigkeiten. Freie Eisenionen stammen praktisch nur vom zweiwertigen Eisen und sind in den sauerstoffhaltigen Wasserschichten unserer Seen in Konzentrationen um $10^{-8} M$ zu erwarten [124]. Mit der Bestimmung des zweiwertigen Eisens wäre es daher möglich, ohne räumliche Trennung der Eisenkomponenten den echt gelösten Anteil zu ermitteln. Um die Reduktion von drei- 
wertigem Eisen zu löslichem $\mathrm{Fe}^{2+}$ zu verhindern, kommt zur Bestimmung nur eine Methode in Frage, die ohne Säure und Reduktionsmittel funktioniert. Es müsste zudem im Dunkeln gearbeitet werden, weil das Licht eine photochemische Reduktion des $\mathrm{Fe}^{3+}$ auslöst [80]. Luft würde Redox-Prozesse fördern und muss daher als Kontaktmedium ausgeschaltet werden. Eine Analytik, die alle diese Kriterien erfüllt, wurde von McMahon [81] entwickelt, verlangt aber eine Messeinrichtung in situ. Da eine solche Einrichtung aber nicht zur Verfügung stand und andere Methoden für diese Zwecke zweifelhaft sind, wurde nur der Gesamteisengehalt im Rohwasser und in der filtrierten Wasserprobe bestimmt. Die Differenz beider Werte entspricht ungefähr dem vom Plankton fixierten Eisen. Der prozentuale Anteil dieses "geformten» Eisens vom Gesamteisengehalt korreliert gut mit analogen Komponenten des Stickstoffs und Phosphors.

Analysenmethode: Im Probewasser ist stets mit mehr oder weniger NTA zu rechnen. Dieser starke Komplexbildner stört die Bildung des BathophenanthrolinKomplexes und muss daher zerstört werden. Es wurde deshalb vor die eigentliche Farbreaktion ein Säureaufschluss geschaltet. Als Farbreagens diente Bathophenanthrolindisulfonsäure-dinatriumsalz; es ist empfindlicher als o-Phenanthrolin und verlangt keine Extraktion wie die übliche Bathophenanthrolin-Methode.

1. Aufschluss: $100 \mathrm{ml}$ der Probe wercen mit $1 \mathrm{ml}$ konz, $\mathrm{H}_{2} \mathrm{SO}_{4}$ versetzt und auf dem Infrabrenner bis $z u$ den ersten $\mathrm{SO}_{3}$-Dämpfen abgedampft. Die erkaltete Probe wird dann mit einigen Tropfen $\mathrm{H}_{2} \mathrm{O}_{2}$ versetzt und bei $260^{\circ} \mathrm{C} 20 \mathrm{Min}$. lang aufgeschlossen. Zur erkalteten Probe fügt man. dann $10 \mathrm{ml}$ dest. $\mathrm{H}_{2} \mathrm{O}$ und verdampft nochmals bis zu den crsten $\mathrm{SO}_{3}$-Dämpfen, um allfällige Spuren des $\mathrm{H}_{2} \mathrm{O}_{2}$ zu zerstören.

2. Neutralisation und Reduktion: $\mathrm{Mit} \mathrm{NH}_{3}$ wird etwa $\mathrm{pH} 4$ eingestellt and auf $100 \mathrm{ml}$ aufgefüllt. $2 \mathrm{ml}$ 10prozentige Ascorbinsäure sorgen für die Überführung des dreiwertigen Eisens in die zweiwertige Form. Zur genauen pH-Einstellung auf $\mathrm{pH} 4,5$ werden $5 \mathrm{ml}$ eines zweimolaren Azctatpuffers zugefügt.

3. Farbreaktion: $1 \mathrm{ml}$ einer 0,1 prozentigen Reagenslösung genügt, um mit Eisen eine Rosafärbung zu erzcugen. Der genügend stabile Farbkomplex wird nach $15 \mathrm{Min}$. bei $535 \mathrm{~nm}$ gemessen und gegen eine in allen Schritten gleich behandelte Typenreihe verglichen. Schwefelsäure und Azetatpuffer wurden als Reagenzien a Suprapur»@ Merck verwendet; für sämtliche andern genügte die Qualität "pro analysi».

Die Erfassungsgrenze liegt bei $2 \mu \mathrm{g} / 1$.

\section{Sedimentanalyse}

Gewichtsanalytisch wurden aus dem Trockengewicht durch 2stündiges Glühen bei $500^{\circ} \mathrm{C}$ die organischen Stoffe (= Glühverlust), die salzsäurelöslichen Teile und die Asche bestimmt. Das Salzsäurelösliche wurde zur Bestimmung von Eisen, Kalzium, Magnesium, Zink und Kupfer verwendet.

\section{Biologische Methoden}

Primärproduktion: Nach der Methode von Steemann-Nielsen [130] wurde eine bekannte Menge Probewasser (etwa $120 \mathrm{ml}$ ) mit ${ }^{14} \mathrm{C}$-markiertem $\mathrm{NaHCO}_{3}$ (mit etwa $8 \mu \mathrm{C}$ ) aus autoklavierten Ampullen versetzt. Die Proben wurden nachher in horizontaler Lage von 10 bis 14 Uhr in jener Tiefe exponiert, aus der sie entnommen worden waren. Zur Ermittlung der Nettoproduktion wurden in jeder Tiefe Parallelproben in verdunkelten Flaschen exponiert. Nach beendeter Exposition wurden $20 \mathrm{ml}$ Probewasser filtriert (Sartorius-Membranfilter $0,2 \mu \mathrm{m}$ ) und die Filter in Alu- 
miniumschälchen geklebt. Um adsorbiertes ${ }^{14} \mathrm{C}$ auszutreiben, wurden die Zählschälchen 20 Min. über rauchender Salzsäure exponiert. Bis zur Messung wurden die Filter im Exsikkator über Blaugel aufbewahrt. Die Ampullenaktivität wurde mit der Bariumkarbonatmethode bestimmt [118]. Die Aktivität der ${ }^{14} \mathrm{C}$-Proben wurde mit einem Methandurchflusszähler FH 407 der Firma Frieseke und Höpfner gemessen. In die Berechnung wurde ein Korrekturfaktor von 1,06 für den Isotopen-Effekt miteinbezogen. Von den Assimilationswerten in den Hellflaschen wurde die Dunkelassimilation subtrahiert.

Pigmentanalyse: Chlorophyllbestimmung nach Goltermann [49].

Qualitative Artenbestimmung: Bestimmung der Algen (Lebendmaterial) nach Huber-Pestalozzi [61], Pascher [98], Rabenhorst [104] und Skuja [125].

Quantitative Planktonuntersuchung und Biomasse: $50 \mathrm{ml}$ der mit Lugolscher Lösung fixierten Wasserproben wurden in Röhrenverbundkammern gefüllt. Die sedimentierten Phytoplankter wurden nach 2tägiger Absetzzeit im Umkehrmikroskop nach UTERMÖHL [144] und UEHLINGER [143] ausgezählt.

Zur Berechnung der Biomasse wurde die Individuenzahl der Art pro Volumeneinheit mit dem gemittelten Volumen der Individuen multipliziert. Das spezifische Gewicht wurde dem des Wassers gleichgesetzt. Die mittleren Volumina stellen eine Annäherung an ähnliche geometrische Körper dar. Gallerte, Kalk- und Kieselskelette und dergleichen wurden nicht als Biomasse berechnet.

\section{Experimente und Resultate}

1. Versuchsdisposition

Neben verschiedenen Vorversuchen wurden insgesamt 7 Nährstofftests durchgeführt, drei davon im Vierwaldstättersee (1970) die andern 4 im Greifensee (1971/72). Ein Versuch bestand immer aus 4 Kultureinheiten (Testzellen). Zwar wäre angesichts der noch unbekannten Streuung der Methode eine streng statistische Versuchsplanung notwendig gewesen. Diese hätte aber mehr Versuchseinheiten erfordert, was für einen einzigen Bearbeiter nicht zu bewältigen gewesen wäre.

\section{Resultate Vierwaldstättersee}

Jedes In-situ-Experiment unterliegt den jeweiligen ökologischen Bedingungen der Umwelt. Demgemäss änderten die Bedingungen für das Algenwachstum wesentlich von Versuch zu Versuch. Aus technischen Gründen konnten während der Versuchsdauer nicht alle wichtigen Parameter kontinuierlich verfolgt werden. Die Untersuchung beschränkte sich auf die analytische Beobachtung der zugefügten Stoffe und die unmittelbare Reaktion des Planktons. Im Laufe der ersten Versuchswoche wurden zusätzlich die Nährstoffe und einige weitere Parameter (Sauerstoffgehalt, SVB, pH, Leitfähigkeit, Temperatur und Sichttiefe) bestimmt. Sämtliche chemischen Parameter wurden im Probewasser aus allen vier Kultureinheiten und dem Seewasser in der näheren Umgebung des Versuchsfeldes analysiert.

Die Messresultate in den Tabellen 2-6 sollen die Randbedingungen für die drei Experimente skizzieren. Die geringe Streuung der Einzelwerte aller Testzellen erlaubte die vereinfachende Berechnung des Mittelwertes aus allen Testzellen (von 0 bis 5 bzw. 0 bis $8 \mathrm{~m}$ Tiefe [in den Tabellen markiert]). 
Tabelle 1. Versuchsanordnung.

Table 1. Experimentation plan.

\begin{tabular}{|c|c|c|c|c|c|c|c|c|}
\hline Probestelle & & \multicolumn{3}{|c|}{ Vierwaldstättersee } & \multicolumn{4}{|l|}{ Greifensee } \\
\hline Versuch Nr. & & 1 & 2 & 3 & 1 & 2 & 3 & 4 \\
\hline Dauer & & $\begin{array}{l}\text { 4.5. bis } \\
16.5 .1970\end{array}$ & $\begin{array}{l}\text { 10.7. bis } \\
19.7 .1970\end{array}$ & $\begin{array}{c}\text { 7.9. bis } \\
30.9 .1970\end{array}$ & $\begin{array}{l}\text { 29.6. bis } \\
21.7 .1971\end{array}$ & $\begin{array}{l}\text { 18.8. bis } \\
2.9 .1971\end{array}$ & $\begin{array}{l}21.10 . \text { bis } \\
16.11 .1971\end{array}$ & $\begin{array}{l}\text { 21.3. bis } \\
10.4 .1972\end{array}$ \\
\hline $\begin{array}{l}\text { Art und Menge der gedüngten Stoffe } \\
\text { (in } \mu \mathrm{g} / 1 \mathrm{Kulturwasser)}\end{array}$ & & $\begin{array}{l}\text { NTA } 50 \\
\text { Fe } 30\end{array}$ & $\begin{array}{l}\text { NTA } 100 \\
\text { Fe } 60\end{array}$ & $\begin{array}{l}\mathrm{NO}_{3}-\mathrm{N} 100 \\
\mathrm{PO}_{4}-\mathrm{P} 20 \\
\mathrm{NTA} 150 \\
\text { Fe } 50\end{array}$ & $\begin{array}{lr}\mathrm{NTA}_{1} & 100 \\
\mathrm{NTA}_{2} & 1000 \\
\mathrm{NTA}_{3} & 9000\end{array}$ & $\begin{array}{l}\text { NTA } 200 \\
\text { Fe } 30\end{array}$ & $\begin{array}{l}\text { NTA } 200 \\
\text { Fe } 60\end{array}$ & $\begin{array}{l}\text { NTA } 300 \\
\text { Fe } 90\end{array}$ \\
\hline $\begin{array}{l}\text { Zugabedaten } \\
\text { (gleiche Etappen) }\end{array}$ & & $\begin{array}{r}5.5 . \\
9.5 . \\
12.5\end{array}$ & $\begin{array}{l}11.7 \\
13.7 \\
16.7\end{array}$ & $\begin{array}{r}8.9 . \\
15.9 \\
25.9\end{array}$ & $\begin{array}{r}30.6 . \\
7.7 \\
17.7\end{array}$ & $\begin{array}{r}21.8 . \\
2.9\end{array}$ & $\begin{array}{r}23.10 \\
2.11\end{array}$ & $\begin{array}{r}22.3 . \\
29.3 \\
4.4\end{array}$ \\
\hline \multirow[t]{3}{*}{ Testzelle } & 0 & $\begin{array}{l}- \\
\text { (Kontrolle } \\
\text { NTA }\end{array}$ & NTA & $\begin{array}{l}\mathrm{NO}_{3}-\mathrm{N} \\
\mathrm{PO}_{4}-\mathrm{P} \\
\mathrm{NO}_{3}-\mathrm{N} \\
\mathrm{PO}_{4}-\mathrm{P} \\
\mathrm{NTA}^{\prime}\end{array}$ & $\mathrm{NTA}_{1}$ & NTA & NTA & NTA \\
\hline & 2 & $\mathrm{Fe}$ & $\mathrm{Fe}$ & $\begin{array}{l}\mathrm{NO}_{3}-\mathrm{N} \\
\mathrm{PO}_{4}-\mathrm{P} \\
\mathrm{Fe}\end{array}$ & $\mathrm{NTA}_{2}$ & verunfallt & $\mathrm{Fe}$ & $\mathrm{Fe}$ \\
\hline & 3 & $\mathrm{NTA}+\mathrm{Fe}$ & $\mathrm{NTA}+\mathrm{Fe}$ & $\begin{array}{l}\mathrm{NO}_{3}-\mathrm{N} \\
\mathrm{PO}_{4}-\mathrm{P} \\
\mathrm{NTA} \\
\mathrm{Fe}\end{array}$ & $\mathrm{NTA}_{3}$ & $\mathrm{NTA}+\mathrm{Fe}$ & $\mathrm{NTA}+\mathrm{Fe}$ & $\mathrm{NTA}+\mathrm{Fe}$ \\
\hline
\end{tabular}


Ein wesentlicher Unterschied zeigte sich nur zwischen den Testzellen und dem See (etwa 20 bis $30 \%$ je nach Parameter).

Die tiefen Phosphatwerte im Vierwaldstättersee sprechen für die das Phytoplankton-Wachstum limitierende Funktion des Phosphors während der Hauptvegetationszeit [40]. Das molare Verhältnis von Gesamtstickstoff zu Gesamtphosphor entspricht mit rund 50:1 in keiner Weise einem idealen Nährsubstrat für Algen. Gegen Ende der Sommerstagnation kann sich dieses Verhältnis aber verändern, so dass Stickstoff auch minimal vorliegt [128]. Anorganische Kohlenstoffverbindungen waren stets im Überfluss vorhanden, so dass eine Wachstumslimitierung durch Kohlenstoff niemals zu erwarten ist.

\subsection{Physikalische Daten}

Tabelle 2. Temperatur, Leitfähigkeit und Sichttiefe des Vierwaldstättersees an der Probestelle. Table 2. Temperature, conductivity and visibility depth at the sampling site on Lake Lucerne.

\begin{tabular}{|c|c|c|c|}
\hline $\begin{array}{l}\text { Temperatur } \\
\text { Tiefe in } \mathrm{m}\end{array}$ & $\begin{array}{l}\text { Versuch } 1 \\
11.5 .1970 \\
{ }^{\circ} \mathrm{C}\end{array}$ & $\begin{array}{l}\text { Versuch } 2 \\
13.7 .1970 \\
{ }^{\circ} \mathrm{C}\end{array}$ & $\begin{array}{l}\text { Versuch } 3 \\
8.9 .1970 \\
{ }^{\circ} \mathrm{C}\end{array}$ \\
\hline 0 & 9,65 & 20,8 & 17,9 \\
\hline 2 & 9,45 & 18,3 & 17,5 \\
\hline 4 & 8,9 & 14,2 & 13,9 \\
\hline 6 & 8,5 & 11,6 & 12,6 \\
\hline 8 & 8,0 & 10,5 & 11,9 \\
\hline 10 & 7,85 & 10,0 & 11,4 \\
\hline 12 & 7,75 & 9,9 & 11,2 \\
\hline 14 & 7,1 & 9,7 & 11,1 \\
\hline \multirow[t]{2}{*}{ Leitfähigkeit } & Versuch 1 & Versuch 2 & Versuch 3 \\
\hline & $\begin{array}{l}11.5 .1970 \\
\mu \mathrm{S} \mathrm{\textrm {cm } ^ { - 1 }}\end{array}$ & $\begin{array}{l}13.7 .1970 \\
\mu S \mathrm{~cm}^{-1}\end{array}$ & $\begin{array}{l}8.9 .1970 \\
\mu S \mathrm{~cm}^{-1}\end{array}$ \\
\hline 0 & 198 & 158 & 143 \\
\hline 2 & 193 & 158 & 148 \\
\hline 4 & 193,5 & 151 & 149 \\
\hline 6 & 193 & 162 & 154 \\
\hline 8 & 195,5 & 166 & 156 \\
\hline 10 & 196 & 170 & 150 \\
\hline 12 & 196,5 & 168 & 154 \\
\hline 14 & 199,5 & 169 & 156 \\
\hline \multirow[t]{2}{*}{ Sichttiefe } & Versuch 1 & Versuch 2 & Versuch 3 \\
\hline & 11.5 .1970 & 13.7 .1970 & 8.9 .1970 \\
\hline Tiefe in $\mathrm{m}$ & 2,8 & 6,2 & 3,4 \\
\hline
\end{tabular}




\subsection{Chemische Daten}

Tabelle 3. Nährstoffe, Sauerstoff, Säureverbrauch und pH-Wert an der Probestelle; TOC und Spurenmetalle im Vierwaldstättersee, Stelle Obermatt. - Die Werte gelten, soweit nichts anderes vermerkt ist, für Mischproben aus 0-8 $\mathrm{m}$ Tiefe. Mit Stern (*) markierte Werte stellen arithmetische Mittelwerte der 4 Testzellen dar.

Table 3. Nutrient, oxygen, alkalinity and pH-values at sampling site; TOC and trace metals at the Obermatt site on Lake Lucerne. - Where nothing else is noted the values are valid for mixed samples $(0-8 \mathrm{~m})$. The asterisk $\left(^{*}\right)$ indicates an average from all sampling units.

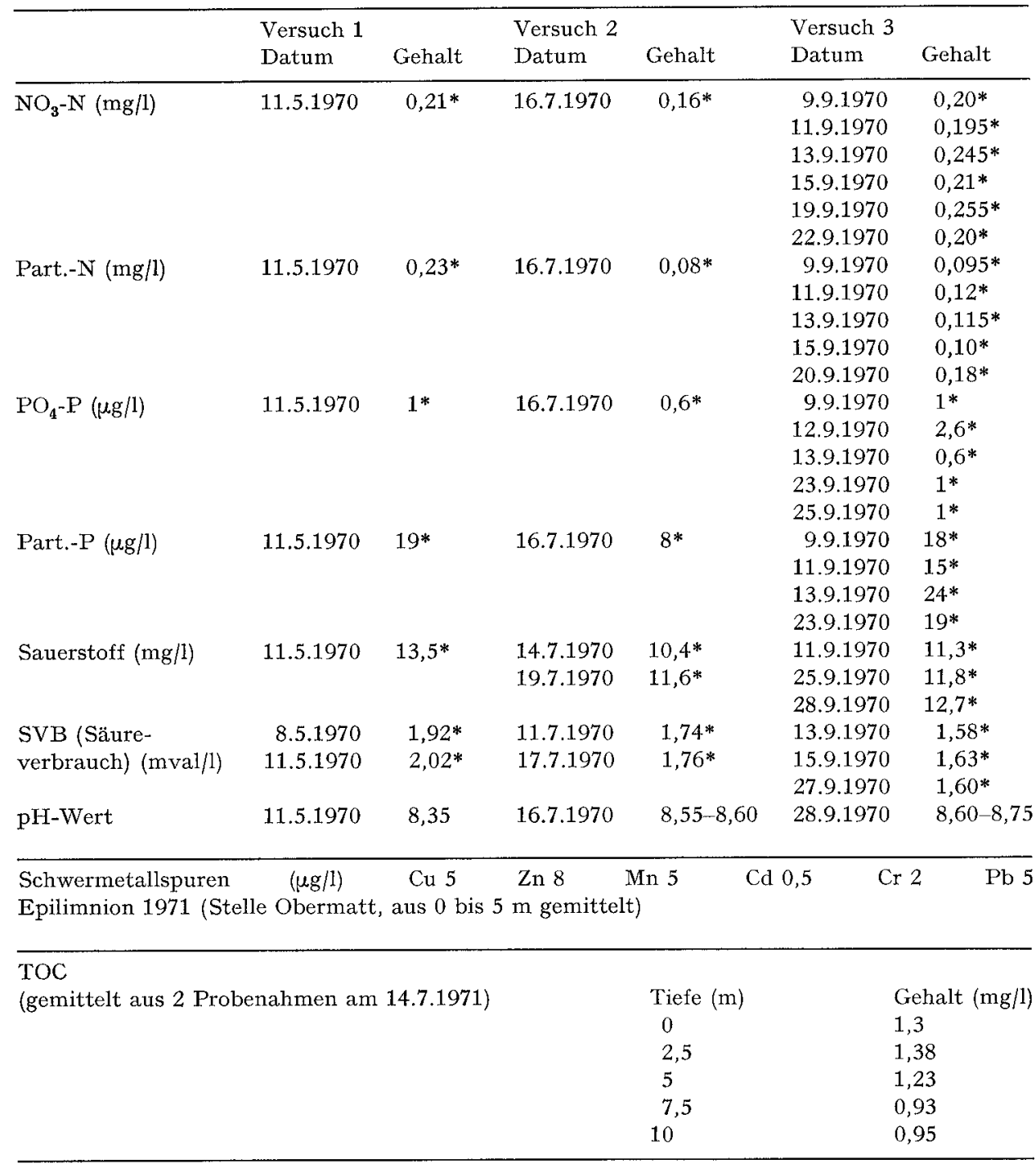


Tabelle 4. Gesamteisengehalt des Rohwassers in den Testzellen in $\mu \mathrm{g} / 1$. Mit Pfeil $(\downarrow)$ sind die Düngungen gemäss Tabelle 1 markiert.

Table 4. Total iron content of the crude water in the sampling units expressed in $\mu g / 1$. The arrow $(\downarrow)$ indicates the moment of input in accordance with the experimentation plan (Table 1 ).

\begin{tabular}{llcccccc}
\hline $\begin{array}{l}\text { Versuch } 1 \\
\text { Testzelle }\end{array}$ & $\downarrow 6.5$. & 7.5. & $\downarrow 9.5$. & $\mathbf{1 0 . 5}$ & $\downarrow$ 12.5. & $\mathbf{1 3 . 5 .}$ & 16.5. \\
\hline 0 (Kontrolle) & 32 & 34 & 40 & 37 & 29 & 27 & 18 \\
1 (NTA) & 28 & - & 39 & 38 & 38 & 26 & 22 \\
$2(\mathrm{Fe})$ & 95 & 96 & 54 & 42 & 71 & $\mathbf{5 0}$ & 27 \\
$3(\mathrm{Fe}+\mathrm{NTA})$ & 74 & 73 & 54 & 37 & $\mathbf{5 5}$ & 45 & $\mathbf{1 9}$ \\
\hline
\end{tabular}

\begin{tabular}{|c|c|c|c|c|c|c|c|}
\hline $\begin{array}{l}\text { Versuch } 2 \\
\text { Testzelle }\end{array}$ & $\downarrow 11.7$ & & $\downarrow 14.7$ & & 16.7 & & $\downarrow 17.7$. \\
\hline 0 (Kontrolle) & 21 & & 15 & & 9 & & 12 \\
\hline $1(\mathrm{NTA})$ & - & & 12 & & 7 & & 12 \\
\hline $2(\mathrm{Fe})$ & 34 & & 22 & & 8 & & 18 \\
\hline $3(\mathrm{NTA}+\mathrm{Fe})$ & 33 & & 22 & & 7 & & 16 \\
\hline \multicolumn{8}{|l|}{ Versuch 3} \\
\hline Testzelle & 15.9. & $\downarrow 19.9$. & 22.9 & 23.9 . & $\downarrow 25.9$ & 26.9 & 30.9 \\
\hline 0 (Kontrolle) & 23 & 24 & 17 & 18 & 17 & 15 & 19 \\
\hline 1 (NTA) & 23 & 26 & 18 & 18 & 22 & 17 & 16 \\
\hline $2(\mathrm{Fe})$ & 22 & 42 & 35 & 34 & 41 & 41 & 21 \\
\hline $3(\mathrm{NTA}+\mathrm{Fe})$ & 21. & 33 & 30 & 33 & 29 & 40 & 24 \\
\hline
\end{tabular}

\subsection{Sedimentuntersuchung}

Tabelle 5 .

\begin{tabular}{|c|c|c|c|c|c|}
\hline \multicolumn{6}{|l|}{ Versuch 1} \\
\hline & & Testze & & & \\
\hline \multirow{3}{*}{$\begin{array}{l}\text { Trockengewicht des Sediments } \\
\text { pro Kultureinheit }\left(0,8 \mathrm{~m}^{2}\right) \text { in } \mathrm{g} \\
\text { Sedimentation in } \mathrm{g} \mathrm{m}^{-2} \mathrm{~d}^{-1}\end{array}$} & See & 0 & 1 & 2 & 3 \\
\hline & & 75 & 81 & 76 & 69 \\
\hline & 4,6 & 7,7 & 8,4 & 7,8 & 7,1 \\
\hline \multicolumn{6}{|l|}{ davon in $\%$} \\
\hline Kalzium & 13 & 13 & 10 & 10 & 16 \\
\hline Magnesium & 0,3 & 0,3 & 0,2 & 0,3 & 0,3 \\
\hline Mangan & 0,02 & 0,02 & 0,02 & 0.02 & 0,02 \\
\hline Eisen & 1 & 0,95 & 0,90 & 0,80 & 0,89 \\
\hline \multicolumn{6}{|c|}{$\begin{array}{l}\text { Zink und Kupfer nicht bestimmbar wegen Kontamination der Sedimentfallen durch Messing- } \\
\text { bauteile }\end{array}$} \\
\hline Org. Stoffe & 16 & 21 & 27 & 21 & 16 \\
\hline
\end{tabular}


Fortsetzung Tabelle 5.

Versuch 2

Trockengewicht des Sediments pro Kultureinheit $\left(0,8 \mathrm{~m}^{2}\right)$ in $\mathrm{g}$ Sedimentation in $\mathrm{g} \mathrm{m}^{-2} \mathrm{~d}^{-1}$

\begin{tabular}{ccccc} 
See & Testzellen & & & \\
& 0 & $\mathbf{1}$ & 2 & $\mathbf{3}$ \\
\hline 4,0 & 44 & 48 & 46 & 42 \\
& 5,5 & 6,0 & 5,8 & 5,3 \\
13 & & & & \\
0,4 & 13 & 13 & 10 & 13 \\
0,03 & 0,3 & 0,3 & 0,3 & 0,3 \\
1,35 & 0,04 & 0,04 & 0,04 & 0,04 \\
0,025 & 1,25 & 1,35 & 1,25 & 1,25 \\
0,08 & 0,024 & 0,03 & 0,07 & 0,12 \\
17 & 0,025 & 0,025 & 0,07 & 0,10 \\
& $\mathbf{1 5}$ & 16 & 17 & 15
\end{tabular}

Versuch 3

davon in \%

Kalzium

Magnesium

Mangan

Eisen

Kupfer

Zink

Organische Stoffe

$\mathrm{m}^{-2} \mathrm{~d}^{-1}$

(n)

13


Fortsetzung Tabelle 6 .

Bacillariophyceae

Fragilaria crotonensis Kitton

Tabellaria fenestrata (Lyngb.) Kg.

Asterionella formosa Hassal

Diatoma elongatum (Lyngb.) Ag.

Diatoma vulgave Bory (tychoplankt.)

Synedra acus $\mathrm{Kg}$.

Synedra acus var. angustissima Grun.

Synedra ulna (Nitzsch.) Ehb. (tychoplankt.)

Synedra berolinensis Lemm.

Synedra "Klein» unbestimmt

Nitzschia acicularis W. Smith.

Ceratoneis arcus (Ehb.) Kütz.

Cyclotella comta (Ehb.) Kütz.

Cyclotella comensis Grun.

Cyclotella glomerata Bachm.

Cyclotella bodanica Eulenst.

Stephanodiscus hantzschii Grun.

Stephanodiscus alpinus Hust.

Stephanodiscus astrea (E.) Grun.

Melosira islandica $\mathrm{O}$. Müll.

Melosiva granulata (Ehb.) Ralfs

* +

* $t$

* +

* +

* +

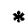

Dinophyceae

Peridinium willei Huitf.-Kaas Peridinium cinctum (Müll.) Ehb. Peridinium aciculiferum Lemm.

Peridinium inconspicuum Lemm. Gymnodinium helveticum Penard Gymnodinium lantzschii Uterm. Ceratium hirundinella Schrank

Chrysophyceae

Mallomonas caudata Iwanoff Chromulina sp.

Pseudopedinella erkensis

Kephyriopsis cincta Schiller Dinobryon sociale Ehb.

Dinobryon divergens Imhof

Dinobryon sertularia Ehb. 
Fortsetzung Tabelle 6 .

Chlorophyceae

Scenedesmus quadricauda (Turp.) Bréb.

Scenedesmus obliquus (Turp.) Kütz.

Selenastrum minutum (Naeg.) Collins

Ankistrodesmus falcatus var. spirilliformis G.S. West

Ankistrodesmus convolutus (Corda) Ralfs

Coelastrum microporum Naeg.

Oocystis lacustris Chodat

Chlorella pyrenoidosa Chick.

Sphaerocystis schroeteri Chodat

Nephrocytium agardhianum Nealg.

Dictyosphaerium ehrenbergianum Naeg.

Elahatothrix gelatinosa Wille

Gemellicystis neglecta Teiling

$=$ Pseudosphaerocystis lacustris (Lemm) Nováková

Pandorina morum Bory

Eudorina elegans Ehb.

Phacotus lenticularis (Ehb.) Stein

Schroederia setigera (Schroed.) Lemm.

Schroederia spiralis (Printz) Korš.

Bitvichia chodatii Rever

Pediastrum duplex Meyen

Pediastrum boryanum (Turp.) Menegh.

Micractinium sp.

Botryococcus braunii Kütz.

Platymonas cordiformis (Carter) Dill.

Cavteria spp.

Chlamydomonas spp.

Ulothrix amphigranulata Skuja

Conjugatophyceae

Cosmarium phaseolus Bréb.

Closterium striolatum Ehb.

Mougeotia sp.

Staurastrum gracile Ralfs

Staurastrum paradoxum Meyen

Closterium acerosum (Schrank) Ehb.

Closterium acicularis T.West

Cryptophyceae

Cryptomonas erosa Ehb.

Cryptomonas tetrapyrenoidosa Skuja

Cryptomonas ovata Ehb.

Rhodomonas lacusivis Pascher et Ruttner

$\begin{aligned} & * \\ & *\end{aligned}+$

Rhodomonas lens Pascher et Ruttner

Katablepharis ovalis Skuja 
Tabelle 7. Assimilationsraten (in $\mathrm{mg} \mathrm{C}_{\text {ass }} \mathrm{h}^{-1} \mathrm{~m}^{-3}$ ) in den Testzellen und im Vierwaldstättersee nahe der Probestelle, - Alle Werte sind gemittelt aus der Nettoproduktion in 2,5 m und $1 \mathrm{~m}$ Tiefe. Table 7. Assimilation rate in the sampling units and in Lake Lucerne at the sampling site, expressed in $\mathrm{mg} \mathrm{C}_{\mathrm{ass}} \mathrm{h}^{-1} \mathrm{~m}^{-\mathbf{3}}$. - All values represent an average of the net production at a depth of 2.5 and $1 \mathrm{~m}$.

\begin{tabular}{|c|c|c|c|c|}
\hline $\begin{array}{l}\text { Versuch } 1 \\
\text { Testzelle }\end{array}$ & 6.5 & 8.5 . & 10.5 & 13.5.1970 \\
\hline See & 14,3 & 6,3 & 11,5 & 2,5 \\
\hline 0 (Kontrolle) & 16,3 & 12,9 & 10,5 & 7,9 \\
\hline $1(\mathrm{NTA})$ & 21,5 & 9,3 & 14,9 & 7,4 \\
\hline $2(\mathrm{Fe})$ & 21,0 & 11,1 & 12,5 & 7,9 \\
\hline 3 (NTA + Fe) & 17,5 & 10,0 & 12,7 & 8,6 \\
\hline \multicolumn{5}{|l|}{ Versuch 2} \\
\hline Testzelle & & 11.7 & 14.7 & 17.7 \\
\hline See & & 7,2 & 5,5 & 5,2 \\
\hline 0 (Kontrolle) & & 6,3 & 5,6 & 10,0 \\
\hline 1 (NTA) & & 8,8 & 6,4 & 9,2 \\
\hline $2(\mathrm{Fe})$ & & 8,5 & 4,5 & 8,0 \\
\hline $3(\mathrm{NTA}+\mathrm{Fe})$ & & 6,2 & 6,1 & 6,8 \\
\hline \multicolumn{5}{|l|}{ Versuch 3} \\
\hline Testzelle & 10.9 . & 13.9. & 19.9 & 26.9 \\
\hline See & 2,6 & 5,0 & 2,6 & 2,5 \\
\hline 0 (Kontrolle) & 3,3 & 4,3 & 2,5 & 4,1 \\
\hline 1 (NTA) & 4,6 & 4,2 & 2,6 & 5,1 \\
\hline $2(\mathrm{Fe})$ & 4,6 & 4,5 & 2,4 & 3,8 \\
\hline 3 (NTA + Fe) & 4,6 & 3,7 & 2,6 & 4,5 \\
\hline
\end{tabular}

Tabelle 8. Summe der Planktonvolumina (Biomasse) der ausgezählten Phytoplanktonarten in $\mathrm{mg} / \mathrm{l}$.

Table 8. Total phytoplankton volume (biomass) expressed in $\mathrm{mg} / \mathrm{l}$.

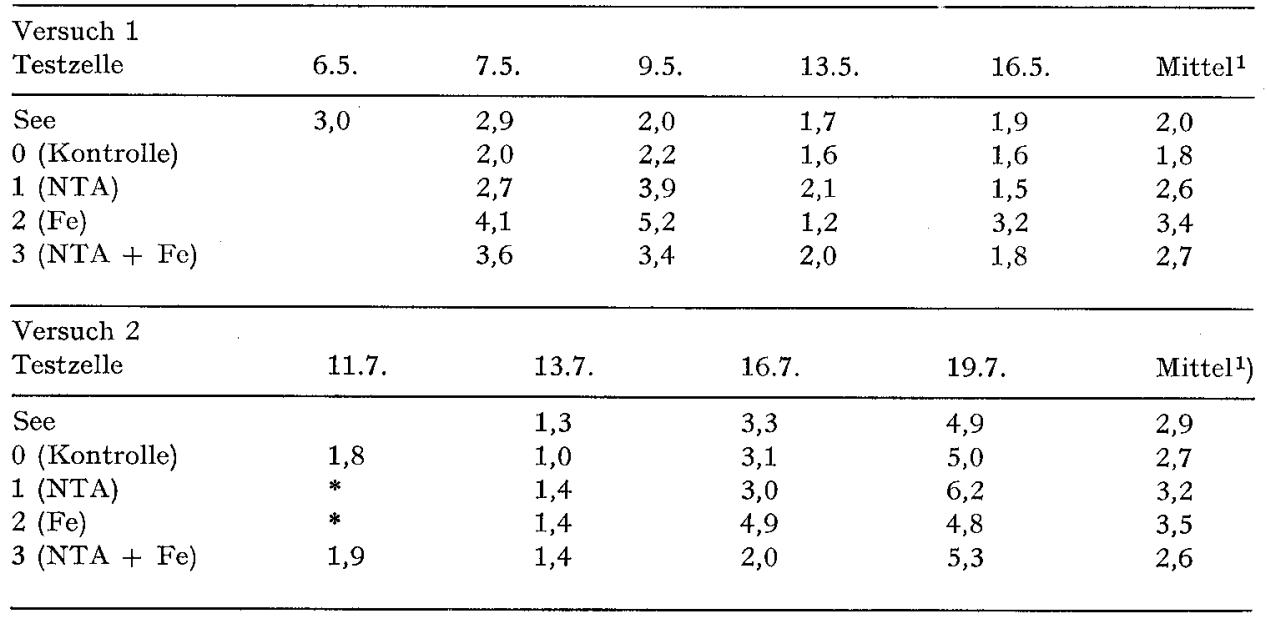


Fortsetzung Tabelle 8 .

\begin{tabular}{|c|c|c|c|c|c|c|c|c|c|c|}
\hline $\begin{array}{l}\text { Versuch } 3 \\
\text { Testzelle }\end{array}$ & 10.9 . & 11.9 . & 13.9 & 15.9. & 19.9. & 22.9 & 25.9 & 27.9 & 30.9 . & Mittel $\left.^{1}\right)$ \\
\hline See & 1,0 & 0,9 & 1,6 & 1,4 & 1,5 & 1,4 & 1,7 & 1,5 & $1, \mathbf{1}$ & 1,4 \\
\hline 0 (Kontrolle) & 1,2 & 1,6 & 1,1 & 1,9 & 1,6 & 2,5 & 2,2 & 2,0 & 1,7 & 1,8 \\
\hline 1 (NTA) & $(0,4)$ & 1,8 & 1,5 & 2,0 & 2,0 & 2,0 & 4,4 & 2,1 & 1,5 & 2,2 \\
\hline $2(\mathrm{Fe})$ & 1,4 & 1,7 & 0,8 & 1,3 & 2,0 & 1,4 & 2,2 & 1,9 & 1,5 & 1,6 \\
\hline $3(\mathrm{NTA}+\mathrm{Fe})$ & $\mathbf{1}, 2$ & 1,6 & 1,3 & 1,0 & 2,3 & 2,0 & 2,7 & 1,6 & 1,2 & 1,8 \\
\hline \multicolumn{11}{|c|}{$\begin{array}{l}\text { 1) Die Mittel wurden nach der Trapezregel berechnet. } \\
\text { *) Verunfallt. } \\
\text { 1) Average biomass calculated according to the trapezoid rule. } \\
\text { *) Failed. }\end{array}$} \\
\hline
\end{tabular}

Tabelle 9. Individuenzahlen der wichtigsten Phytoplanktonarten in der Kontrolle (K) und im See (in Zellen/1).

Table 9. Number of individuals of the most important phytoplankton species in the control (K) and in the lake, expressed in cells/1.

\begin{tabular}{|c|c|c|c|c|c|c|}
\hline $\begin{array}{l}\text { Versuch } 1 \\
\text { Gattung/Art }\end{array}$ & Faktor & & 7.5. & 9.5 & 13.5 & 16.5 \\
\hline \multirow[t]{2}{*}{ Oscillatoria rubescens } & $10^{5}$ & See & 44 & 14 & 14 & 95 \\
\hline & & $\mathrm{K}$ & 34 & 30 & 29 & 33 \\
\hline \multirow[t]{2}{*}{ Fragilaria crotonensis } & $10^{3}$ & See & 259 & 267 & 30 & 64 \\
\hline & & $\mathrm{K}$ & 196 & 107 & 38 & 50 \\
\hline \multirow[t]{2}{*}{ Synedra acus } & $10^{3}$ & See & 224 & 306 & 340 & 94 \\
\hline & & $\mathrm{K}$ & 171 & 415 & 84 & 53 \\
\hline \multirow[t]{2}{*}{ Synedra acus var.ang. } & $10^{3}$ & See & 11 & 12 & 32 & 21 \\
\hline & & $K$ & 15 & 49 & 28 & 15 \\
\hline \multirow[t]{2}{*}{ Tabellaria fenestrata } & $10^{4}$ & See & 43 & 26 & 30 & 17 \\
\hline & & $\mathbf{K}$ & 38 & 33 & 17 & 43 \\
\hline \multirow[t]{2}{*}{ Cyclotella spp. } & $10^{3}$ & See & 118 & 35 & 15 & 1.5 \\
\hline & & $\mathrm{K}$ & 96 & 24 & 30 & 30 \\
\hline \multirow[t]{2}{*}{ Stephanodiscus spp. } & $10^{3}$ & See & 340 & 150 & 310 & 70 \\
\hline & & $K$ & 190 & 190 & 130 & 180 \\
\hline \multirow[t]{2}{*}{ Erkenia subaequiciliata } & $10^{4}$ & See & 47 & 23 & 10 & 35 \\
\hline & & $\mathrm{K}$ & 30 & 23 & 46 & 18 \\
\hline \multirow[t]{2}{*}{ Ankistrodesmus spp. } & $10^{3}$ & See & 180 & 80 & 20 & 110 \\
\hline & & $\mathrm{K}$ & 120 & 70 & 40 & 50 \\
\hline \multirow[t]{2}{*}{ Chlorella pyrenoidosa } & $10^{5}$ & See & 110 & 100 & 16 & 97 \\
\hline & & $\mathrm{K}$ & 68 & 61 & 146 & 39 \\
\hline \multirow[t]{2}{*}{ Cryptomonas spp. } & $10^{2}$ & See & 240 & 30 & 80 & 110 \\
\hline & & $\mathrm{K}$ & 180 & 70 & 50 & 190 \\
\hline \multirow[t]{2}{*}{ Rhodomonas spp. } & $10^{3}$ & See & 120 & 360 & 170 & 300 \\
\hline & & $\mathbf{K}$ & 70 & 60 & 700 & 110 \\
\hline
\end{tabular}


Fortsetzung Tabelle 9.

\begin{tabular}{|c|c|c|c|c|c|c|c|c|c|c|}
\hline \multirow{3}{*}{$\begin{array}{l}\text { Versuch } 2 \\
\text { Gattung/Art } \\
\text { Oscillatoria rubescens }\end{array}$} & \multicolumn{2}{|l|}{ Faktor } & 11.7. & \multicolumn{2}{|c|}{13.7} & \multicolumn{2}{|c|}{16.7} & \multicolumn{2}{|l|}{16.7} & \multirow{2}{*}{$\frac{19.7}{48}$} \\
\hline & \multirow[t]{2}{*}{$10^{4}$} & & See & \multicolumn{2}{|c|}{95} & \multicolumn{2}{|c|}{26} & \multicolumn{2}{|l|}{61} & \\
\hline & & & $\mathrm{K}$ & \multicolumn{2}{|c|}{75} & \multicolumn{2}{|l|}{43} & \multicolumn{2}{|l|}{83} & 90 \\
\hline \multirow[t]{2}{*}{ Fragilaria crotonensis } & \multirow[t]{2}{*}{$10^{4}$} & & See & \multicolumn{2}{|c|}{19} & \multicolumn{2}{|c|}{35} & \multicolumn{2}{|l|}{53} & 260 \\
\hline & & & $\mathrm{K}$ & 3 & 0 & 25 & & 109 & & 232 \\
\hline Synedra acus var. ang. & $10^{1}$ & & See & 9 & & 90 & & 260 & & 510 \\
\hline & & & $\mathrm{K}$ & 10 & & 100 & & 270 & & 480 \\
\hline A sterionella formosa & $10^{4}$ & & See & 11 & & 29 & & 42 & & 54 \\
\hline & & & $\mathbf{K}$ & 8 & & 21 & & 80 & & 67 \\
\hline Tabellaria fenestrata & $10^{4}$ & & See & 3 & & 17 & & 34 & & 45 \\
\hline & & & $\mathrm{K}$ & 4 & & 26 & & 50 & & 61. \\
\hline Cyclotella spp. & $10^{3}$ & & See & 9 & & 15 & & 105 & & 130 \\
\hline & & & $\mathrm{K}$ & 9 & & 15 & & 112 & & 130 \\
\hline Erkenia subaequiciliata & $10^{3}$ & & See & $\mathbf{1}$ & & 50 & & 260 & & 370 \\
\hline & & & $\mathrm{K}$ & 3 & & 50 & & 230 & & 305 \\
\hline Mougeotia sp. & $10^{3}$ & & See & 1 & & 15 & & 51 & & 72 \\
\hline & & & $\mathrm{K}$ & 1 & & 6 & & 27 & & 38 \\
\hline Cryptomonas spp. & $10^{3}$ & & See & 13 & & 134 & & 141 & & 240 \\
\hline & & & $\mathrm{K}$ & 11 & & 18 & & 34 & & 175 \\
\hline Rhodomonas spp. & $10^{4}$ & & See & 5 & & 73 & & 18 & & 74 \\
\hline & & & K & 3 & & 48 & & 22 & & 57 \\
\hline Versuch 3 & & & & & & & & & & \\
\hline Grattung/Art & Faktor & & 11.9 . & 13.9. & 15.9 & 19.9 . & 22.9 & 25.9 & 27.9 & 30.9 \\
\hline Oscillatoria rubescens & $10^{5}$ & See & 6 & 64 & 34 & 18 & 5 & 27 & 13 & 35 \\
\hline & & $\mathrm{K}$ & 91 & 48 & 78 & 60 & 21 & 36 & 44 & 47 \\
\hline Fragilaria crotonensis & $10^{3}$ & See & 23 & 57 & 72 & 42 & 30 & 8 & & 8 \\
\hline & & $\mathrm{K}$ & 23 & 13 & 32 & 27 & 12 & 9 & 21 & 22 \\
\hline Synedra acus & $10^{2}$ & See & 180 & 420 & 130 & & 60 & 80 & 60 & \\
\hline & & $\mathrm{K}$ & 180 & 420 & 320 & & & 90 & 40 & 150 \\
\hline Synedra acus var. ang. & $10^{3}$ & See & 12 & 23 & 23 & 21 & 30 & 18 & 30 & 17 \\
\hline & & $\mathrm{K}$ & 6 & 35 & 17 & 23 & 19 & 22 & 23 & 18 \\
\hline A sterionella formosa & $10^{3}$ & See & 10 & 39 & 63 & 17 & 30 & 44 & 21 & 27 \\
\hline & & $\mathrm{K}$ & 17 & 50 & 117 & 18 & 84 & 60 & 53 & 50 \\
\hline Cyclotella spp. & $10^{4}$ & See & 16 & 15 & 44 & 19 & 16 & 26 & 13 & 18 \\
\hline & & $\mathrm{K}$ & 43 & 6 & 24 & 39 & 13 & 19 & 6 & 15 \\
\hline Stephanodiscus spp. & $10^{4}$ & See & 45 & 80 & 49 & 23 & 23 & 29 & 09 & 16 \\
\hline & & $\mathbf{K}$ & 42 & 34 & 56 & 48 & 29 & 18 & 15 & 38 \\
\hline Erkenia subaequiciliata & $10^{4}$ & See & 25 & 49 & 63 & 15 & 23 & 38 & & \\
\hline & & $\mathrm{K}$ & 17 & 19 & 21 & 22 & 28 & 4 & & 5 \\
\hline Ankistrodesmus spp. & $10^{3}$ & See & 15 & 30 & 21 & 24 & 15 & 9 & 15 & 30 \\
\hline & & $\mathrm{K}$ & 3 & 5 & 18 & 12 & 21 & 9 & 6 & \\
\hline Chlorella pyrenoidosa & $10^{5}$ & See & 78 & 55 & 18 & 8 & 13 & 24 & 8 & 5 \\
\hline & & $K$ & 69 & 9 & 26 & 10 & 22 & 23 & 14 & 9 \\
\hline Mougeotia sp. & $10^{4}$ & See & 6 & 11 & 14 & 6 & 7 & 4 & 5 & 6 \\
\hline & & $\mathrm{K}$ & 12 & 4 & 16 & 6 & 4 & 8 & 5 & 16 \\
\hline Cryptomonas spp. & $10^{4}$ & See & 13 & 8 & 14 & 9 & 11 & 15 & 10 & 11 \\
\hline & & $\mathbf{K}$ & 8 & 2 & 12 & 12 & 10 & 11 & 15 & 6 \\
\hline Rhodomonas spp. & $10^{4}$ & See & 8 & 16 & 29 & 14 & 7 & 50 & 26 & 19 \\
\hline & & $\mathrm{K}$ & 11 & 2 & 18 & 14 & 27 & 35 & 15 & 12 \\
\hline
\end{tabular}




\subsection{Düngexperimente}

Versuch 1

Dauer 4.-16. Mai 1970.

Düngung $50 \mu g / 1$ NTA und/oder $30 \mu \mathrm{g} / 1 \mathrm{Fe}$ gemäss Tabelle 1 .

Ziel Wirkung kleiner Mengen Eisen und NTA im nährstoffarmen Oberflächenwasser eines mesotrophen Sees.

Das Experiment konnte erst gestartet werden, nachdem sich die thermische Schichtung des Wasserkörpers stabilisiert hatte. Die Temperaturdifferenz vom Oberflächenwasser zum Wasser in $10 \mathrm{~m}$ Tiefe betrug nur $2^{\circ} \mathrm{C}$. Das ruhige sonnige Wetter, das nur vom 11. bis 13. Mai durch Regenfälle unterbrochen wurde, gestattete aber eine einwandfreie Durchführung des Experiments. Die Gefahr einer stärkeren Turbulenz und damit eines erhöhten Austausches durch die untere Testzellenöffnung bestand nicht.

In den ersten beiden Versuchen im Vierwaldstättersee war eine wellengetriebene Rühreinrichtung eingebaut worden. In einem speziellen Düngexperiment mit Chlorid (im Anschluss an den zweiten Versuch im Vierwaldstättersee) wurde festgestellt, dass die Zeitspanne, in der die Hälfte des zugegebenen Chlorids aus der Testzelle verschwand (Halbwertszeit), in einer Testzelle mit Rührer 3 Tage und in den Testzellen ohne Rühreinrichtung 4-5 Tage betrug. Um den Austausch des Kulturwassers mit den Wasserschichten der Umgebung nicht noch zu fördern, wurde in den späteren Experimenten die Rühreinrichtung weggelassen. Die Turbulenz in den Kultureinheiten war auch ohne Rührer stark genug, um grosse, passive Plankter lange Zeit in der Schwebezone zu halten. Die Chlorid-Halbwertszeiten wurden im allgemeinen durch die Analytik der Gesamteisengehalte bestätigt. Somit ist anzunehmen, dass das zugefügte Eisen nicht zu grossen, schneller sedimentierenden Flocken koagulierte.

Das Phytoplankton setzte sich zur Zeit des ersten Versuchs vorwiegend aus Bacillariophyceen zusammen: Tabellaria fenestrata, Fragilaria crotonensis, Synedra acus, Stephanodiscus hantzschii. Die andern häufig beobachteten Arten gehören zu den Klassen Cyanophyceae (Oscillatoria rubescens), Chlorophyceae (Chlorella pyrenoidosa, Ankistrodesmus spp.) und Cryptophyceae (Cryptomonas spp. und Rhodomonas spp.). Da $\epsilon$ sich bei den zuletzt genannten vier Algengattungen um Vertreter des Nannoplanktons handelt, fielen sie trotz grosser Zellendichte als Biomasse nicht stark ins Gewicht. Die Biomasse, die mit 2-3 mg/l für den Vierwaldstättersee eher hoch war, wurde zu $80 \%$ von Kieselalgen gebildet. Die Sichttiefe von 2,8 m wies darauf hin, dass die grösste Planktondichte vermutlich unterhalb 2,5 $\mathrm{m}$ Wassertiefe lag.

Die Reaktion des Phytoplanktons ist zusammen mit den Resultaten der weiteren zwei Versuche im Vierwaldstättersee in den Abb. 4, 5, 6, 8 und 9 dargestellt. Alle Darstellungen zeigen die Reaktion der gedüngten Algen summarisch oder nach Arten aufgeteilt gegenüber der Kontrolle als Bezugswert. Der Bezugswert wurde in den Abb. 4, 5 und 6 als 100\% gesetzt; für die Abb. 8 und 9 gilt die Erklärung in Abb. 7.

Sowohl Biomasse als auch Photosyntheserate wurden durch alle Zusätze erhöht. Am Tage nach der ersten und zweiten Düngung war die Primärproduktion in allen gedüngten Testzellen deutlich erhöht, nach der dritten Düngung war keine Wirkung 
mehr zu beobachten (alle Werte liegen im Bereich der Kontrolle $\pm 10 \%$ ). Die Biomasse erreichte den Höhepunkt ihrer Entwicklung etwa 4 Tage nach der ersten Düngung (Maximalwert in der Testzelle 2 [Eisenzugabe] mit 220\% am 9. Mai). Die Abnahme der Biomasse, die im wesentlichen auf Sedimentation und bakterieller Destruktion beruhte, erfolgte nicht so schnell wie die Abnahme der Biomasseaktivität (= Produktion pro Biomasse-Einheit). Bereits nach drei Tagen war diese Aktivität in den gedüngten Testzellen geringer als in der Kontrolle.

Für die Zunahme der Biomasse waren in erster Linie Chlorophyceen und Cryptophyceen und erst in zweiter Linie Bacillariophyceen und Cyanophyceen verantwortlich. Cryptomonas und Rhodomonas-Arten, die sich durch einen schnellen Teilungsrhythmus auszeichnen, waren in den gedüngten Testzellen 2-bis 5 mal so häufig wie in der Kontrolle. Von den Kieselalgen reagieren Cyclotella- und Synedra-Arten positiv, insbesondere auf Eisendüngung.

Versuch 2

Dauer 10.-19. Juli 1970.

Düngung $60 \mu \mathrm{g} / \mathrm{l} \mathrm{Fe}$ und/oder $100 \mu \mathrm{g} / \mathrm{l}$ NTA.

Ziel Aufschluss über die Wirkung der Fe- und NTA-Zufuhr durch eine Abwasserreinigungsanlage mit dritter (Fe-Fällungs-)Stufe nach erfolgtem Ersatz der Polyphosphate in den Waschmitteln durch NTA.

Da zur Versuchszeit sowohl Phosphor als auch Stickstoff in sehr geringen Konzentrationen vorlagen, konnte die Wirkung der Zusätze auf das Plankton eines schwach mesotrophen Sees studiert werden. Das ausgesprochene Nährstoffdefizit kam in den trotz schönem Wetter geringen Photosyntheseraten und der grossen Sichttiefe von 6,2 $\mathrm{m}$ zum Ausdruck. Eine lang dauernde Schönwetterperiode, die auch im Verlaufe des Versuchs 2 nur am 15. und 16. Juli durch einen Sturmregen unterbrochen wurde, bewirkte die Erwärmung des Oberflächenwassers auf über $20^{\circ} \mathrm{C}$. Der Temperaturgradient betrug bis in $10 \mathrm{~m}$ Tiefe etwa $1{ }^{\circ} \mathrm{C}$ pro Meter.

Das Experiment musste nach 10 Tagen wegen Beschädigung der Versuchseinrichtung vorzeitig abgebrochen werden.

Die Zusammensetzung des Planktons hatte sich seit dem ersten Versuch nur unwesentlich verändert. Noch immer dominierten Bacillariophyceen, von denen z.B. Fragilaria crotonensis und Tabellaria fenestrata zusammen die Hälfte der gesamten Biomasse ausmachten.

Die Chlorophyceen waren weitgehend verschwunden, dafür waren die Cryptophyceen stärker vertreten. Die Konjugaten waren durch die fädige Form Mougeotia relativ zahlreich vertreten. Die Reaktion des Phytoplanktons auf die Zusätze war äusserst schwach. Die Primärproduktion lag nur in den ersten 2 Tagen nach der Düngung über der Kontrolle. Schon nach einer Woche wiesen alle gedüngten Testzellen geringere Photosyntheseleistung auf als die Kontrolle. Im See und in sämtlichen Testzellen nahm die Biomasse nach dem Sturm am 15. und 16. Juli sprunghaft zu. Dieser Anstieg ging unzweifelhaft auf die allochthone Zufuhr aus der Tiefe infolge erhöhter Turbulenz zurück.

Versuch 3

Dauer 7.-30. September 1970. 
Düngung In allen Testzellen $20 \mu \mathrm{g} / 1 \mathrm{PO}_{4}-\mathrm{P}$ und $100 \mu \mathrm{g} / 1 \mathrm{NO}_{3}-\mathrm{N}$ zusätzlich in den Testzellen 1-3 $50 \mu \mathrm{g} / 1 \mathrm{Fe}$ und/oder $150 \mu \mathrm{g} / \mathrm{l}$ NTA.

Ziel Einfluss von NTA und Eisen unter den Verhältnissen eines stärker eutrophierten Sees. Abklärung, ob die Resorption der zusätzlichen Nährstoffe durch Fe und NTA beeinflusst wird.

Das Experiment geriet in die erste Abkühlungsphase des Sees. Die nächtliche Abkühlung des Wassers glich die Erwärmung während des Tages aus und dominierte schliesslich. Konvektionsbedingte Durchmischung bis in die Tiefe von 4 bis $5 \mathrm{~m}$ war die Folge.

Das Plankton, von fädigen Formen (Oscillatoria und Mougeotia) dominiert, hatte im See eine Biomasse zwischen 0,9 und 1,7 mg/l. In der Kontrolle (Phosphat- und Nitratdüngung) variierte die Biomasse von $1,1 \mathrm{bis} 2,2 \mathrm{mg} / \mathrm{l}$. Die durchschnittliche Erhöhung der Biomasse lag bei etwa 20\% (See =100\%). Die zusätzliche Düngung mit NTA und der Kombination NTA + Eisen bewirkte, wie schon in den ersten beiden Versuchen, eine anfängliche Erhöhung der Photosyntheserate und - verspätet - auch eine Steigerung der Biomasse. In der Testzelle mit Eisendüngung konnte zwar nach der ersten Zugabe eine Steigerung der Photosyntheserate beobachtet werden, da aber die Photosynthese schnell auf 50-70\% der Kontrolle absank, resultierte ein mittlerer Verlust an Biomasse um 11\% (Kontrolle $=100 \%$ ). In Abb. 5 ist die Reaktion der Biomasse mit durchbrochenen Sternsymbolen dargestellt, um die abweichende Reaktion dieser Testzelle deutlich zu machen.

Die Reaktion der einzelnen Planktonarten war unterschiedlich, aber im Mittel schwach (vgl. Abb. 8 und 9).

Die Sedimentationsraten in den Testzellen lagen in der gleichen Grössenordnung wie im See. Obwohl keine Rühreinrichtung mehr verwendet wurde, war die tägliche Sedimentation geringer als in den ersten beiden Versuchen.

\subsection{Die Wirkung der einzelnen Zusätze auf die Entwicklung des gesamten Phytoplanktons}

In den Abb. 4, 5 und 6 ist der Einfluss der drei Düngkombinationen auf das Wachstum (gemessen an Photosyntheserate und Biomasse) relativ zur Kontrolle dargestellt. Diese Darstellung ergibt zwar eine grosse Streuung, weil der Bezugswert (Kontrolle $=100 \%$ ) selbst variabel ist; gestattet aber die gleichzeitige Darstellung verschiedener Werte (hier Primärproduktion und Biomasse) mehrerer Experimente. Durch Schraffur (senkrecht für Photosyntheseleistung, waagrecht für Biomasse) wurde die ungefähre Breite der Streuung optisch verdeutlicht, wobei Extremwerte, die durch inhomogene Verteilung des Planktons in den Testzellen verursacht sind (Klonbildung eigenbeweglicher Phytoplankter), vernachlässigt wurden.

Aus technischen Gründen war es nicht möglich, die Zahl der Analysen so weit zu erhöhen, dass für das Verhalten des Phytoplanktons in jeder Testzelle eine gesicherte Regression berechnet werden konnte.

Die Primärproduktion zeigt in allen drei Abbildungen einen andern Verlauf als die Biomasse: In der Form einer gedämpften Sinusschwingung sinkt die Photosyntheserate von einem Ausgangswert, der im Mittel etwa 130\% der Kontrolle beträgt, über 100\% (am 3.-4. Tag) auf 90\%, um sich gegen Ende der Versuche um die Bezugsachse einzupendeln. Die Biomassemaxima wandern mit einer zeitlichen Verzögerung 

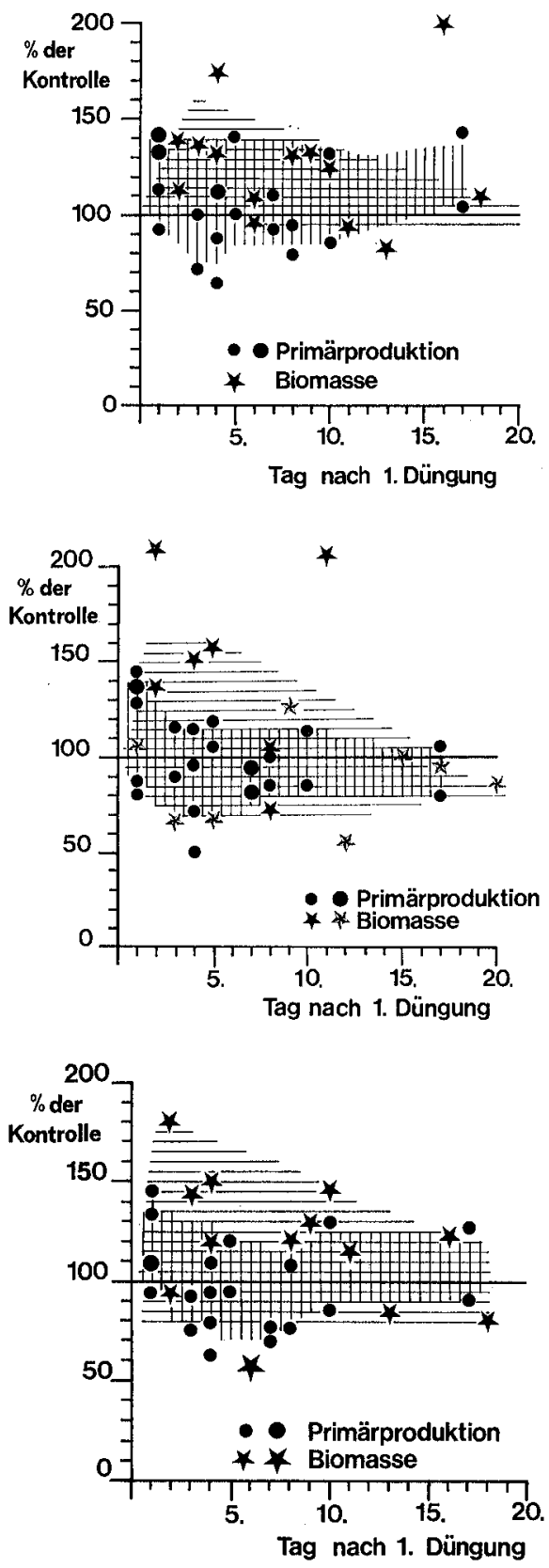

Abb. 4. Die Wirkung von 50 bis $150 \mu \mathrm{g} / \mathrm{l}$ NTA auf das Wachstum des Phytoplanktons im Vierwaldstättersee während der Sommerstagnation. Kleine Zeichen: 1 Einzelwert; grosse Zeichen: 2 Einzelwerte; Schraffur senkrecht: Bereich der Primärproduktionswerte ohne Extremwerte; Schraffur waagrecht: Bereich der Biomassewerte ohne Extremwerte.

Fig. 4. Effect of 50 to $150 \mu \mathrm{g} / 1$ NTA on phytoplankton growth in Lake Lucerne during the summer stagnation period.

Small symbols: 1 single value; large symbols: 2 single values; vertical hatching: Reach of the primary production (without extreme values); horizontal hatching: Reach of the biomass (without extreme values).

Abb. 5. Die Wirkung von 30 bis $60 \mu g / 1$ Fe auf das Wachstum des Phytoplanktons im Vierwaldstättersee während der Sommerstagnation. Biomassewerte des 3. Versuchs mit durchbrochenen Sternsymbolen, sonst Symbole wie Abb. 4 . Fig. 5. Effect of 30 to $60 \mu \mathrm{g} / \mathrm{l}$ Fe on phytoplankton growth in Lake Lucerne during the summer stagnation period. Partially filled out star symbols represent biomass values of the third experiment, the other values are represented in accordance with Figure 4.

Abb. 6. Die Wirkung von 50 bis $150 \mu g / 1$ NTA kombiniert mit 30 bis $60 \mu \mathrm{g} / \mathrm{l}$ Fe auf das Wachstum des Phytoplanktons im Vierwaldstättersee während der Sommerstagnation. Schraffur und Symbole wie in Abb. 4.

Fig. 6. Effect of 50 to $150 \mu \mathrm{g} / \mathrm{l}$ NTA combined with 30 to $60 \mu \mathrm{g} / \mathrm{l} \mathrm{Fe}$ on phytoplankton growth in Lake Lucerne during the summer stagnation period. All symbols are represented in accordance with Figure 4.

von 1 bis 3 Tagen hinter den maximalen Assimilationswerten nach. Der Abbau der Biomasse erfolgt trotz geringer photosynthetischer Aktivität des Planktons nicht so schnell wie der Aufbau; aus diesem Grunde ist es möglich, dass das Maximum der Biomasse mit einem Assimilationsminimum zusammenfällt. Dieses Verhalten ist durch die Nährstoffsituation erklärbar. 
Mittelt man für jedes Experiment nach der Trapezregel die Biomassewerte aller gedüngten Testzellen, erhält man Werte, die 103\% (Versuch 3) bzw. 114\% (Versuch 2) und $161 \%$ (Versuch 1) der Kontrolle betragen. Fortgesetzte Eisen- oder NTADüngung steigert nach 10-14 Tagen die Primärproduktion nicht weiter; auf längere Sicht wird demnach auch die Biomasse nicht wesentlich erhöht. Der Entwicklungsverlauf einzelner Planktonarten wird durch die Zusätze schwach verändert, in dem Sinne, dass jene Arten, die innerhalb der Sukzession ihr Entwicklungsmaximum noch nicht erreicht haben, beschleunigt wachsen und Arten, die bereits von andern Planktern verdrängt werden, schneller verschwinden. In der kurzen Versuchszeit (14 Tage) ist nie beobachtet worden, dass durch den Zusatz von NTA oder Fe eine Art besonders gefördert oder gehemmt wurde. In den Sedimentfallen kommt die kurzfristig veränderte Biomasse nicht zum Ausdruck.

\subsection{Die Wirkung der Zusätze auf die Entwicklung der einzelnen Phytoplanktonarten}

Summarische Methoden wie die Messung der Primärproduktion oder des Pigmentgehalts geben keinen Anhaltspunkt dafür, ob die beobachtete Wirkung auf eine mässige Reaktion vieler Arten oder auf besonders ausgeprägtes Reagieren einer einzigen Art zurückzuführen ist. Hier beginnt die Aufgabe des Ökologen. Sie ist durch ihr Objekt bedingt - recht mühsam, indem die Algen Art für Art in statistisch genügender Zahl (>100 Individuen) auszuzählen und für die Biomasseberechnung auszumessen sind. Von den 67 ausgezählten Algenarten sind in den Abb. 8 und 9 nur 14 Arten bzw. Gattungen aufgetragen. Alle nicht dargestellten Arten und Gattungen waren entweder nur sporadisch oder in statistisch ungenügender Zahl im Plankton vertreten.

Die Reaktion der einzelnen Arten auf die Zusätze wurde in ähnlicher Weise wie in den Abb. 4-6 durch die relative Hemmung oder Steigerung des Wachstums dargestellt. Für beide Reaktionen wurde der gleiche Maßstab gewählt.

Das Zellzahlverhältnis wurde gemäss Abb. 7 dargestellt.

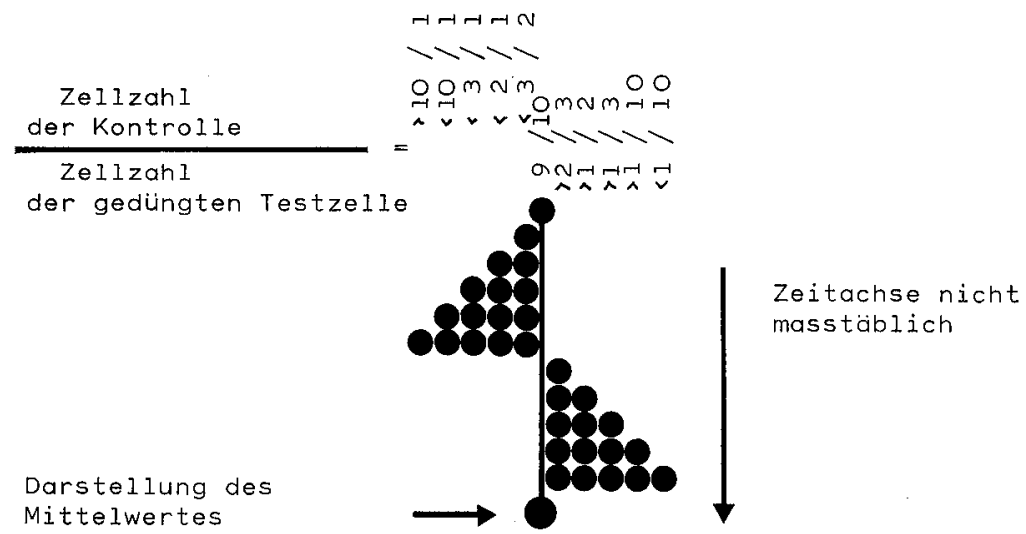

Abb. 7. Schema zur. Darstellung der Reaktion einzelner Planktonarten auf die Zusätze in den Abb. 8, 9, 15, 16 und 17.

Fig. 7. Representation of the reaction of individual plankton species to input in Figures 8, 9, 15, 16 and 17. 
Die Zeitachse ist nicht maßstäblich; zwischen zwei Probenahmen liegen 2-4 Tage, entsprechend den Probenahmedaten in den Tabellen 7 und 8.

Punkte rechts des Orientierungsstrichs zeigen eine erhöhte Zellzahl in der gedüngten Testzelle gegenüber der Kontrolle, Punkte links des Strichs relative Hemmung, d.h. geringere Zellendichte als in der Kontrolle. Die Mittelwerte (arithmetisches Mittel) sind nach der gleichen Skala mit grossen Punkten relativ zum Mittelwert der Kontrolle dargestellt.

Die Reaktion der Algenarten auf die Düngstoffe spricht im allgemeinen eher für einen unspezifisch wirkenden Mechanismus. Man erkennt zwar Unterschiede in der Reaktion der verschiedenen Algenklassen; so reagieren die Cryptophyceen sehr deutlich in 8 von 9 gedüngten Testzellen, die Chlorophyceen in 15 von 21 Fällen, die übrigen Algengruppen zu mehr als 30\% positiv, d.h. mit einer Wachstumssteigerung auf die angebotenen Stoffe. Der gleiche Zusatz wirkt aber im Laufe der Zeit auf die gleiche Spezies nicht stets einheitlich. Geringfügige Verschiebungen können durch die besonders grosse Streuung der Zellendichte erklärt werden. Ebenso ist es möglich, dass Änderungen in der Planktonzusammensetzung (z.B. Entwicklung des Zooplanktons, Grazing) selektiv einzelne Arten beeinträchtigt. Wo die Mittelwerte aus $>300$ effektiv ausgezählten Individuen ermittelt worden sind, ist der methodi-

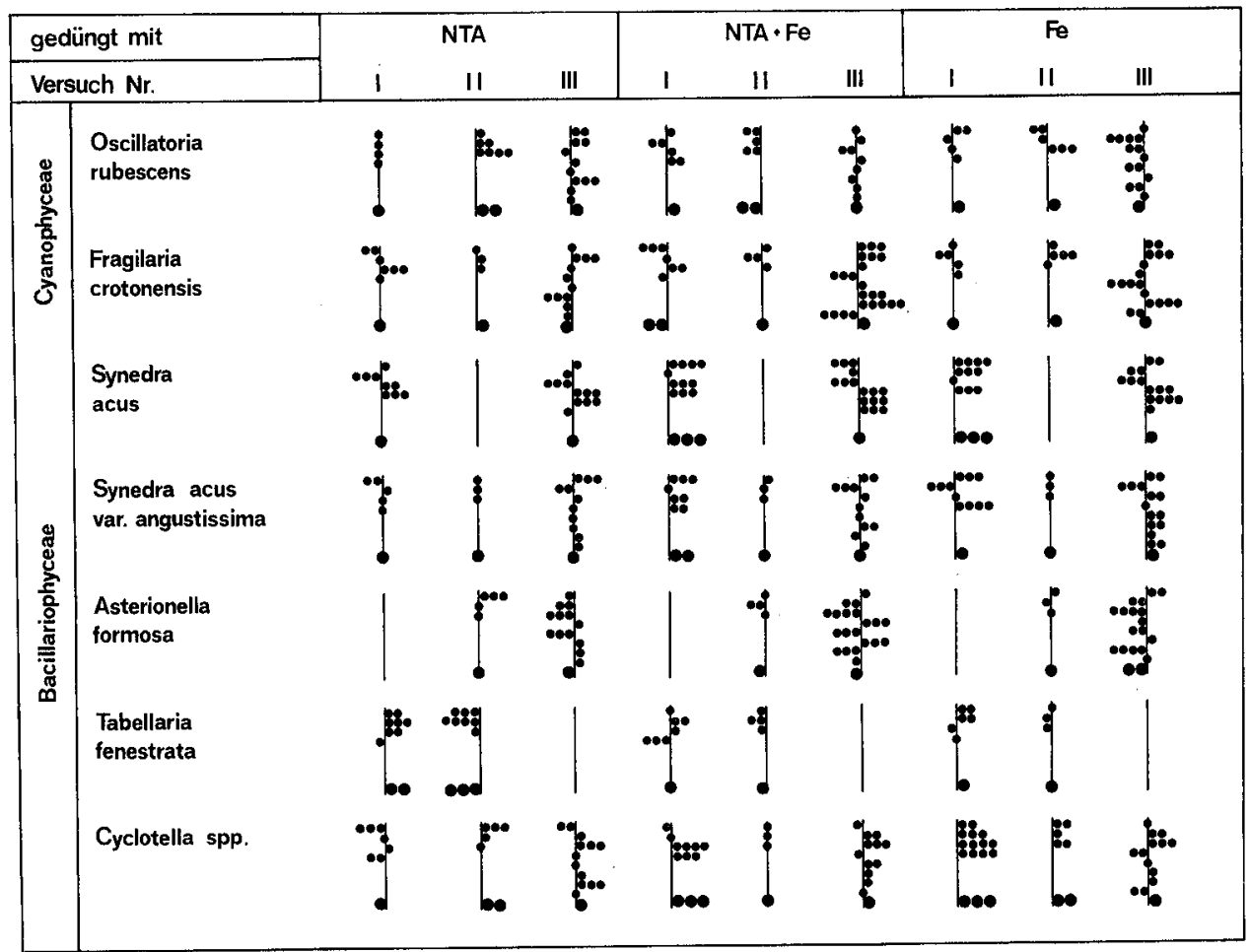

Abb. 8. Die Reaktion der wichtigsten Phytoplanktonarten (1. Teil) im Vierwaldstättersee auf die Zusätze NTA und/oder Eisen.

Fig. 8. Reaction of the main phytoplankton species (part 1) to NTA and/or iron input in Lake Lucerne. 


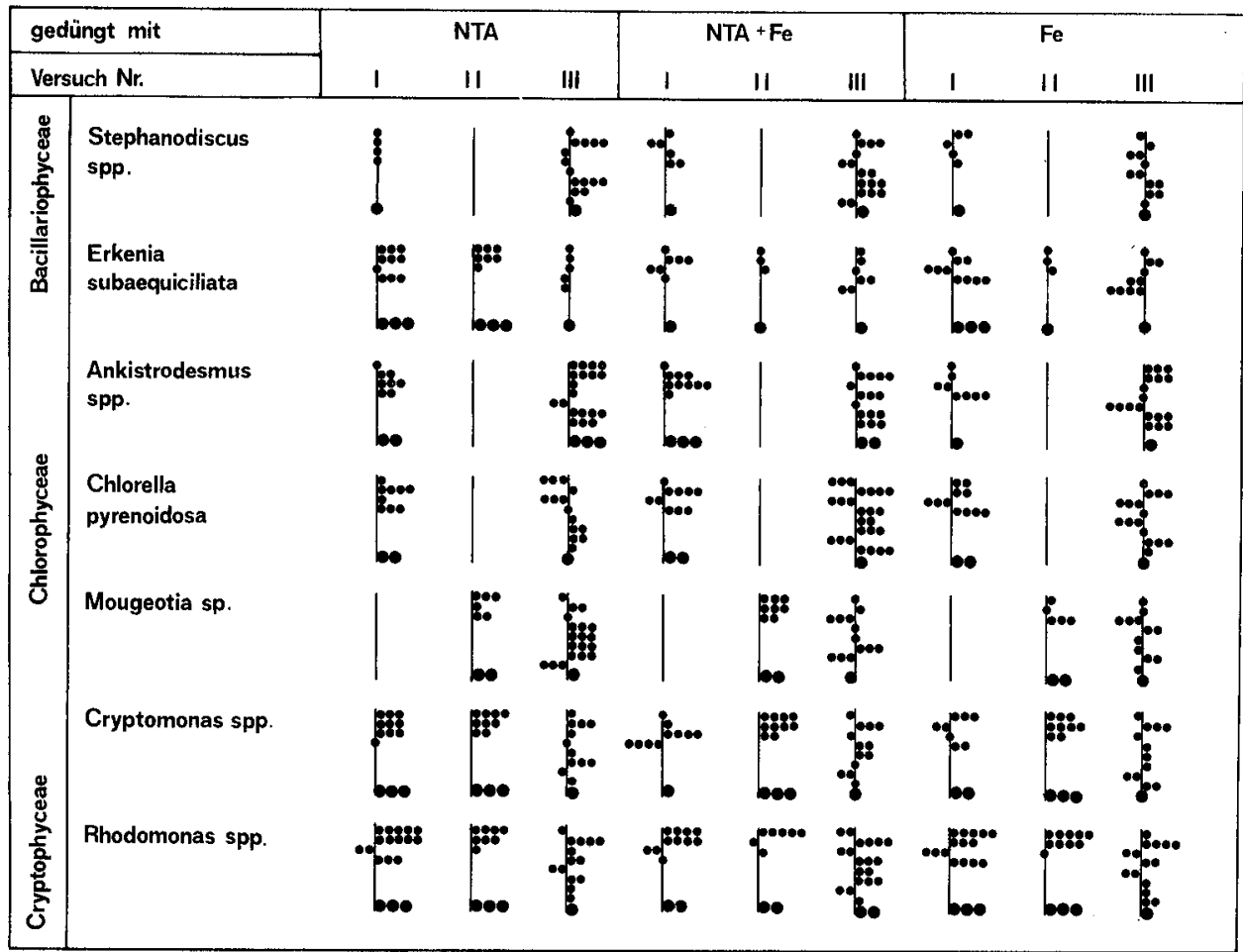

Abb. 9. Die Reaktion der wichtigsten Phytoplanktonarten (2. Teil) im Vierwaldstättersee auf die Zusätze NTA und/oder Eisen.

Fig. 9. Reaction of the main phytoplankton species (part 2) to NTA and/or iron input in Lake Lucerne.

sche Zählfehler $<20 \%$ [143]. Ausgeprägte Unterschiede, welche ein und dieselbe Art von Experiment zu Experiment bei dem gleichen Zusatz zeigt, sind nicht durch methodische Analysenfehler zu erklären. Der Grund für die beobachteten Schwankungen von Experiment zu Experiment wird in der Diskussion behandelt.

\section{Resultate Greifensee}

\subsection{Physikalische Daten}

Tabelle 10. Temperatur, Leitfähigkeit und Sichttiefe an der Probestelle Greifensee.

Table 10. Temperature, conductivity and visiblity depth at the sampling site in the Greifensee.

\begin{tabular}{lllll}
\hline $\begin{array}{l}\text { Temperatur } \\
\left({ }^{\circ} \mathrm{C}\right)\end{array}$ & Versuch & & & \\
Tiefe in m & 1 & 2 & 3 & 4 \\
\hline 0 & 9.7 .1971 & 18.8 .1971 & 21.10 .1971 & 22.3 .1972 \\
2 & 26,6 & 24,9 & 13,9 & 8,2 \\
4 & 23,4 & 24,5 & 13,1 & 7,4 \\
6 & 20,2 & 21,3 & 13,0 & 6,8 \\
8 & 17,8 & 14,0 & 13,0 & 5,8 \\
10 & 13,4 & 12,0 & 12,9 & 4,8 \\
& 10,8 & 10,2 & 12,0 & 4,5 \\
\hline
\end{tabular}


Tabelle 11. Nährstoffe, Sauerstoff, Säureverbrauch und pH-Wert an der Probestelle Greifensee. Aufgetragen sind die Maxima und Minima aus Mischproben von 0 bis $5 \mathrm{~m}$ Tiefe (aller Testzellen).

Table 11. Nutrient, oxygen, alcalinity and pH-values at the sampling site in the Greifensee. Maximum and minimum values from mixed samples $(0-5 \mathrm{~m})$, from all sampling units are indicated.

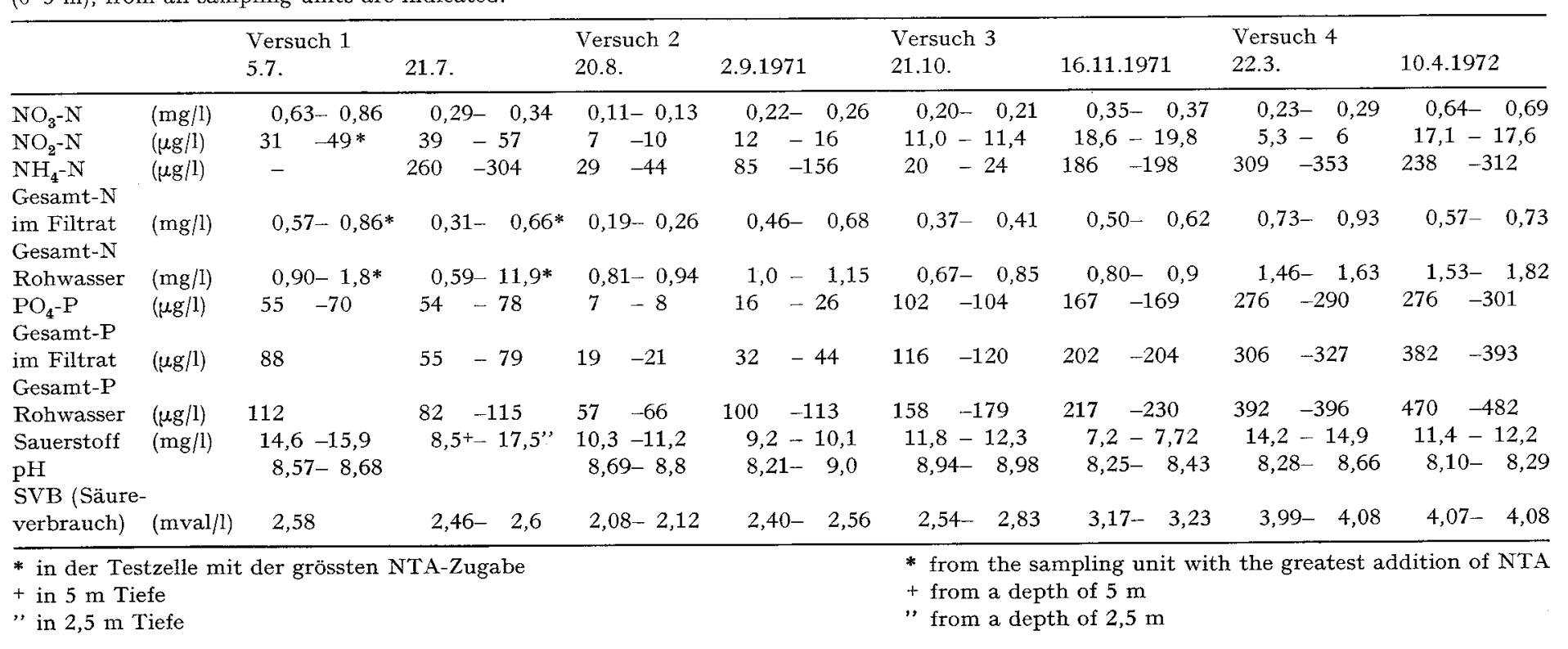


Fortsetzung Tabelle 10.

\begin{tabular}{|c|c|c|c|c|}
\hline $\begin{array}{l}\text { Leitfähigkeit } \\
{\left[\mu \mathrm{S} \mathrm{cm} \mathrm{cm}^{-1} ; 20^{\circ} \mathrm{C}\right]} \\
\text { Tiefe in } \mathrm{m}\end{array}$ & 9.7 .1971 & 18.8 .1971 & 21.10 .1971 & 22.3 .1972 \\
\hline 0 & 248 & 229 & 290 & 387 \\
\hline 2 & 281 & 231 & 296 & 388 \\
\hline 4 & 368 & 298 & 298 & 395 \\
\hline 6 & 388 & 377 & 299 & 400 \\
\hline 8 & 407 & 410 & 308 & 406 \\
\hline 10 & 397 & 421 & 347 & 409 \\
\hline Sichttiefe $[\mathrm{m}]$ & 1,4 & 1,2 & 1,0 & 0,7 \\
\hline
\end{tabular}

\subsection{Chemische Daten}

Tabelle 12. Spurenmetalle und TOC im Greifensee: TOC bei der Experimentierstelle, Spurenmetalle bei der Stelle "Profil». Table 12. Trace metals (at the site 'Profil') and TOC (at the place of experimentation) in the Grei-
fensee.

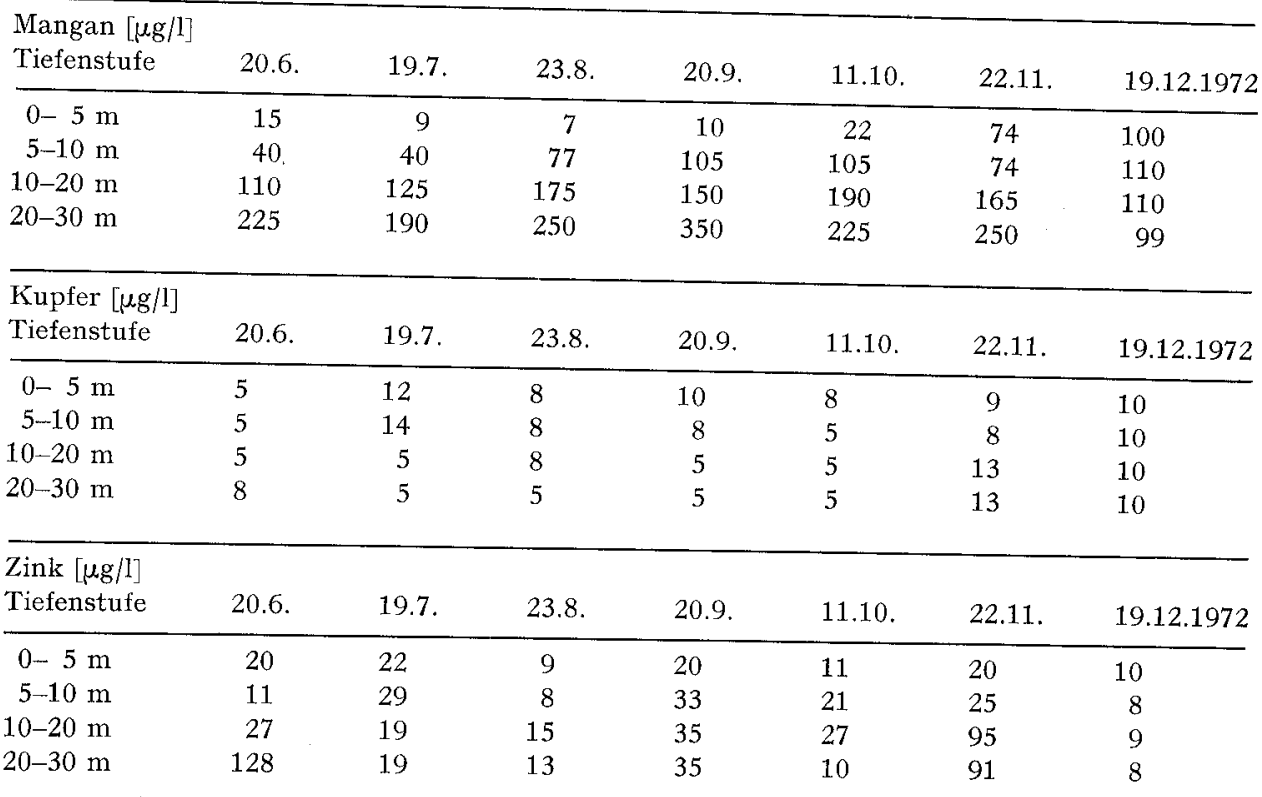

Kadmium lag 1972/73 immer unter der Erfassungsgrenze von 0,5 $\mu \mathrm{g} / \mathrm{l}$.

Chrom lag 1972/73 immer unter der Erfassungsgrenze von $2 \mu \mathrm{g} / \mathrm{l}$.

Blei lag 1972/73 immer unter der Erfassungsgrenze von $5 \mu \mathrm{g} / 1$.

TOC (Totaler organischer Kohlenstoff im Filtrat) [mg/1]
Juli-August
September-Oktober
$2,9-3,3$
November-Dezember 1971
5, 15-5,6
3,0-3,3

Es wurden jeweils 5 Mischproben von der Experimentierstelle (0-5) m analysiert und die Maxima und Minima aufgeführt. 
Tabelle 13. Gesamteisengehalte im Rohwasser (in $\mu \mathrm{g} / \mathrm{l}$ ) und Gesamteisengehalte des filtrierten Wassers (in $\mu \mathrm{g} / 1$ in Klammern). - Mit Pfeil $(\downarrow)$ sind die Düngungen gemäss Tabelle 1 markiert. Alle Werte sind gemittelt aus 3 Tiefen: 1, 2, $4 \mathrm{~m}$.

Table 13. Total iron content in the crude water (expressed in $\mu g / l$ ) and total iron content of the filtered water (in parentheses). - The arrow $(\downarrow)$ indicates the moment of input in accordance with the experimentation plan. All values are based on the average of 3 depths: 1,2 and $4 \mathrm{~m}$.

\begin{tabular}{lcccr}
\hline $\begin{array}{l}\text { Versuch } 1 \\
5.7 .1971\end{array}$ & 76,5 & $(59)$ & (Keine Eisendüngung) & \\
\hline $\begin{array}{llll}\text { Versuch 2 } \\
\text { Testzelle }\end{array}$ & $20.8 . \downarrow$ & 25.8 & $28.8 . \downarrow$ & 2.9 .1971 \\
\hline 0 (Kontrolle) & $34(25)$ & $30(19)$ & $32(17)$ & $28(15)$ \\
1 (NTA) & $28(16)$ & $24(16)$ & $25(16)$ & $28(16)$ \\
3 (NTA + Fe) & $25(21)$ & $53(21)$ & $41(19)$ & $81(23)$ \\
2 verunfallt & & & & \\
\end{tabular}

\begin{tabular}{lcccccc}
\hline $\begin{array}{l}\text { Versuch 3 } \\
\text { Testzelle }\end{array}$ & $21.10 . \downarrow$ & 24.10. & $27.10 . \downarrow$ & 3.11. & 10.11. & 16.11. \\
\hline 0 (Kontrolle) & $61(16)$ & $46(15)$ & $47(19)$ & $28(12)$ & $46(9)$ & $38(15)$ \\
$1(\mathrm{NTA})$ & $54(16)$ & $42(29)$ & $46(22)$ & $26(10)$ & $48(10)$ & $43(11)$ \\
$2(\mathrm{Fe})$ & $52(20)$ & $65(29)$ & $40(18)$ & $49(11)$ & $46(10)$ & $39(11)$ \\
$3(\mathrm{NTA}+\mathrm{Fe})$ & $53(17)$ & $81(37)$ & $81(19)$ & $52(17)$ & $47(8)$ & $39(9)$ \\
\hline
\end{tabular}

\begin{tabular}{llllllll}
\hline $\begin{array}{l}\text { Versuch 4 } \\
\text { Testzelle }\end{array}$ & $22.3 . \downarrow$ & 23.3. & 26.3. & $27.3 . \downarrow$ & 30.3. & $4.4 . \downarrow$ & 10.4. \\
\hline 0 (Kontrolle) & $47(20)$ & $31(15)$ & $34(8)$ & $34(8)$ & $48(8)$ & $39(7)$ & $49(10)$ \\
1 (NTA) & $41(17)$ & $31(12)$ & $36(10)$ & $40(7)$ & $50(8)$ & $42(9)$ & $51(13)$ \\
$2($ Fe) & $40(22)$ & $46(15)$ & $55(12)$ & $55(12)$ & $80(7)$ & $49(10)$ & $54(11)$ \\
3 (NTA + Fe) & $41(23)$ & $48(25)$ & $39(10)$ & $57(11)$ & $80(13)$ & $46(11)$ & $56(12)$
\end{tabular}

\subsection{Eisenkreislauf im Greifensee (Stelle "Profil»)}

In Abb. 10 sind die Gesamteisengehalte im Rohwasser und der prozentuale Anteil des partikulären Eisens (im Sinne von nicht filtrierbar durch $0,45 \mu \mathrm{m}$ Porenweite) zusammengestellt.

Die kräftig ausgezogenen Linien begrenzen die homotherme Schicht während der Zirkulation im Winter 1971/72 bzw. Herbst 1972. Die höchsten Eisengehalte werden nach einsetzender Zirkulation im Tiefenwasser gemessen. Das Oberflächenwasser verliert in dieser Zeit durch Sedimentation einen grossen Teil seines Eisens, welches sich sodann über Grund, vorwiegend in partikulärem Zustand, akkumuliert und am Ende der Frühjahrszirkulation zu $80 \%$ sedimentiert.

Die Akkumulation des Eisens dauerte bis zum Februar; erst von diesem Moment an wurde auch die unterste Wasserschicht ( $>20 \mathrm{~m}$ Tiefe) so weit mit Sauerstoff versorgt, dass ein grosser Teil des Gesamteisens oxydierte und sedimentierte. Die Gesamteisengehalte beim Beginn der Zirkulation 1971 unterschieden sich deutlich vom Gesamteisen bei der Zirkulation 1972/73, insbesondere in den oberen $10 \mathrm{~m}: 1971$ setzte die Zirkulation sehr zaghaft ein, so dass die auftretenden Turbulenzen zu schwach waren, um das Eisen, das an der Kontaktzone des Tiefenwassers mit sauer- 

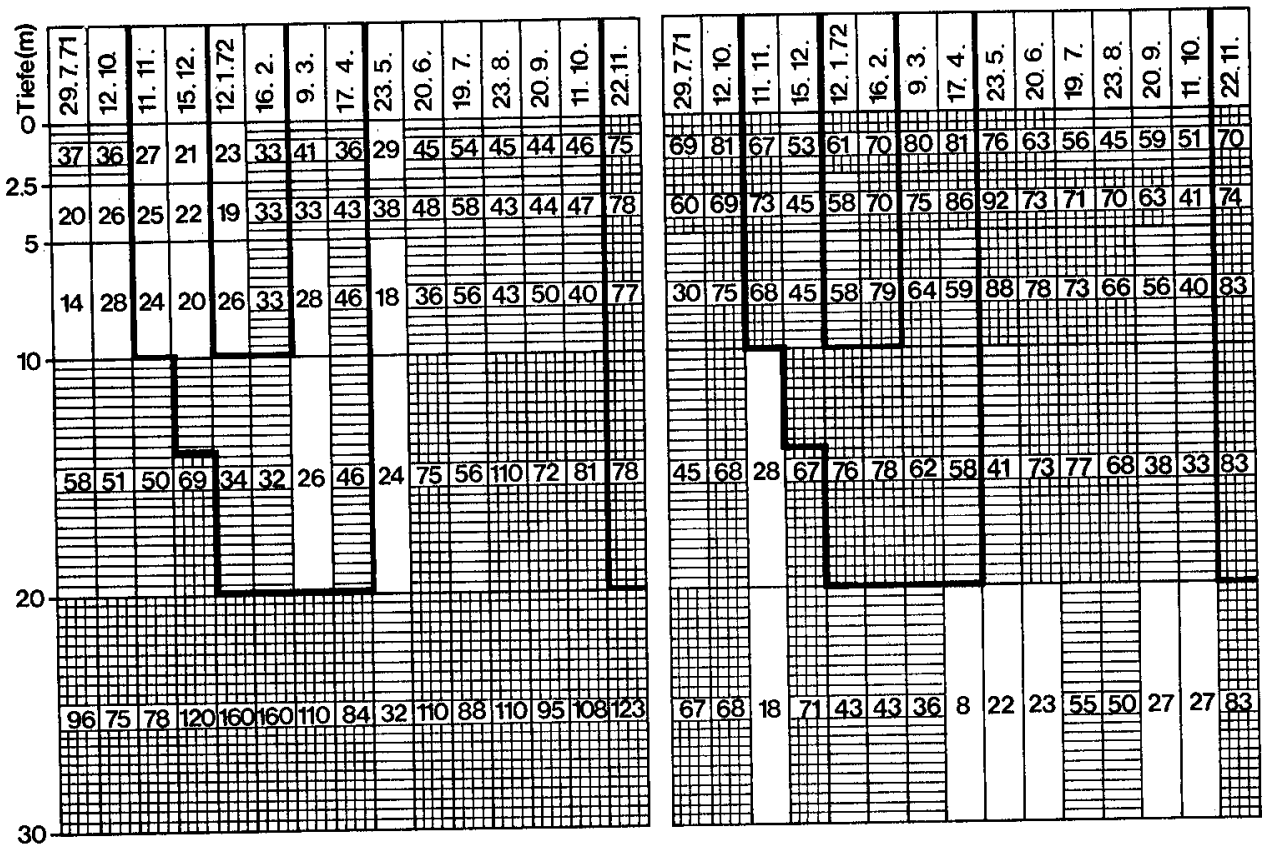

Abb. 10. Gesamteisenkonzentrationen (in $\mu g / 1)$ an der tiefsten Stelle im Greifensee (= Stelle «Profil») (links) und der prozentuale Anteil des nichtfiltrierbaren $(>0,45 \mu \mathrm{m})$ Eisens vom Gesamteisengehalt (rechts).

Fig. 10. Total iron concentration (expressed in $\mu \mathrm{g} / 1$ ) at the deepest point of the Greifensee (= site 'Profil' (left) and the percent of non-filtrable $(>0,45 \mu \mathrm{m})$ iron in the total iron content (right).

stoffhaltigem Wasser oxydiert und in den partikulären Zustand überführt wurde, in Schwebe zu halten. Stürmisches Wetter und Hochwasser liessen hingegen im Winter 1972/73 die Zirkulation so rasch vorstossen, dass sie schon Mitte Dezember den Grund erreichte. Die Bewegung der Wassermengen war so stark, dass die Sedimentation des Planktons und des partikulären Eisens durch die turbulente Mischung verlangsamt wurde. Die Gesamteisengehalte sanken dann aber im Dezember und Januar rapide ab (in den Tabellen 1 und 2 nicht mehr dargestellt), auf etwa $30 \mu \mathrm{g} / 1$. In der Zeit vom Mai bis November 1972 nahm der Eisengehalt der gesamten Wassersäule durch Rücklösung aus dem Sediment einerseits und durch allochthone Zufuhr aus Flüssen anderseits zu. Unterhalb $10 \mathrm{~m}$ Tiefe lag dieses Eisen vorwiegend in filtrierbarer, oberhalb $10 \mathrm{~m}$ vorwiegend in nichtfiltrierbarer Form vor.

Für die grossen Schwankungen des relativen Anteils an "partikulärem» Eisen über Grund scheinen, neben ungleichmässiger Sedimentation des Planktons, auch methodische Unzulänglichkeiten verantwortlich, z.B. die Zeit zwischen der Probenahme bis zum Filtrieren und die Dauer der Filtration. Jedenfalls beobachteten wir, dass einige Stunden Wartezeit beachtliche Verschiebungen des prozentualen Anteils der Eisenkomponenten zur Folge haben. Die Bedingungen des Filtrierens liessen sich aber nicht konstant halten, weil Nebel und Eisbildung mitunter die Probenahmen stark verzögerten. 


\subsection{Sedimentuntersuchung}

Tabelle 14.

\begin{tabular}{|c|c|c|c|c|c|}
\hline \multicolumn{6}{|l|}{ Versuch 1} \\
\hline $\begin{array}{l}\text { Trockensubstanz in } \mathrm{g} \\
\text { pro Kultureinheit }\left(0,8 \mathrm{~m}^{2} \text { total }\right.\end{array}$ & Sec & $\begin{array}{l}\text { Testzellen } \\
0\end{array}$ & 1 & 2 & 3 \\
\hline in $10 \mathrm{~m}$ Tiefe) & & 500 & 810 & 810 & 840 \\
\hline Tagesrate $\left(\mathrm{g} \mathrm{m}^{-2} \mathrm{~d}^{-1}\right.$ & 30 & 27 & 44 & 44 & 46 \\
\hline \multicolumn{6}{|l|}{ davon in $\%$ : } \\
\hline Organische Stoffe & 11 & 13 & 12 & 12 & 12 \\
\hline HCl-Lösliches & 71 & 76 & 71 & 72 & 70 \\
\hline Asche & 18 & 11 & 17 & 16 & 18 \\
\hline \multicolumn{6}{|l|}{$\begin{array}{l}\text { Asche } \\
\text { Im HCl-Löslichen wurde bestimmt } \\
\text { (in \% der Trockensubstanz) }\end{array}$} \\
\hline Kalzium & 26 & 28 & 27 & 25 & 26 \\
\hline Magnesium & 1,3 & 1,4 & 0,8 & 1,5 & 1,7 \\
\hline Mangan & 0,015 & 0,015 & 0,015 & 0,015 & 0,015 \\
\hline Eisen & 0,6 & 0,5 & 0,65 & 0,65 & 0,65 \\
\hline Kupfer & 0,005 & 0,005 & 0,01 & 0,005 & 0,005 \\
\hline Zink & 0,01 & 0,025 & 0,022 & 0,015 & 0,015 \\
\hline \multicolumn{6}{|l|}{ Versuch 2} \\
\hline $\begin{array}{l}\text { Trockensubstanz in } g \\
\text { pro Kultureinheit total }\end{array}$ & & Testzellen & & & \\
\hline $\begin{array}{l}\text { pro Kultureinheit total } \\
\left(0,8 \mathrm{~m}^{2} \text { in } 10 \mathrm{~m} \text { Tiefe }\right)\end{array}$ & See & 0 & 1 & 2 & 3 \\
\hline $\begin{array}{l}\left(0,8 \mathrm{~m}^{2} \text { in } 10 \mathrm{~m}^{\text {Tiefe }}\right) \\
\text { Tagesrate }\left(\mathrm{g} \mathrm{m}^{-2} \mathrm{~d}^{-1}\right)\end{array}$ & & 122 & 120 & verunfallt & 118 \\
\hline$\frac{\text { Tagesrate }\left(\mathrm{g} \mathrm{m}^{-2} \mathrm{~d}^{-1}\right)}{\text { davon in } \%:}$ & 12 & 10 & 10 & & 10 \\
\hline \multicolumn{6}{|l|}{$\frac{\text { lagesrate }(\mathrm{g} \mathrm{m}}{\text { davon in } \% \text { : }}$} \\
\hline Organische Stoffe & 14,4 & 14,0 & 14,3 & & 11,0 \\
\hline HCl-Lösliches & 69,9 & 71,0 & 72,7 & & 76,5 \\
\hline Asche & 15,7 & 15,0 & 13,0 & & 12,5 \\
\hline \multicolumn{6}{|l|}{$\begin{array}{l}\text { Asche } \\
\text { Im HCl-Löslichen wurde bestimmt } \\
\text { (in \% der Trockensubstanz) }\end{array}$} \\
\hline Kalzium & 25 & 27 & 27 & & 27 \\
\hline Magnesium & 1,3 & 1,4 & 1,5 & & 1,7 \\
\hline Mangan & 0,025 & 0,02 & 0,02 & & 0,015 \\
\hline Eisen & 0,75 & 0,60 & 0,60 & & 0,75 \\
\hline Kupfer & 0,005 & 0,005 & 0,005 & & 0,005 \\
\hline Zink & 0,015 & 0,13 & 0,025 & & 0,015 \\
\hline
\end{tabular}

Versuch 3

'Trockensubstanz in $\mathrm{g}$ pro Kultureinheit total

$\left(0,8 \mathrm{~m}^{2}\right.$ in $10 \mathrm{~m}$ Tiefe $)$

Tagesrate $\left(\mathrm{g} \mathrm{m}^{-2} \mathrm{~d}^{-1}\right)$

davon in \%:

Organische Stoffe

HCl-Lösliches

Asche

Im HCl-Löslichen wurde bestimmt

(in \% der Trockensubstanz)

Kalzium

Magnesium

Mangan

Eisen

Kupfer

Zink

\begin{tabular}{lllll}
11 & 7 & 6 & 6 & 6 \\
0,8 & 0,6 & 0,7 & 0,5 & 0,7 \\
0,06 & 0,02 & 0,03 & 0,02 & 0,03 \\
0,8 & 0,75 & 0,75 & 0,75 & 0,65 \\
0,008 & 0,005 & 0,01 & 0,01 & 0,01 \\
0,03 & 0,025 & 0,025 & 0,03 & 0,03 \\
\hline
\end{tabular}

Testzellen

\begin{tabular}{lllll} 
See & 0 & 1 & 2 & 3 \\
\hline & 47 & 48 & 45 & 48 \\
1,1 & 2,2 & 2,2 & 2,1 & 2,2 \\
\hline
\end{tabular}

45

34

21

63
24
13

63
24
13

13

67

19

14

19

19

62

24

14

0,015

0,005

0,015 
Fortsetzung Tabelle 14 .

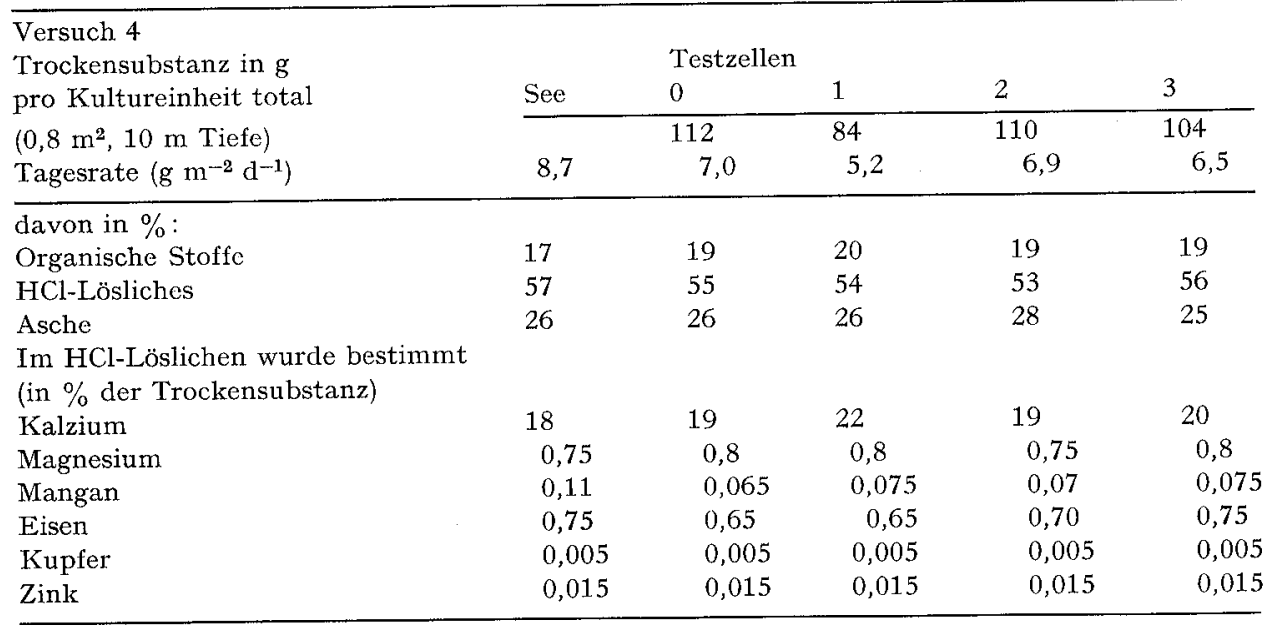

\subsection{Biologische Daten}

Tabelle 15. An der Experimentierstelle Greifensee während der Versuchszeit beobachtete Phytoplankter. - Mit* sind die Arten markiert, die zur Biomasse-Berechnung herangezogen wurden. Die mit + versehenen Arten und Gattungen sind in den Abb. 15, 16 und 17 dargestellt.

Table 15. Phytoplankton species observed at the sampling site on the Greifensee during the duration of the experiments. - The asterisk indicates the species included in the biomass calculation. Species and genera marked with + are shown in Figures 15, 16 and 17.

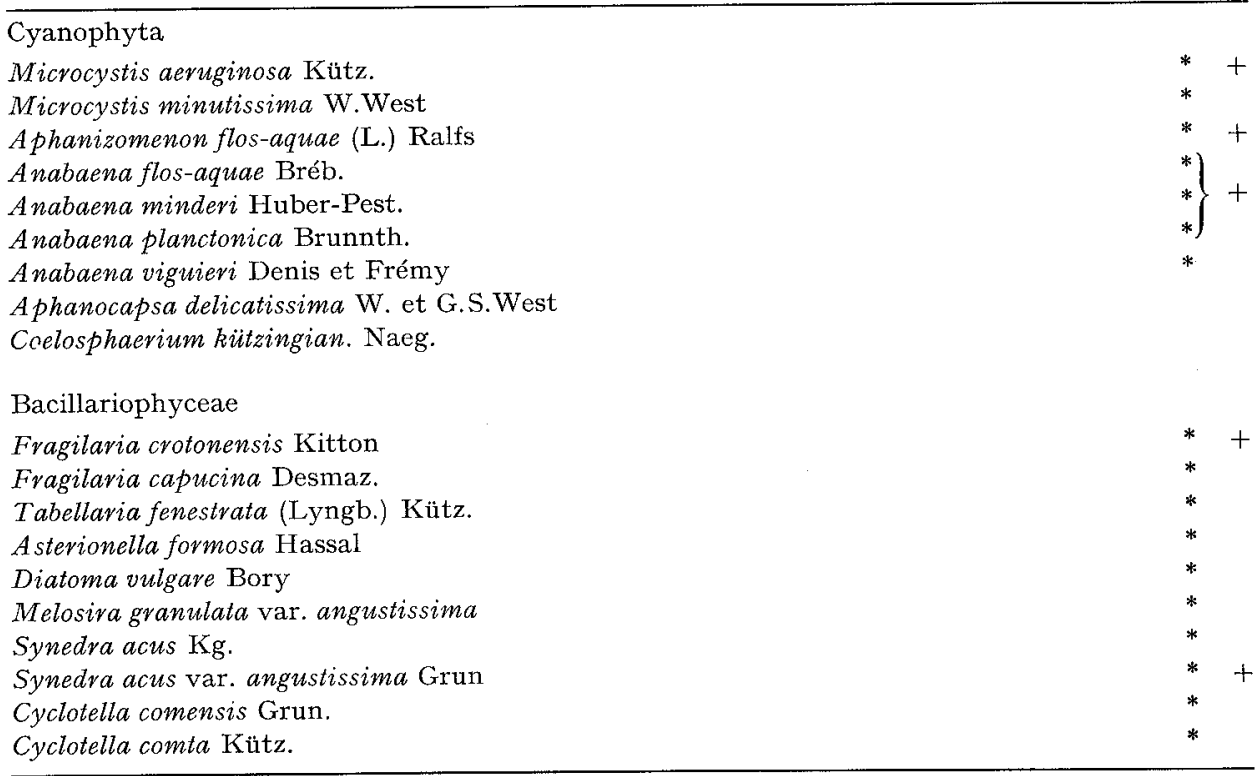


Fortsetzung Tabelle 15.

Dinophyceae

Ceratium hirundinella (mit Zysten) Schrank

Peridinium cinctum Ehb.

Gymnodinium helveticum Penard

Gymnodinium lantzschii Uterm.

Glenodinium sp. (mit Zysten)

Chrysophyceae

Pseudopedinella erkensis

Dinobryon sociale Ehb.

Dinobryon divergens Imhof

Dinobryon sertularia Ehb.

Heterochromonas $\mathrm{sp}$.

Kephyrion sp.

Erkenia subaequiciliata

Chlorophyceae

Pediastrum auplex var. clathratum Al. Braun

Pediastrum boryanum (Turp) Menegh.

Tetraedron minimum Hansg.

Coelastrum microporum Naeg.

Coelastrum reticulatum (Dang.) Senn

Sphaerocystis schröteri Chodat

Selenastrum minutum Collins

Scenedesmus quadricauda Bréb.

Scenedesmus disciformis Chodat

Raphidium aciculave

Raphidium contortum

Chlamydomonas sp. (mit Zysten)

Ankistrodesmus convolutus (Corda) Ralfs

Ankistrodesmus falcatus var mirabile

* +

* +

$*+$

* +

Dictyosphaerium pulchellum Wood.

Chodatella sp.

Phacotus lenticulavis (Ehb) Stein

Phacotus lendneri Chodat

Schroederia setigera (Schrocd.) Lemm.

Pandorina morum Bory

Eudorina elegans Ehb.

Gloeocystis planctonica Korš.

Kirchneriella contorta Bohlin

Gonium pectorale Müll.

Oocystis solitaria Wittr.

Oocystis lacustris Chodat

Nephrocytium agardhianum Naeg.

Elakatothrix gelatinosa Wille

Pseudosphaerocystis lacustris (Lemm.) Nováková

Ulothrix sp.

Conjugatophyceae

Cosmarium crenulatum Naeg.

Clostevium parvulum Naeg.

Clostevium acut. var. variabile (Lemm.) Krieg

Staurastrum gracile Ralfs

Staurastrum sebaldi Reinsch 
Fortsetzung Tabelle 15

Cryptophyceae

Cryptomonas erosa Ehb.

Cryptomonas ovata Ehb.

Rhodomonas lens Pascher et Ruttner

Rhodomonas lacustris Pascher et Ruttner

Katablepharis ovalis Skuja

Flagellatae

Colacium sp.

Vakuolaria virescens Cienk.

Tabelle 16. Assimilationsraten (in $\mathrm{mg} \mathrm{C}_{\mathbf{a s s}} \mathrm{h}^{-1} \mathrm{~m}^{-\mathbf{3}}$ ) in den Testzellen und im Greifensee nahe der Experimentierstelle. - Alle Werte sind gemittelt aus der Nettoproduktion in 2,5 und $1 \mathrm{~m}$ Tiefe. Table 16. Rate of assimilation expressed in $\mathrm{mg} \mathrm{C}_{\mathbf{a s s}} \mathrm{h}^{-1} \mathrm{~m}^{-3}$. - All values represent an average of the net production at a depth of 2.5 and $1 \mathrm{~m}$.

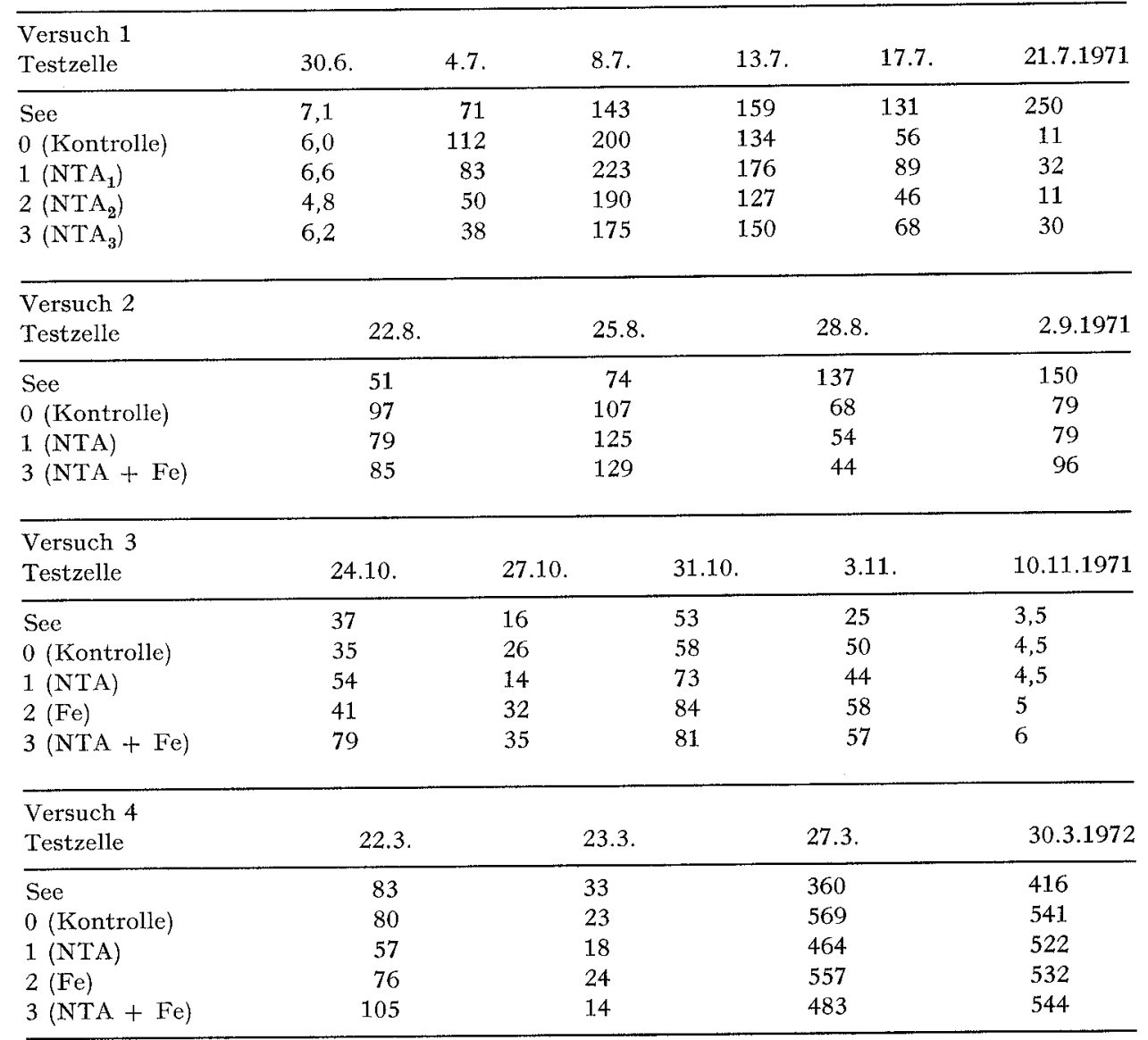


Tabelle 17. Summe der Planktonvolumina (Biomasse) der ausgezählten Phytoplanktonarten in $\mathrm{mg} / \mathrm{l}$.

Table 17. Total phytoplankton volume (biomass) expressed in $\mathrm{mg} / \mathrm{l}$.

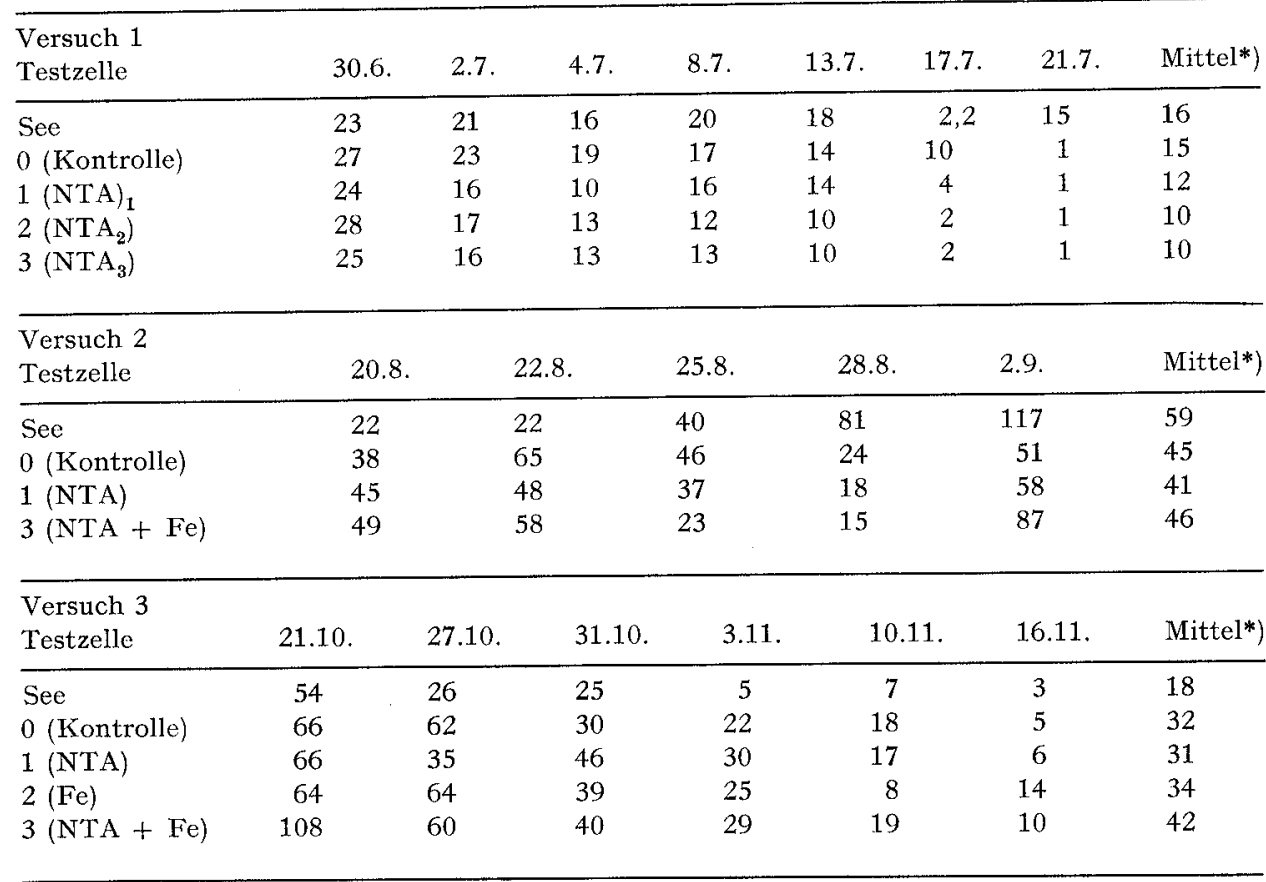

\begin{tabular}{lllllllll}
\hline $\begin{array}{l}\text { Versuch } 4 \\
\text { Testzelle }\end{array}$ & 22.3. & 23.3. & 26.3. & 29.3. & 30.3. & 4.4. & 10.4. & Mittel*) \\
\hline See & 20 & 48 & 14 & 25 & 29 & 15 & 24 & 26 \\
0 (Kontrolle) & 25 & 42 & 31 & 29 & 32 & 26 & 30 & 31 \\
1 (NTA) & 20 & 40 & 26 & 25 & 27 & 24 & 24 & 27 \\
2 (Fe) & 21 & 48 & 27 & 20 & 34 & 27 & 32 & 31 \\
3 (NTA + Fe) & 18 & 56 & 26 & 33 & 28 & 20 & 24 & 29 \\
\hline
\end{tabular}

*) Die Mittel wurden nach der Trapezregel berechnet.

*) Averaged out according to the trapezoid rule.

Tabelle 18. Pigmentgehalt in $\mathrm{mg} / \mathrm{m}^{3}$.

Table 18. Pigmentation content expressed in $\mathrm{mg} / \mathrm{m}^{3}$.

\begin{tabular}{lllrrr}
\hline $\begin{array}{l}\text { Versuch } 1 \\
\text { Testzelle }\end{array}$ & 8.7 & 13.7 & 17.7 & 21.7 & Mittel*) \\
\hline See & 30 & 39 & 19 & 24 & 29 \\
0 (Kontrolle) & 30 & 38 & 6 & 8 & 22 \\
$1\left(\mathrm{NTA}_{1}\right)$ & 14 & 44 & 12 & 8 & 21 \\
$2\left(\mathrm{NTA}_{2}\right.$ & 31 & 18 & 11 & 4 & 17 \\
$3\left(\mathrm{NTA}_{3}\right)$ & 29 & 30 & & & 21 \\
\hline
\end{tabular}


Fortsetzung Tabelle 18.

\begin{tabular}{lrrr}
\hline $\begin{array}{l}\text { Versuch } 2 \\
\text { Testzelle }\end{array}$ & 22.8 & 2.9 & Mittel*) $^{*}$ \\
\hline See & 106 & 194 & 150 \\
0 (Kontrolle) & 120 & 160 & 140 \\
1 (NTA) & 94 & 132 & 113 \\
3 (NTA + Fe) & 88 & 143 & 116 \\
\hline
\end{tabular}

\begin{tabular}{lrlllllr}
\hline $\begin{array}{l}\text { Versuch } 3 \\
\text { Testzelle }\end{array}$ & 21.10 & 27.10 & 31.10 & 3.11 & 10.11. & 16.11. & Mitte1*) \\
\hline Sec & 77 & 32 & 55 & 28 & 38 & 5 & 38 \\
0 (Kontrolle) & 104 & 70 & 51 & 47 & 40 & 11 & 51 \\
1 (NTA) & 87 & 63 & 57 & 58 & 36 & 10 & 50 \\
$2(\mathrm{Fe})$ & 100 & 63 & 55 & 63 & 35 & 23 & 55 \\
$3(\mathrm{NTA}+\mathrm{Fe})$ & 104 & 82 & 55 & 57 & 35 & 21 & 57 \\
\hline
\end{tabular}

\begin{tabular}{lrlrrrrrrr}
\hline $\begin{array}{l}\text { Versuch 4 } \\
\text { Testzelle }\end{array}$ & 22.3. & 23.3. & 26.3. & 27.3. & 29.3 & 30.3. & 4.4. & 10.4. & Mittel*) $^{*}$ \\
\hline See & 104 & 88 & 186 & 133 & 101 & 99 & 59 & 105 & 112 \\
0 (Kontrolle) & 95 & 74 & 112 & 200 & 89 & 125 & 98 & 92 & 123 \\
1 (NTA) & 77 & 66 & 87 & 191 & 100 & 114 & 88 & 75 & 110 \\
2 (Fe) & 83 & 71 & 93 & 187 & 120 & 121 & 108 & 94 & 119 \\
3 (NTA + Fe) & 103 & 57 & 87 & 191 & 145 & 124 & 81 & 83 & 114 \\
\hline
\end{tabular}

*) Die Mittel wurden nach der Trapezregel berechnet.

*) Averaged out according to the trapezoid rule.

Tabelle 19. Individuenzahlen der wichtigsten Phytoplanktonarten in der Kontrolle (K) und im See (in Zellen/l).

Table 19. Number of individuals of the main phytoplankton species in the control (K) and in the lake expressed in cells/l.

\begin{tabular}{|c|c|c|c|c|c|c|c|c|c|}
\hline $\begin{array}{l}\text { Versuch } 1 \\
\text { Gattung/Art }\end{array}$ & Faktor & & 30.6 & 2.7 & 4.7. & 8.7 & 13.7 . & 17.7 & 21.7 \\
\hline \multirow[t]{2}{*}{ Microcystis aeruginosa } & \multirow[t]{2}{*}{$10^{5}$} & See & 22 & 12 & 9 & 1 & 8 & 24 & 110 \\
\hline & & $\mathrm{K}$ & 24 & 24 & 9 & 20 & 3 & 25 & 11 \\
\hline \multirow{2}{*}{ Aphanizomenon flos-aquae } & \multirow[t]{2}{*}{$10^{4}$} & See & 4 & 1 & 2 & 2 & 24 & 100 & 35 \\
\hline & & $\mathrm{K}$ & - & - & 10 & 5 & 55 & 95 & 27 \\
\hline \multirow{2}{*}{ Anabaena flos-aquae } & \multirow[t]{2}{*}{$10^{3}$} & See & 380 & 286 & 135 & 223 & 132 & 16 & - \\
\hline & & $K$ & 395 & 222 & 80 & 159 & 11 & 20 & - \\
\hline \multirow{2}{*}{ Ceratium hirundinella } & \multirow[t]{2}{*}{$10^{2}$} & See & 13 & 13 & 21 & 11 & 16 & - & 11 \\
\hline & & $\mathrm{K}$ & 5 & 5 & 10 & 11 & 8 & 3 & 5 \\
\hline \multirow{2}{*}{ Peridinium spp. } & \multirow[t]{2}{*}{$10^{2}$} & See & 16 & 13 & 16 & 11 & 53 & 20 & 11 \\
\hline & & $\mathrm{K}$ & 8 & 13 & 16 & $\ldots$ & 43 & 3 & - \\
\hline \multirow[t]{2}{*}{ Fragilaria crotonensis } & \multirow[t]{2}{*}{$10^{4}$} & See & 1.46 & 248 & 435 & 306 & 11 & 3 & 1 \\
\hline & & $\mathrm{K}$ & 135 & 240 & 238 & 85 & 12 & 17 & - \\
\hline \multirow{2}{*}{ Pandorina morum } & \multirow[t]{2}{*}{$10^{4}$} & See & 61 & 69 & 222 & 1530 & 48 & 207 & 48 \\
\hline & & $\mathrm{K}$ & 76 & 85 & 275 & 307 & 50 & 16 & 9 \\
\hline \multirow[t]{2}{*}{ Eudorina elegans } & \multirow[t]{2}{*}{$10^{4}$} & See & 472 & 315 & 73 & 6 & 55 & 160 & 48 \\
\hline & & $\mathrm{K}$ & 670 & 370 & 410 & 51 & 34 & 22 & - \\
\hline
\end{tabular}


Fortsetzung Tabelle 19.

\begin{tabular}{|c|c|c|c|c|c|c|c|c|}
\hline $\begin{array}{l}\text { Versuch } 1 \\
\text { Gattung/Art }\end{array}$ & Faktor & & 30.6 & 2.7 & 8.7 & 13.7 & 17.7 & 21.7 \\
\hline \multirow[t]{2}{*}{ Phacotus lenticularis } & $10^{4}$ & See & 600 & 740 & 1040 & 810 & - & 89 \\
\hline & & $\mathrm{K}$ & 48 & 44 & 100 & - & - & - \\
\hline \multirow[t]{2}{*}{ Ankistrodesmus falcatus var.mir. } & $10^{4}$ & See & 61 & 84 & 145 & 67 & 40 & 104 \\
\hline & & $\mathrm{K}$ & 5 & 7 & 4 & 2 & 2 & 1 \\
\hline \multirow[t]{2}{*}{ Coelastrum microporum } & $10^{6}$ & See & 120 & 89 & 44 & 97 & 120 & 81 \\
\hline & & $\mathrm{K}$ & 132 & 104 & 84 & 77 & 55 & 3 \\
\hline \multirow[t]{2}{*}{ Scenedesmus quadricauda } & $10^{3}$ & See & 52 & 43 & 102 & 106 & 480 & 1140 \\
\hline & & $\mathrm{K}$ & 64 & 48 & 64 & 82 & 32 & 10 \\
\hline \multirow[t]{2}{*}{ Pediastrum spp. } & $10^{4}$ & See & 92 & 69 & 39 & 76 & 51 & 32 \\
\hline & & $\mathrm{K}$ & 111 & 72 & 69 & 69 & 34 & 1 \\
\hline \multirow[t]{2}{*}{ Schroederia setigera } & $10^{4}$ & See & 13 & 7 & 36 & 80 & 6 & 8 \\
\hline & & K & 16 & 9 & 19 & 35 & 8 & 2 \\
\hline \multirow[t]{2}{*}{ Cosmarium spp. } & $10^{3}$ & See & 10 & 10 & 20 & 13 & 24 & 51 \\
\hline & & $\mathrm{K}$ & 8 & 4 & 4 & 4 & 2 & 2 \\
\hline \multirow[t]{2}{*}{ Cryptomonas spp. } & $10^{3}$ & See & 32 & 20 & 98 & 177 & 265 & 95 \\
\hline & & $\mathrm{K}$ & 43 & 5 & 52 & 85 & 20 & - \\
\hline \multirow[t]{2}{*}{ Rhodomonas spp. } & $10^{4}$ & See & 70 & 17 & 97 & 13 & 41 & 19 \\
\hline & & K & 87 & 7 & 13 & 8 & 5 & 6 \\
\hline \multicolumn{9}{|l|}{ Versuch 2} \\
\hline Gattung/Art & Faktor & & 20.8 & 22.8 & 25.8 & 28.8 & & 9.1971 \\
\hline \multirow[t]{2}{*}{ Microcystis aeruginosa } & $10^{6}$ & See & 4 & 8 & 9 & 16 & & 45 \\
\hline & & $\mathrm{K}$ & 4 & 7 & 10 & 11 & & 70 \\
\hline \multirow[t]{2}{*}{ Aphanizomenon flos-aquae } & $10^{7}$ & See & 23 & 30 & 35 & 13 & & 5 \\
\hline & & $\mathrm{K}$ & 42 & 91 & 40 & 23 & & 37 \\
\hline \multirow[t]{2}{*}{ Anabaena planctonica } & $10^{4}$ & See & 57 & 76 & 17 & 16 & & 13 \\
\hline & & $\mathrm{K}$ & 53 & 58 & 29 & 16 & & 2 \\
\hline \multirow[t]{2}{*}{ Ceratium hirundinella } & $10^{4}$ & $\mathrm{Sec}$ & 9 & 8 & 36 & 121 & & 84 \\
\hline & & $\mathrm{K}$ & 23 & 40 & 24 & 28 & & 63 \\
\hline \multirow[t]{2}{*}{ Peridinium spp. } & $10^{2}$ & See & 68 & 69 & 10 & 64 & & 21 \\
\hline & & $\mathrm{K}$ & 79 & 95 & 30 & 21 & & 11 \\
\hline \multirow[t]{2}{*}{ Pandorina morum } & $10^{4}$ & See & 74 & 40 & 46 & 54 & & 35 \\
\hline & & $\mathrm{K}$ & 56 & 32 & 8 & 16 & & 27 \\
\hline \multirow[t]{2}{*}{ Eudorina elegans } & $10^{3}$ & See & 76 & 32 & 32 & 223 & & - \\
\hline & & $\mathrm{K}$ & 48 & 32 & 10 & 42 & & - \\
\hline \multirow[t]{2}{*}{ Ankistrodesmus falc. var. mir. } & $10^{2}$ & See & 74 & 11 & 30 & 32 & & 65 \\
\hline & & $\mathrm{K}$ & 30 & 27 & - & 58 & & 32 \\
\hline \multirow[t]{2}{*}{ Coelastrum microporum } & $10^{5}$ & See & 19 & 5 & 15 & 9 & & 1 \\
\hline & & $K$ & 11 & 22 & - & 2 & & - \\
\hline \multirow[t]{2}{*}{ Scenedesmus quadricauda } & $10^{3}$ & See & 74 & 75 & 11 & 6 & & - \\
\hline & & $\mathrm{K}$ & 89 & 38 & - & 6 & & - \\
\hline Pediastrum spp. & $10^{3}$ & See & 76 & 80 & 160 & 85 & & 67 \\
\hline & & $\mathrm{K}$ & 37 & 80 & 40 & 64 & & 21 \\
\hline Cosmarium spp. & $10^{2}$ & See & 36 & 50 & 27 & 32 & & - \\
\hline & & $\mathrm{K}$ & 35 & 32 & 5 & 21 & & 11 \\
\hline Cryptomonas spp. & $10^{4}$ & See & 138 & 30 & 13 & 22 & & 21 \\
\hline & & $\mathrm{K}$ & 102 & 59 & 6 & 3 & & 6 \\
\hline Rhodomonas spp & $10^{3}$ & See & 233 & 80 & 160 & 290 & & 60 \\
\hline & & $\mathrm{K}$ & 360 & 16 & - & 48 & & 32 \\
\hline
\end{tabular}


Fortsetzung Tabelle 19.

\begin{tabular}{|c|c|c|c|c|c|c|c|c|}
\hline $\begin{array}{l}\text { Versuch } 3 \\
\text { Gattung/Art }\end{array}$ & Faktc & & 21.10 & 27.10 & 31.10 & 3.11 & 10.11 & 16.11 \\
\hline \multirow{2}{*}{ Microcystis aeruginosa } & \multirow[t]{2}{*}{$10^{5}$} & See & 114 & 94 & 82 & 135 & 49 & 38 \\
\hline & & $\mathrm{K}$ & 138 & 137 & 135 & 130 & 42 & 45 \\
\hline \multirow{2}{*}{ Aphanizomenon flos-aquae } & \multirow[t]{2}{*}{$10^{3}$} & See & 162 & 24 & 56 & 24 & 93 & 19 \\
\hline & & K & 66 & 119 & 48 & 82 & 127 & 24 \\
\hline \multirow{2}{*}{ Ceratium hirundinella } & \multirow[t]{2}{*}{$10^{4}$} & See & 90 & 43 & 42 & 9 & 11 & 5 \\
\hline & & $\mathrm{K}$ & 110 & 102 & 49 & 37 & 31 & 8 \\
\hline Peridinium spp. & \multirow[t]{2}{*}{10} & See & 80 & 80 & 104 & 53 & 80 & 21 \\
\hline \multirow{2}{*}{ Pandorina morum } & & $\mathrm{K}$ & 53 & 106 & 104 & 80 & 53 & 64 \\
\hline & \multirow[t]{2}{*}{$10^{3}$} & See & 80 & 80 & 127 & - & 4 & - \\
\hline \multirow{2}{*}{ Phacotus lenticulavis } & & $\mathrm{K}$ & 96 & 128 & 104 & - & 13 & - \\
\hline & \multirow[t]{2}{*}{$10^{2}$} & See & 355 & 93 & 240 & 64 & - & 122 \\
\hline \multirow{2}{*}{ Ankistrodesmus falc. var. miv. } & & $\begin{array}{l}\mathrm{K} \\
\text { See }\end{array}$ & $\begin{array}{r}360 \\
88\end{array}$ & 200 & 160 & 40 & 63 & 85 \\
\hline & \multirow[t]{2}{*}{$10^{2}$} & $\begin{array}{l}\text { See } \\
K\end{array}$ & $\begin{array}{r}88 \\
186\end{array}$ & 64 & 104 & 187 & 127 & 95 \\
\hline \multirow{2}{*}{ Cosmarium spp. } & & $\begin{array}{l}\text { K } \\
\text { See }\end{array}$ & $\begin{array}{r}186 \\
32\end{array}$ & 127 & 103 & 110 & 127 & 64 \\
\hline & $10^{2}$ & $\mathrm{~K}$ & $\begin{array}{l}32 \\
13\end{array}$ & 27 & 27 & 16 & 8 & 9 \\
\hline \multirow{2}{*}{ Cryptomonas spp. } & \multirow{2}{*}{$10^{3}$} & $\mathrm{Sec}$ & $\begin{array}{l}13 \\
24\end{array}$ & 16 & 10 & 16 & 8 & 10 \\
\hline & & $\mathrm{K}$ & $\begin{array}{l}24 \\
34\end{array}$ & 13 & 16 & 3 & 15 & 4 \\
\hline \multirow{3}{*}{ Rhodomonas spp. } & \multirow[t]{3}{*}{$10^{3}$} & See & $\begin{array}{r}34 \\
550\end{array}$ & 32 & 20 & 13 & 16 & 2 \\
\hline & & $\mathrm{K}$ & $\begin{array}{l}550 \\
106\end{array}$ & 111 & 64 & 48 & 63 & 11 \\
\hline & & & & 111 & 80 & 95 & 80 & 45 \\
\hline
\end{tabular}

\begin{tabular}{|c|c|c|c|c|c|c|c|c|c|}
\hline $\begin{array}{l}\text { Versuch } 4 \\
\text { Gattung/Art }\end{array}$ & Faktor & & 22.3 & 23.3 & 26.3 & 29.3 & 30.3 & 4.4 & 10.4 .1972 \\
\hline \multirow{2}{*}{ Gymnodinium lantzschii } & \multirow[t]{2}{*}{$10^{4}$} & See & 89 & 259 & 310 & 240 & 222 & 91 & 100 \\
\hline & & $\mathrm{K}$ & 191 & 159 & 164 & 235 & 270 & 175 & 188 \\
\hline \multirow{2}{*}{ Gymnodinium helveticum } & \multirow[t]{2}{*}{$10^{3}$} & See & 16 & 48 & 19 & 44 & 16 & 62 & 1.4 \\
\hline & & $\mathrm{K}$ & 20 & 28 & 24 & 93 & 21 & 130 & 35 \\
\hline Synedva acus var. angust. & \multirow[t]{2}{*}{$10^{3}$} & See & 27 & 24 & 23 & 29 & 35 & 35 & 28 \\
\hline \multirow{2}{*}{ Stephanodiscus hantzschii } & & $\mathrm{K}$ & 27 & 25 & 28 & 21 & 25 & 29 & 52 \\
\hline & \multirow[t]{2}{*}{$10^{6}$} & See & 37 & 55 & 20 & 29 & 53 & 34 & 22 \\
\hline \multirow{2}{*}{ Pandorina morum } & & K & 23 & 42 & 64 & 20 & 60 & 56 & 33 \\
\hline & \multirow[t]{2}{*}{$10^{4}$} & See & 33 & 169 & 240 & 106 & 72 & 69 & 77 \\
\hline \multirow{2}{*}{ Schroederia setigera } & & $\begin{array}{l}\text { K } \\
\text { See }\end{array}$ & 103 & 126 & 47 & 114 & 92 & 70 & 94 \\
\hline & $10^{3}$ & $\begin{array}{l}\text { See } \\
\text { K }\end{array}$ & $\begin{array}{l}64 \\
72\end{array}$ & 123 & 56 & 27 & 48 & 32 & 27 \\
\hline \multirow{2}{*}{ Cryptomonas spp. } & \multirow[t]{2}{*}{$10^{4}$} & See & $\begin{array}{l}72 \\
41\end{array}$ & $\begin{array}{r}48 \\
883\end{array}$ & $\begin{array}{r}27 \\
1100\end{array}$ & $\begin{array}{r}27 \\
540\end{array}$ & $\begin{array}{r}21 \\
690\end{array}$ & $\begin{array}{r}40 \\
257\end{array}$ & 27 \\
\hline & & $\mathrm{K}$ & 340 & $\begin{array}{l}883 \\
610\end{array}$ & $\begin{array}{r}1100 \\
455\end{array}$ & $\begin{array}{l}540 \\
690\end{array}$ & $\begin{array}{l}690 \\
765\end{array}$ & $\begin{array}{l}257 \\
600\end{array}$ & $\begin{array}{l}820 \\
870\end{array}$ \\
\hline \multirow{2}{*}{ Rhodomonas spp. } & \multirow[t]{2}{*}{$10^{5}$} & See & 5 & - & 200 & 69 & 52 & 25 & $\begin{array}{l}870 \\
190\end{array}$ \\
\hline & & $\mathrm{K}$ & 23 & 68 & 56 & 40 & 57 & 29 & $\begin{array}{l}190 \\
154\end{array}$ \\
\hline
\end{tabular}

$\mathrm{K}=$ Kontrolle

\subsection{Düngexperimente (Greifensee)}

Versuch 1

Dauer 29. Juni bis 21. Juli 1971.

Düngung In drei Etappen wurden $100 \mu \mathrm{g} / 1$ NTA (Testzelle 1), $1000 \mu \mathrm{g} / 1$ N'TA (Testzelle 2), $9000 \mu \mathrm{g} / 1$ NTA (Testzelle 3) pro Liter Kulturwasser zugefügt. 
Ziel Abklärung, ob und von welcher Konzentration an NTA das Wachstum des Phytoplanktons unter eutrophen Bedingungen beeinflusst.

Das Wasser des Greifensees wies zur Versuchszeit im Filtrat 5 bis $6 \mathrm{mg} / \mathrm{l}$ totalen organischen Kohlenstoff (TOC) auf. Es war daher zu erwarten, dass a priori natürliche, wenn auch nicht starke Komplexbildner vorhanden waren. Dem Versuchsziel gemäss wurden die NTA-Konzentrationen stufenweise gesteigert bis zu Werten, welche in der Praxis selbst nach vollständigem Ersatz aller Waschmittelphosphate durch NTA im Seewasser niemals auftreten könnten.

Der See hatte anfangs Juli eine deutliche, oft zur Wasserblüte neigende Vegetationstrübung, vorwiegend verursacht durch Coelastrum, Pediastrum, Oocystis und Microcystis. Die Chlorophyceen bildeten allein mit den Gattungen Coelastrum, Pandorina und Oocystis mehr als 70\% der gesamten Biomasse, die zu Beginn des Versuchs zwischen 23 und $28 \mathrm{mg} / \mathrm{l}$ betrug. Neben den Cyanophyceen mit Microcystis und Aphanizomenon bildeten nur noch die Bacillariophyceen mit Asterionella und Fragilaria wesentliche Biomasseanteile. Die Nährstoffsituation wie die geringe Sichttiefe $(1,4 \mathrm{~m})$ und andere Daten deuten darauf hin, dass weder Phosphor noch Stickstoff, sondern vor allem physikalische und biologische Faktoren (Licht, Temperatur, Teilungsrhythmus der Algen usw.) das Wachstum limitierten. Dementsprechend sind auch die Schwankungen der Primärproduktion sehr gross. Innerhalb einer Woche schwankte sie von 6 bis $200 \mathrm{mg} \mathrm{C}_{\text {ass }} \mathrm{h}^{-1} \mathrm{~m}^{-3}$.

Die Wirkung der Zusätze konnte in den Greifensee-Experimenten zusätzlich durch die Pigmentmessung erfasst werden. Die Resultate weisen allerdings eine grosse, methodisch bedingte Streuung auf. Dafür ergibt die rund 10mal höhere Zelldichte der Phytoplankter im Greifensee entsprechend exaktere Daten der Biomassebestimmung als die Planktonpopulation im Vierwaldstättersee.

Der Einfluss der drei NTA-Konzentrationen auf das Wachstum des pflanzlichen Planktons zeigte in allen gedüngten Testzellen die gleiche Tendenz: Nach den ersten zwei Reagenzienzusätzen sank die Produktion und damit auch die Biomasse relativ zur Kontrolle ab. Nach etwa 14 Tagen glichen sich die gedüngten Testzellen der Kontrolle an, die Primärproduktion war relativ zum Bezugswert sogar etwas erhöht.

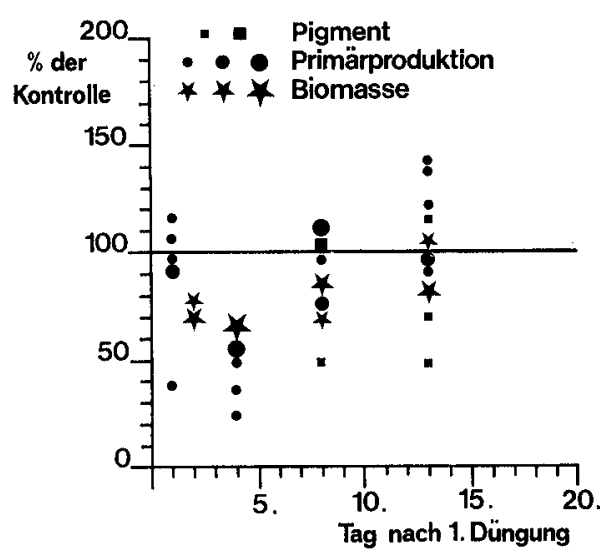

Abb. 11. Die Wirkung von 100 bis $9000 \mu \mathrm{g} / \mathrm{l}$ NTA auf das Wachstum des Phytoplanktons im Greifensee vom 30. Juni bis 13. Juli 1971. Kleine Zeichen: 1 Einzelwert; mittlere Zeichen: 2 Einzelwerte; grosse Zeichen: 3 Einzelwerte. Fig. 11. Effect of 100 to $9,000 \mu \mathrm{g} / 1$ NTA on phytoplankton growth in the Greifensee between 30 June and 13 July 1971.

Small symbols: 1 single value; medium-size symbols: 2 single values. large symbols: 3 single values. 
Die Intensität der Reaktion war abhängig von der Konzentration; so betrug der Biomasseverlust in der Testzelle $1 \mathrm{im}$ Mittel 20\%, in den beiden andern gedüngten Testzellen über 30\% gegenüber der Kontrolle. In Abb. 11 ist die letzte Versuchswoche nicht mehr dargestellt, nach dem 13. Juli 1971 sank nämlich die Biomasse rapide ab auf rund 5\% des Ausgangswertes. Diese Beobachtung deckt sich mit der enorm hohen Sedimentationsrate von etwa $30 \mathrm{~g} \mathrm{~m}^{-2} \mathrm{~d}^{-1}$, was einem täglichen Verlust an Biomasse von $10 \%$ in der überstehenden Wassersäule entspricht.

Die NTA-Konzentration und der NTA-Abbau konnten leider mangels geeigneter analytischer Ausrüstung wie schon bei den Versuchen im Vierwaldstättersee nicht verfolgt werden. Die aktuelle NTA-Konzentration wurde geschätzt anhand der Halbwertszeiten der Verdünnung, die mittels Chlorid- und Eisendüngung ermittelt worden waren (4,5 Tage).

Versuch 2

Dauer 18. August bis 2. September 1971.

Düngung In zwei Etappen wurden $200 \mu \mathrm{g} / \mathrm{l}$ NTA und/oder $30 \mu \mathrm{g} / \mathrm{l} \mathrm{Fe}$ zudosiert,

Ziel entsprechend der Versuchsanordnung in Tabelle 1.

Wirkung realistischer Zusätze von NTA und/oder Eisen auf das Wachstum des Phytoplanktons. (Gemäss Experiment 1 haben schon geringe Mengen NTA einen Einfluss.)

Testzelle 2 wurde zwei Tage nach Versuchsbeginn durch einen darin ertrunkenen Vogel ausser Betrieb gesetzt. Leider musste der ganze Versuch wegen Verschmutzung durch Wasservögel vorzeitig abgebrochen werden.

Die physikalischen und chemischen Bedingungen waren ähnlich wie beim Versuch 1 (Greifensee); die Phosphatreserven begannen sich nun aber zu erschöpfen. Die Biomasse hatte im See anfangs September den höchsten Wert in sämtlichen Versuchen erreicht $\left(117 \mathrm{~g} \mathrm{~m}^{-3}\right)$. Die Sichttiefe verringerte sich dementsprechend auf 1,2 m. Der totale Eisengehalt lag bei $30 \mu \mathrm{g} / \mathrm{l}$ (Seewasser oder Kontrolle), entsprechend einem prozentualen Anteil an der Biomasse von weniger als 0,05\%. Das Zusammentreffen des Biomasseoptimums mit dem Eisenminimum war für die Prüfung des Eiseneinflusses auf das Phytoplankton besonders günstig.

Das Phytoplankton setzte sich zwar noch aus den gleichen Arten zusammen wie im vorhergehenden Versuch, aber die Biomasse wurde nun vor allem durch Aphanizomenon (Cyanophyceae) und Ceratium (Dinophyceae) gebildet (etwa 90\%). Die Resultate der summarischen Parameter (Primärproduktion, Biomasse, Pigment) sind in Abb. 12 dargestellt, die Reaktion der einzelnen wichtigen Phytoplankter in den Abb. 15, 16 und 17 ist, entsprechend dem Schema Abb. 7, wie bei den Vierwaldstättersee-Auswertungen aufgetragen. Die aus den verbliebenen Kultureinheiten gewonnenen Werte brachten gegenüber dem Experiment 1 keine weitere Aussage. Sowohl NTA allein als auch die Kombination NTA + Eisen hemmen das Wachstum gleich stark, weshalb die Werte wiederum in einer einzigen Graphik dargestellt sind (Abb. 12).

Die Hemmung des Wachstums war wiederum nur auf die ersten 8 Tage beschränkt und in der Grössenordnung mit der Wirkung der niedersten NTA-Konzentration im Versuch 1 vergleichbar. Wird die Biomasse über die ganze Versuchszeit nach der 


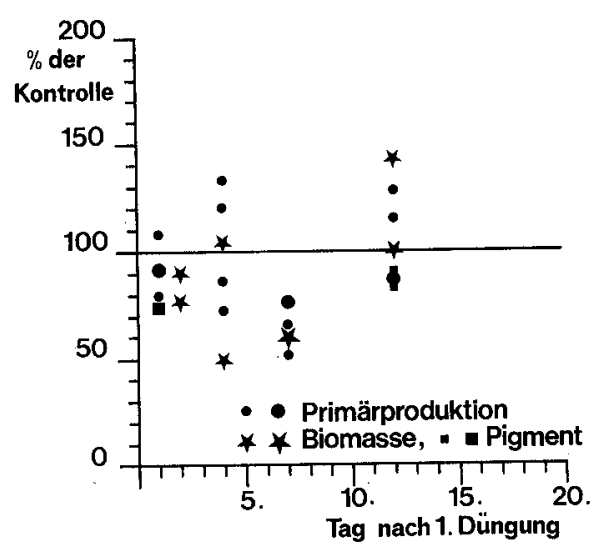

Abb. 12. Die Wirkung von $200 \mu \mathrm{g} / 1$ NTA mit und ohne $30 \mu \mathrm{g} / 1$ Eisen auf das Wachstum des Phytoplanktons im Greifensee vom 21. August bis 2. September 1971.

Kleine Zeichen: 1 Einzelwert; grosse Zeichen: 2 Einzelwerte.

Fig. 12. Effect of $200 \mu \mathrm{g} / 1 \mathrm{NTA}$ with and without $30 \mu \mathrm{g} / 1$ iron on phytoplankton growth in the Greifensee between 21 August and 2 September 1971.

Small symbols: 1 single value; large symbols: 2 single values.

Trapezregel gemittelt, ergibt sich gegenüber der Kontrolle praktisch keine Änderung, da die anfänglichen Verluste durch leicht erhöhte Photosyntheseleistung am Ende des Versuchs ausgeglichen wird.

Die Sedimentationsrate war mit $10 \mathrm{~g} \mathrm{~m}^{-2} \mathrm{~d}^{-1}$ in $10 \mathrm{~m}$ Tiefe noch erheblich, machte aber nur $2 \%$ der gesamten überstehenden Biomasse aus. Dank der Eigenbeweglichkeit der Dinophyceen und den Gasvakuolen von Aphanizomenon kam es nicht zu einem mit dem Versuch 1 vergleichbaren Aussedimentieren der Biomasse.

Versuch 3

Dauer 21. Oktober bis 16. November 1971.

Düngung In zwei Etappen wurden $200 \mu \mathrm{g}$ NTA und/oder $60 \mu \mathrm{g}$ Fe pro Liter Kulturwasser zugefügt.

Ziel Wie im Versuch 2 (Greifensee), aber mit erhöhter Eisenzugabe.

Die thermische Schichtung des Sees erlaubte gerade noch eine einwandfreie Durchführung des Versuchs, der sodann dank unerwartet lang anhaltender schöner Witterung bis in den November ausgedehnt werden konnte. Die Zirkulation hatte bereits eingesetzt, reichte aber nur bis $6 \mathrm{~m}$ hinab. Die Turbulenz innerhalb der Testzellen brachte einerseits eine Verdünnung des Planktons mit sich, anderseits wurden Nährstoffe und Spurenmetalle aus Tiefen unter der 1\%-Strahlungsintensität heraufgefördert. Die geringe Sichttiefe von $1 \mathrm{~m}$ entsprach der noch immer enormen Biomasse von 60 bis $70 \mathrm{mg} / \mathrm{l}$. Der Temperaturwechsel von kühler Nacht zu sonnigwarmem Tag und die damit zusammenhängende Zirkulationsströmung wirkte selektiv auf die Artenzusammensetzung. Hohe Zellendichte erreichten nur eigenbewegliche Spezies (Dinophyceen, Cryptophyceen und volvocale Grünalgen) oder sich aktiv einschichtende Cyanophyceen mit Gasvakuolen. Die Biomasse wurde zu 95\% durch eine einzige Art, Ceratium hirundinella, gebildet. Die beobachtete Reaktion (Primärproduktion, Biomasse und Pigmentgehalt) - in Abb. 13 dargestellt war somit im wesentlichen die Antwort dieser einen Alge auf die Zusätze. Aber auch Rhodomonas, Cosmarium und Peridinium sp. reagierten wie Ceratium.

Mit dem Zusatz der Reagenzien setzte in den gedüngten Testzellen relativ zur Kontrolle eine Steigerung der Primärproduktion ein, die während der ganzen Ver- 
suchsdauer etwa $140 \%$ der Kontrolle ausmachte. Die relative Biomassesteigerung war mit einer mittleren Zunahme von 12\% gegenüber dem Bezugswert bescheiden. Dass die beiden Grössen nicht miteinander korrelieren, kann durch die verschiedenen Probenahmen erklärt werden: Die Primärproduktion wurde in $1 \mathrm{~m}$ und 2,5 m Tiefe gemessen; für die Planktonzählungen wurden Mischproben aus 0-5 m Tiefe geschöpft.

Die erhöhte Produktion hatte keinen Einfluss auf die Sedimentationsrate, die mit 1-2 $\mathrm{g} \mathrm{m}^{-2} \mathrm{~d}^{-1}$ kleiner war als im Vierwaldstättersee. Gegen Ende des Versuchs kündigte sich das nahende Verschwinden von Ceratium durch Zystenbildung an. Da die Zysten von Dinophyceen leicht sedimentieren, ist anzunehmen, dass die Sedimentationsrate unmittelbar nach Versuchsende stark angestiegen ist.

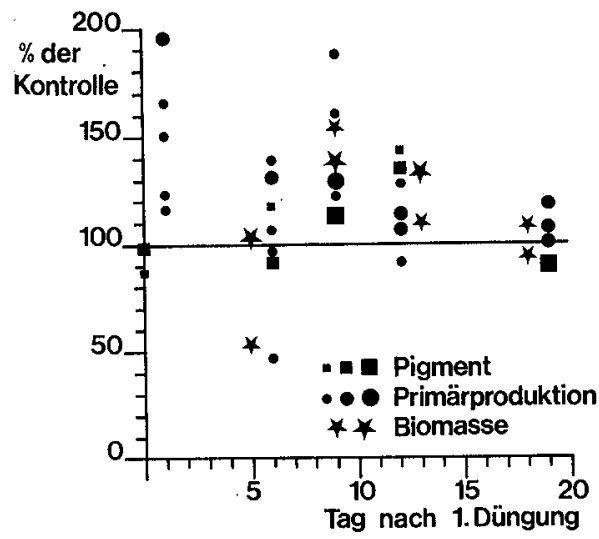

Abb. 13. Die Wirkung von $200 \mu \mathrm{g} / 1$ NTA und/ oder $60 \mu \mathrm{g} / \mathrm{l}$ Eisen auf das Wachstum des Phytoplanktons im Greifensee vom 23. Oktober bis 11 . November 1971.

Kleine Zeichen: 1 Einzelwert; grosse Zeichen: 2 Einzelwerte.

Fig. 13. Effect of $200 \mu \mathrm{g} / \mathrm{l}$ NTA and/or $60 \mu \mathrm{g} / \mathrm{l}$ iron on phytoplankton growth in the Greifensee between 23 October and 11 November 1971. Small symbols: 1 single value; large symbols: 2 single values.

Versuch 4

Dauer 21. März bis 10.April 1972.

Düngung $300 \mu g / 1$ NTA und/oder $90 \mu \mathrm{g} / \mathrm{l} \mathrm{Fe}$ in drei Etappen.

Ziel Reaktion der Nannoplankter auf Zusatz von NTA und Eisen.

Mit der beginnenden Sommerstagnation konnte der letzte Versuch gestartet werden. Nach der Frühjahrszirkulation 1972 wurden besonders hohe Assimilationsraten gemessen, so Ende März in der Kontrolle $569 \mathrm{mg} \mathrm{C}_{\text {ass }} \mathrm{h}^{-1} \mathrm{~m}^{-3}$.

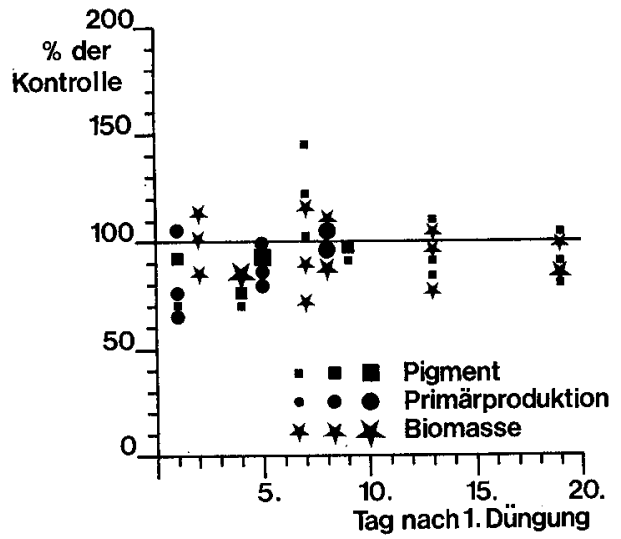

Abb. 14. Die Wirkung von $300 \mu \mathrm{g} / \mathrm{l}$ NTA und/oder $90 \mu \mathrm{g} / 1$ Eisen auf das Wachstum des Phytoplanktons im Greifensee vom 22. März bis 10. April 1972.

Kleine Zeichen: 1 Einzelwert; mittlere Zeichen: 2 Einzelwerte; grosse Zeichen: 3 Einzelwerte. Fig. 14. Effect of $300 \mu \mathrm{g} / \mathrm{l}$ NTA and/or $90 \mu \mathrm{g} / \mathrm{l}$ iron on phytoplankton growth in the Greifensee between 22 March and 10 April 1972.

Small symbols: 1 single value, medium-size symbols: 2 single values; large symbols: 3 single values. 
Die Biomasse, die sich nun vor allem aus Cryptophyceen (Cryptomonas und Rhodomonas), Bacillariophyceen (Stephanodiscus) und kleineren Dinophyceen (Gymnodinium) zusammensetzte, betrug im Mittel nur $26 \mathrm{mg} / 1000 \mathrm{ml}$ Seewasser. Die Sichttiefe wurde nicht nur durch das Plankton, sondern zusätzlich durch biogene Entkalkung auf $0,7 \mathrm{~m}$ verringert. Die chemischen Versuchsbedingungen wurden durch hohe Phosphat- und Nitrat- bzw. Ammoniumkonzentrationen charakterisiert. Eisen war in der Grössenordnung von $40 \mu \mathrm{g} / 1$ vorhanden (Tab. 10-13).

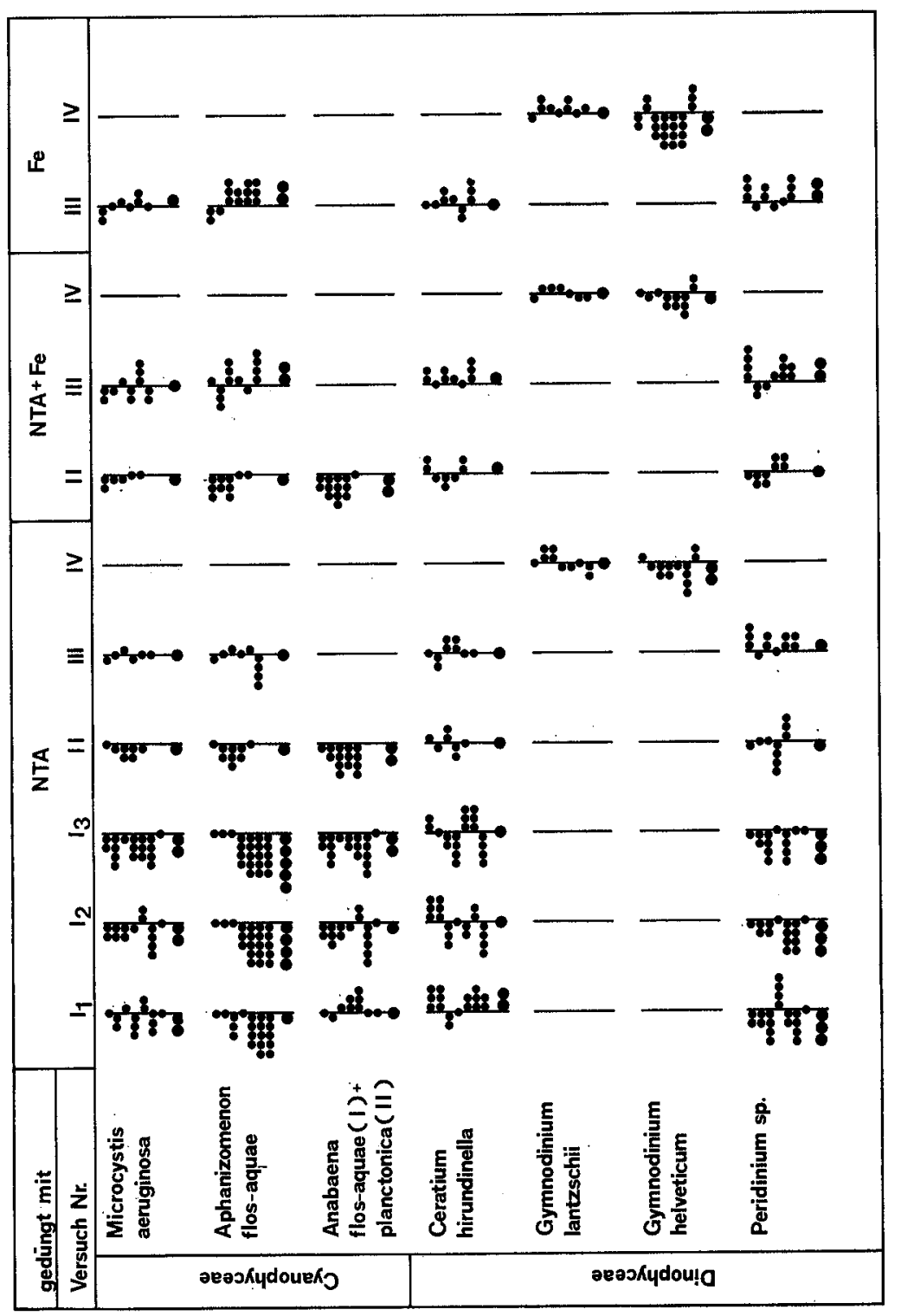


Die Wirkung der Zusätze (in Abb. 14 summarisch dargestellt) unterscheidet sich nicht von den Ergebnissen der Versuche 1 und 2 im Greifensee: In der ersten Versuchswoche war ein deutlicher Rückgang der Produktion feststellbar, nachher unterschieden sich die gedüngten Testzellen nicht mehr von der Kontrolle.

Nur Gymnodinium helveticum und Cryptomonas sp. zeigten eine stärkere Hemmung, alle andern Phytoplankter wurden durch NTA oder Eisen nicht beeinflusst oder in zwei Fällen (Pandorina und Schroederia) im Wachstum leicht gefördert.

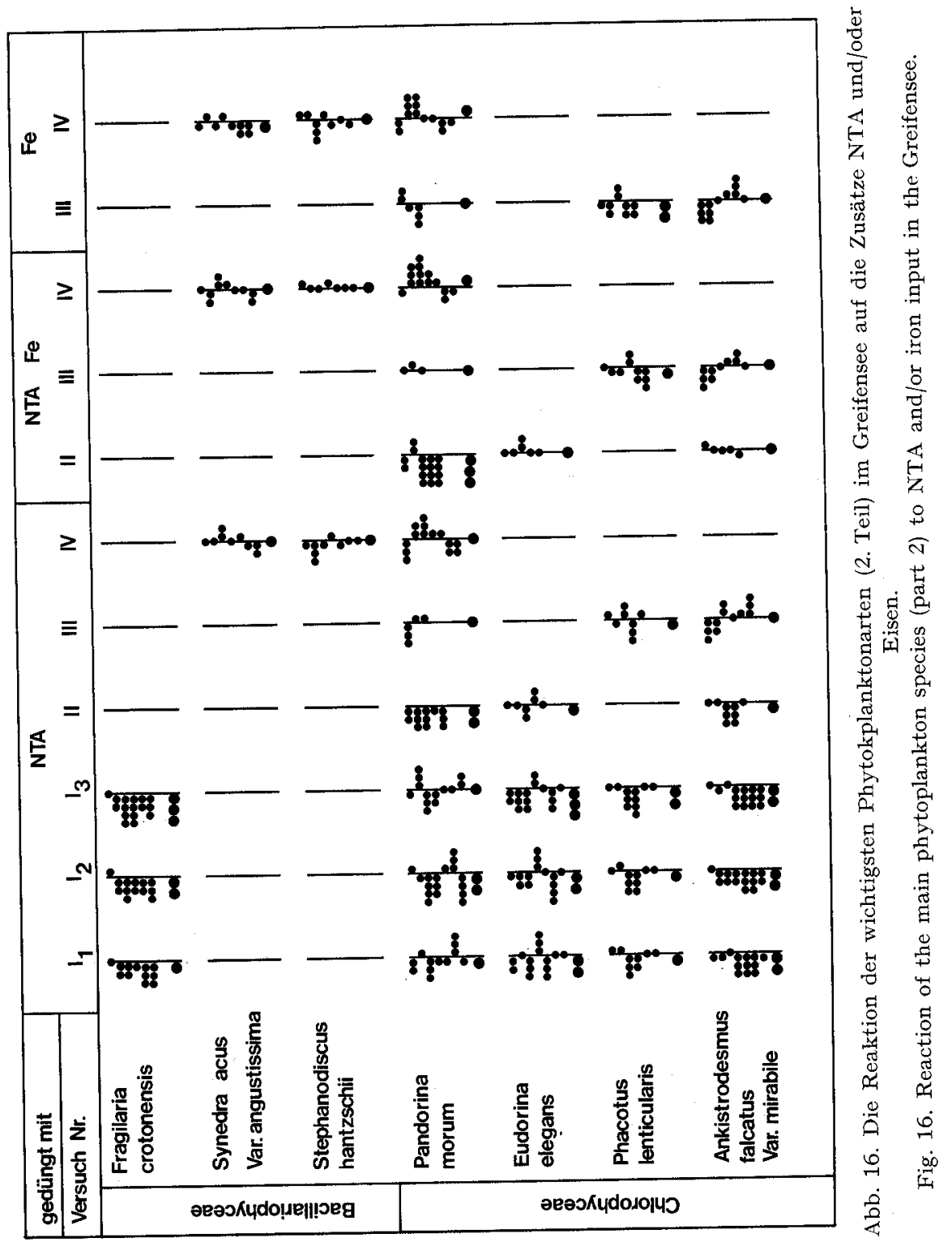


Über die ganze Versuchszeit gemittelt ergibt sich ein Biomasse- und Pigmentverlust von etwa $7 \%$ gegenüber der Kontrolle; die Testzelle 2 (Eisendüngung) zeigte im Mittel überhaupt keine Reaktion, da die anfängliche Verminderung der Produktion durch erhöhte Assimilationsleistung in der zweiten Versuchshälfte wettgemacht wurde.

Im Sediment spiegelte sich die Reaktion der überstehenden Wassersäule deutlich; so lagen die Sedimentationsraten der Testzelle 2 und 0 (Kontrolle) mit 6,9 bzw. $7 \mathrm{~g}$ $\mathrm{m}^{-2} \mathrm{~d}^{-1} 8-22 \%$ höher als in den andern beiden Kultureinheiten.
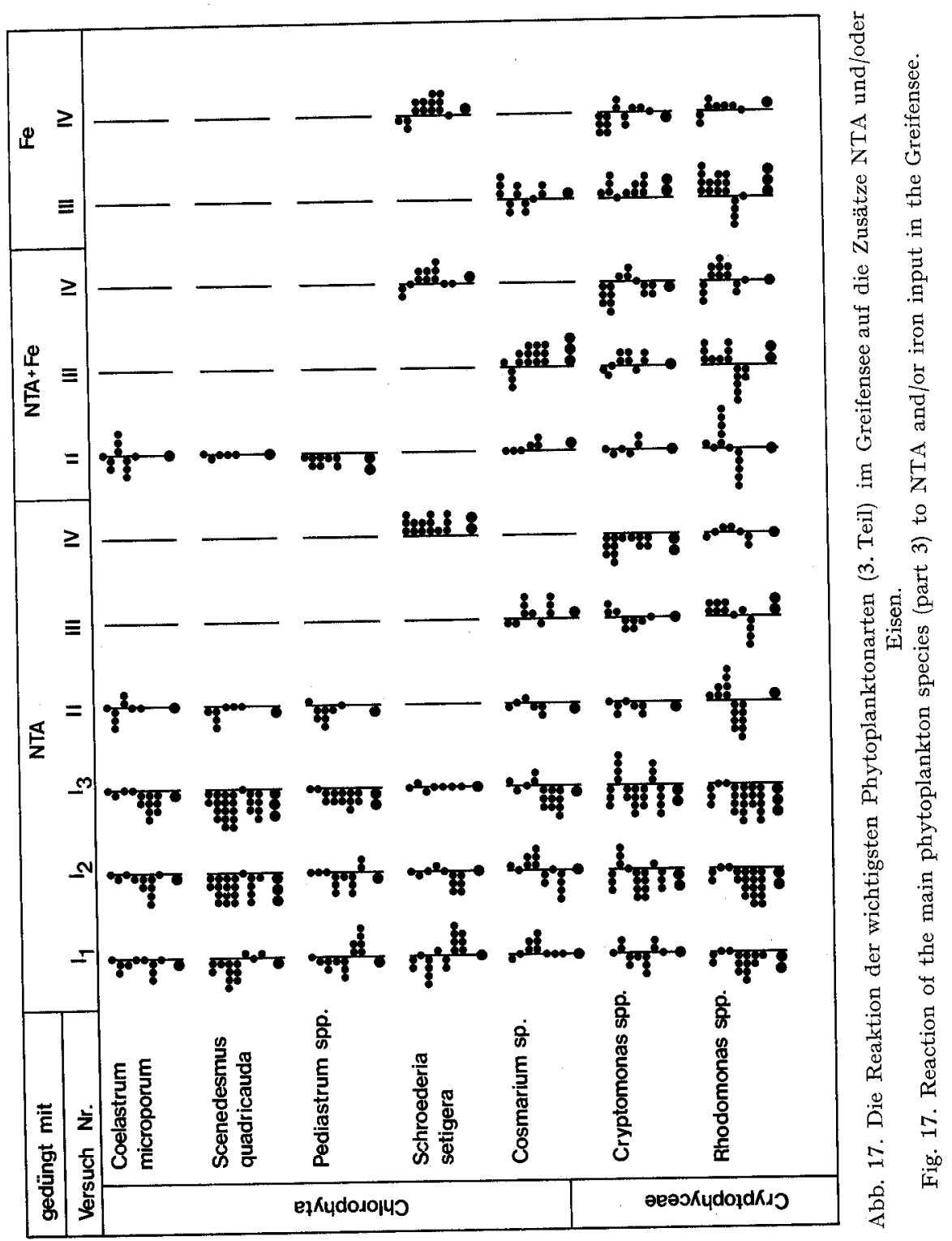
3.7 Die Wirkung der Zusätze auf die Entwicklung der einzelnen

Phytoplanktonarten

In den Abb. 15, 16 und 17 sind die Massenformen, die alle zusammen 90 bis $95 \%$ der totalen Biomasse bilden, dargestellt. Die Kontrolle, auf die sich die Darstellung gemäss der Erklärung in Abb. 7 bezieht, ist zusammen mit den Seewerten in Tab. 19 (Individuenzahlen pro Liter) zusammengestellt. Da im Greifensee die Massenformen mit wesentlich höheren Zelldichten auftraten, war hier das Bild der Reaktion fast aller dargestellten Phytoplanktonarten einheitlicher, besonders ausgeprägt bei den Versuchen 1 und 2. In den Experimenten 1, 2 und 4 lässt sich summarisch eine verringerte Biomasse bei 58 von 98 Fällen feststellen. Nur 10 mal konnte eine leicht wachstumsfördernde Wirkung, in den übrigen 30 Fällen keine Reaktion festgestellt werden. - Im Versuch 3 zeigen von 30 Darstellungen 13 keine, 14 positive und 3 negative Reaktion. - In allen vier Versuchen waren nur Cryptomonas- und Rhodomonas-Arten sowie Pandorina morum in genügender Zellzahl dauernd vertreten. Mit Ausnahme von Ceratium hirundinella, das im allgemeinen nicht, oder mit einer schwachen Wachstumssteigerung, auf die Zusätze reagierte, zeigten alle Planktonorganismen, die im dritten Experiment die Biomassesteigerung bewirkten, während der übrigen Versuchszeit ein anderes Verhalten. So betrug beispielsweise im Versuch 1 der relative Verlust der Zellzahl gegenüber der Kontrolle bei den Gattungen Microcystis, Aphanizomenon, Peridinium, Ankistrodesmus, Rhodomonas und Cryptomonas $30-70 \%$.

\section{Diskussion}

\section{Methodik}

\subsection{Versuchseinrichtung}

Um die Extrapolation von Düngungsexperimenten auf natürliche Verhältnisse eher zu ermöglichen, entwickelten zahlreiche Autoren In-situ-Versuchseinrichtungen mit Volumen von einigen Litern bis einigen Kubikmetern [9, 40, 47, 69, 78, 79, 132]. Je grösser die Versuchseinrichtung ist, um so eher erlaubt sie, die gewonnenen Resultate auf natürliche Verhältnisse zu beziehen. Aus praktischen Erwägungen wurde der Inhalt der hier verwendeten Testzellen auf rund 70001 beschränkt.

Die verwendeten Testzellen waren an beiden Enden offen (Abb. 3). Das obere Ende war über die Wasseroberfläche hochgezogen, das untere Ende erlaubte jedoch den Austausch des Wassers der gedüngten Testzelle mit dem Seewasser. Um diesen Austausch gering zu halten, wurde die Versuchszeit beschränkt auf die Stagnationsperiode mit stabiler Schichtung.

Es ist zu erwarten, dass durch die Abgrenzung des Kulturvolumens mit Hilfe der Folien die natürliche Turbulenz geschwächt wird. In den ersten zwei Experimenten im Vierwaldstättersee wurde diesem Umstand Rechnung getragen durch Einhängen kleiner, wellengetriebener Plexiglas-Rührteller. Da sich der Fehler infolge verringerter Turbulenz später als kleiner erwies als der durch die Rührteller bewirkte Austausch des Testwassers mit der Umgebung, wurde in den späteren Experimenten auf diese zusätzliche Einrichtung verzichtet. Um die Wirkung des Austauschs zu verringern, wurden die Düngstoffe über die ganze Länge der Testzelle verteilt zuge- 
geben, zur Messung aber nur die oberen 0-5 $\mathrm{m}$ im Greifensee bzw. 0-8 $\mathrm{m}$ im Vierwaldstättersee berücksichtigt. Die Streuung der In-situ-Methode ist nicht bekannt; immerhin zeigen physikalische, chemische und biologische Parameter im Laufe der Versuchszeit nur zunehmende Divergenz der Werte im See und der Testzellen, untereinander streuen die Daten der Testzellen ausgeprochen wenig (vgl. die MaximaMinima-Werte in Tab. 11).

Zu Beginn der Versuche liegen die Streuungen der Nährstoffkonzentrationen, der Biomassen und Pigmentgehalte in der Grössenordnung der Fehlergrenzen der Analytik und Probenahmetechnik. Gleichzeitig unterscheiden sich ferner die physikalischen Daten in den verschiedenen Testzellen nicht messbar voneinander. Gegenüber dem See zeigen Strahlung und Temperatur einen leicht anderen Verlauf. Aus den Abb. 18, 19 und 20 ist leicht zu erkennen, dass die nach einer Versuchswoche aufgetretenen Veränderungen gering sind. Die Strahlung wird nur im obersten Teil der Testzelle spürbar beeinträchtigt (Absorption durch die zweifach verstärkte Plastikfolie). Die Veralgung der Plastikfolie, die etwa nach 10 Tagen messbar einsetzt, bewirkt dann aber schnell eine Verringerung der Tiefe mit 3\% Lichtintensität bis $2 \mathrm{~m}$.
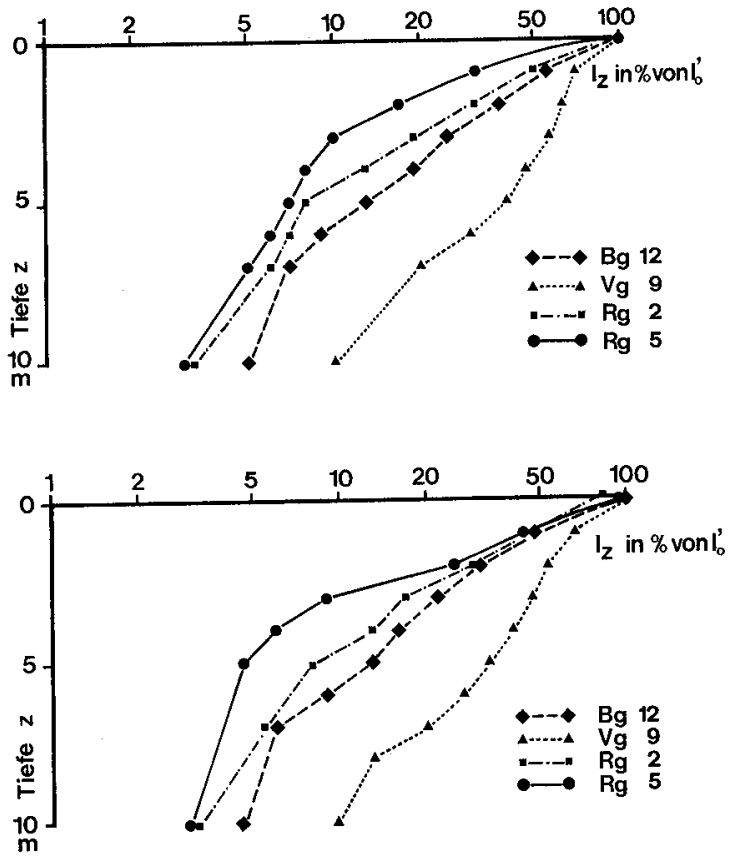

Abb. 18. Strahlungsintensität $I_{z}$ (in \% der Oberflächen-Intensität unmittelbar unter der Wasseroberfläche $I^{\prime \prime}{ }_{0}$ ) im Vierwaldstättersee in $30 \mathrm{~m}$ Entfernung von der Versuchseinrichtung. Fig. 18. Radiation intensity $I_{z}$ (expressed in \% of the surface intensity directly under the surface of the water $I^{\prime \prime}{ }_{0}$ ) in Lake Lucerne near the experimentation gear.
Abb. 19. Strahlungsintensität in der Testzelle 0 (in \% von $I^{\prime \prime}{ }_{0}$ des Sees). Fig. 19. Radiation intensity in the sampling unit 0 (expressed in \% of $I^{\prime \prime}{ }_{0}$ of the lake).

Der Temperaturverlauf zeigt in der Testzelle nicht die gleich scharfe Schichtung wie im See; zusätzliche Turbulenzen und das Fehlen horizontaler Strömungen sind dafür wohl verantwortlich. Die Temperaturdifferenz betrug in der gleichen Tiefe stets weniger als $1^{\circ} \mathrm{C}$. Die in Abb. 20 dargestellten Messungen wurden bei stabiler Schichtung vorgenommen, die Werte stellen somit Extreme dar. 


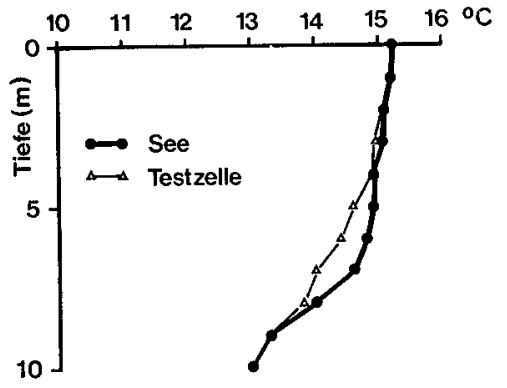

Abb. 20. Temperaturvergleich zwischen Testzelle und See (Vierwaldstättersee) am 25. September 1970 .

Fig. 20. Temperature comparison between sampling unit and Lake Lucerne on 25 September 1970 .

Obwohl die verwendete Methode in bezug auf Genauigkeit und Kontrollierbarkeit Mängel aufweist, stellt sie doch eine der wenigen Möglichkeiten dar, die es gestatten, die gewonnenen Resultate für die Praxis auszuwerten, zumal die Reaktion des natürlichen, unveränderten Seeplanktons geprüft wird und der kleine Nährstoffkreislauf intakt bleibt. Ferner sind auch Abbauvorgänge und Sedimentation naturnah. Gegenüber einer Laboreinrichtung weisen die Kultureinheiten ein viel günstigeres Verhältnis von Volumen zu Oberfläche auf $(500 \mathrm{ml}$ Nährlösung enthaltende In-vitro-Kulturen hätten pro Volumeneinheit eine rund $14 \mathrm{mal}$ grössere Oberfläche als die In-situ-Methode).

Anhand der chemischen Analysen zu Beginn und am Schluss der Experimente konnte gezeigt werden, dass die Gesamt-P- und Gesamt-N-Werte der Testzellen im Laufe eines Versuchs ansteigen, was auf eine Nährstoffzufuhr durch das untere, offene Schlauchende der Versuchseinrichtung hinweist. Im Gegensatz zu einem In-vitro-Batch-Experiment kommt es dadurch nicht so schnell zum Absterben der Algenpopulation.

Da für die Probenahme schliesslich das grosse Reservoir von etwa 7000 l zur Verfügung stand, musste nicht mit Mikromethoden gearbeitet werden, sondern es konnten bewährte Analysenverfahren eingesetzt werden.

\subsection{NTA-Analytik}

Chelatometrische Bestimmung des NTA bzw. der $\mathrm{BSB}_{5}$-Messungen, wie sie in Abbauversuchen des NTA häufig verwendet wurden $[17,62,64,100]$, waren für die vorliegenden NTA-Konzentrationen zu wenig genau; Methoden, welche NTA-Konzentrationen unter $0,1 \mathrm{mg} / \mathrm{l}$ zuverlässig erfassen, verlangten wiederum eine technische Ausrüstung, die mir nicht zur Verfügung stand $[1,18,54,76,92,108]$.

Die aktuellen Konzentrationen des NTA in den gedüngten Testzellen wurden auf Grund der Halbwertszeiten der Chlorid- bzw. Eisendüngung geschätzt.

Da in keinem der untersuchten Gewässer eine adaptierte Bakterienflora vorhanden war, durfte angenommen werden, dass der Abbau von NTA erst nach 10-14 Tagen oder später einsetzte. Diese Annahme wird gestützt durch die gemessenen Stickstoffwerte im ersten Greifensee-Versuch. Die relativ hohen NTA-Zugaben kommen dort in der Erhöhung der Gesamtstickstoffwerte sowohl des Rohwassers als auch im Filtrat zum Ausdruck, nicht aber beim Nitrat- oder Ammoniumstickstoff (Abbauprodukte des NTA).

Auf Grund der Angaben von ScHEGG [113] muss angenommen werden, dass grosse Mengen organischer Substanzen im Epilimnion eine entsprechend reiche 
Bakterienflora am Leben erhalten. Die Voraussetzungen für einen Abbau sind daher in eutrophen Gewässern günstig. Sollen der Abbau bzw. die Abbauprodukte bei Experimenten mit NTA unberücksichtigt bleiben, so muss die Versuchsdauer auf 2 bis höchstens 3 Wochen limitiert sein.

\section{Resultate und Experimente}

Die Resultate der Experimente ergaben gesamthaft, dass Eisen oder NTA-Zugaben die Primärproduktion kurzfristig erhöhen können; dadurch wird bis $87 \%$ mehr Biomasse gebildet. Aus dem Zusammenhang herausgelöst, könnte darin eine Düngewirkung dieser Stoffe oder sinngemäss eine wachstumslimitierende Wirkung derselben bei Aufbrauch oder Unterdotierung abgeleitet werden. Tatsächlich sind Fälle denkbar und experimentell nachgewiesen, in welchen Eisen und Komplexbildner limitierende Funktionen ausüben [82, 148]. Anderseits trifft es zu, dass oligotrophe Seen (und damit in erster Näherung auch mesotrophe Seen) entsprechend ihrer niedrigen Produktion relativ niedere Gehalte an organischen Stoffen aufweisen. Ob nun die Produktionserhöhung, welche mit der Zugabe von Eisenchelat erreicht wurde, darauf zurückzuführen ist, dass das Eisen (als Organokomplex) in einer Form vorlag bzw. in eine solche überführt wurde, die für die Zelle besser verwertbar ist, oder ob andere Mechanismen (antagonistische Reaktionen usw.) wirksam werden, lässt sich weder mit den vorliegenden noch mit den bisher bekannten Ergebnissen anderer Autoren beweisen.

Unter der Annahme, dass etwa 80\% des "partikulären» Eisens (im Sinne von nichtfiltrierbar) durch die Zellen aufgenommen oder an der Zellwand adsorbiert sind, kann der Eisengehalt der Biomasse errechnet werden. Im Vierwaldstättersee liegt dieser in der Grössenordnung von 0,7\% und variiert wenig. Im Greifensee liegt dieser Gehalt etwa bei $0,07 \%$. Bei Annahme herkömmlicher Limitierung wäre also in erster Linie im Greifensee eine Wachstumssteigerung zu erwarten, zumal dort Phosphor und Stickstoff im Überschuss vorliegen. Der Einwand, dass Eisen im Greifensee wegen Chelatisierung durch natürliche Komplexbildner besser verwertbar sei und daher das Wachstum nur in wesentlich kleineren Konzentrationen als im Vierwaldstättersee limitiere, wird durch verschiedene Beobachtungen entkräftet: Erstens ist die Depression des Algenwachstums als Folge der Eisendüngung im Greifensee auf diese Weise nicht erklärbar, und zweitens wurde in den Sedimentfallen aller Testzellen, unabhängig von Art und Menge der Düngung, Eisen in der gleichen Grössenordnung gefunden. Somit hängt die Sedimentation des Eisens direkt mit dem Absinken der Planktonten zusammen. Die NTA-Zugabe schliesslich verschiebt den prozentualen, filtrierbaren Anteil des Eisens nicht messbar. Berechnungen von STUMm [136] zufolge können auch grössere Mengen NTA oder ÄDTA $\left(10^{-5} M / 1\right)$ Eisen nicht am Ausflocken hindern, wenn $\mathrm{Ca}^{2+}$ in natürlichen Konzentrationen $\left(10^{-3} M / 1\right)$ anwesend ist.

Aus allen Experimenten im Greifensee und im Vierwaldstättersee geht hervor, dass das divergierende Wachstumsverhalten auch nicht auf den verschiedenen Artbestand der Planktonpopulationen zurückgeht. Es sind zum Teil dieselben Arten und sogar Varietäten, die im Vierwaldstättersee positiv, im Greifensee negativ ansprechen. Hemmung bzw. Förderung des Wachstums werden somit sicher von Eisen und/oder NTA beeinflusst, aber nicht durch direkte Einwirkung als Nährstoff, son- 
dern durch Veränderung der chemischen Verhältnisse des Wassers. NTA bzw. Eisen wirken beide im gleichen Sinne, die Kombination beider Stoffe summiert die Einzeleffekte kaum spürbar. Es ist daher wahrscheinlich, dass durch die Zugabe der Stoffe ein und derselbe Prozess ausgelöst wird. Da die physikalischen Parameter beider Gewässer vergleichbar sind, muss dieser Prozess, der bald fördernd, bald hemmend auf das Wachstum der Phytoplankter wirkt, aus der divergierenden Nährstoffsituation beider untersuchter Gewässer abgeleitet werden. Dabei sind aber auch die Wechselwirkungen der Biologie mit zu berücksichtigen: So sind die organischen Stoffe, die als Stoffwechselexkrete in erster Linie vom Plankton herrühren, von Bedeutung. Der total messbare organische Kohlenstoff im Filtrat steht in einem ungefähr konstanten Verhältnis zur Biomasse (gewichtsmässig 1:4).

Obwohl die genaue Zusammensetzung der natürlichen organischen Stoffe nicht im Detail bekannt ist, weist doch die Assoziierung von Eisen und Mangan mit grösseren Gehalten an organischen Stoffen darauf hin, dass sich darunter Komplexbildner bzw. Stoffe befinden, die eine Kolloiddispersion mit Metallen stabilisieren [120, 121]. Die organischen Komplexbildner weisen eine geringe Spezifität zu einzelnen Kationen auf [27].

Die Wirkung der Eisendüngung auf das Phytoplankton des Vierwaldstättersees liesse sich durch die Ionentauscherfunktion des Eisens, wie sie unter A 6.3 beschrieben wurde, erklären. Danach wäre an die Zellwand adsorbiertes Eisen fähig, Phosphat (und evtl. Silikat?) aus dem Wasser zu binden und damit die Zelle zu versorgen. HARvey zeigte diese Möglichkeit, als er im mikroskopischen Präparat mit einer Fesensitiven Reaktion einen Farbhof rund um die Zellen erhielt [56]. Auch die Wirkung des NTA liesse sich mit diesem Mechanismus erklären, erhöht doch seine Gegenwart die Austauschkapazität des schon vorhandenen oder zugefügten Eisens. Da der pHWert beider Gewässer im alkalischen Bereich liegt (im Greifensee bis zum Extremwert von pH 9,14), wird die Anlagerung von Kationen gefördert. Somit scheint es wahrscheinlicher, dass sowohl NTA als auch Eisen die Gleichgewichte anderer Spurenelemente beeinträchtigen. Ein Rechnungsmodell nach dem Programm von Morel und MoRGAN [88] zeigt, dass wir beim Variieren der NTA-Konzentrationen $\left(0^{-10^{-4,5}} \mathrm{M} / 1\right.$ die freie Kupferionenkonzentration um 1,5 Zehnerpotenzen verschieben können. Neben Kupfer reagieren auch andere Spurenmetalle im alkalischen Bereich in vergleichbarer Weise sowohl mit NTA als auch mit Eisenhydroxiden. Die nachstehenden Überlegungen gelten deshalb sinngemäss auch für andere Spurenelemente (Zn, Mo, Co usw.).

Die Beeinflussung des Pflanzenwachstums kommt demnach so zustande, dass von den Pflanzen nur freie Kupferionen verlangt werden, dass aber eine zu hohe Konzentration dieser freien Ionen für die Pflanzen toxisch wirkt [45]. Für den Fall des Kupfers wurde von Smith und ManaHan [126] gezeigt, dass bei Grünalgenarten nur $\mathrm{Cu}^{2+-I o n e n, ~ n i c h t ~ a b e r ~} \mathrm{Cu}-\mathrm{NTA}$, zur Zellproduktion benützt werden, dass somit die Zellen keinen Metabolismus für den NTA-Abbau besitzen. Mittels Tracer-Methoden mit ${ }^{14} \mathrm{C}$-markiertem NTA gelangte man bei Tierversuchen zu analogen Schlüssen [5]. In der Natur kommt Kupfer assoziiert mit organischen Stoffen vor [153]. Die freien Kupferionen werden also zum Teil durch organische Stoffe gebunden.

Die Wachstumserfolge, welche in Algenkulturen mit Fe-Chelaten erzielt werden, lassen sich damit erklären, dass von den mit «reinen", aber keineswegs völlig $\mathrm{Cu}^{2+-}$ 
freien Chemikalien zubereiteten Nährlösungen her verhältnismässig viel $\mathrm{Cu}^{2+} \mathrm{kommt}$, dass aber bei Verwendung von hochreinem destilliertem Wasser ohne organische Stoffe das Kupfer als anorganische, toxisch wirkende Spezies vorliegt [70, 129]. Die natürlichen organischen Stoffe in den Gewässern haben kaum jene Fähigkeit der Komplexbildung wie NTA oder vergleichbare andere synthetische Chelatbildner. Weil hier ferner ein Gemisch vieler Stoffe anzunehmen ist, ist kaum eine selektive Bevorzugung einzelner Metallionen bei der Komplexbildung zu erwarten. Um das Lebensmilieu für die Algen ganz zu entgiften, braucht es daher Konzentrationen, die wesentlich höher sind als die Konzentrationen des zugefügten NTA. Offenbar genügt dazu $1 \mathrm{mg} \mathrm{C/1} \mathrm{TOC} \mathrm{(Vierwaldstättersee)} \mathrm{nicht,} \mathrm{so} \mathrm{dass} \mathrm{durch} \mathrm{die} \mathrm{Zugabe} \mathrm{von}$ NTA günstigere Wachstumsbedingungen entstehen.

Im Greifensee liegen etwa 6- bis 10 mal soviel organische Stoffe vor, mit Ausnahme von Mangan und Eisen aber die gleichen Spurenmetallkonzentrationen. Die organischen Stoffe entziehen hier den Algen einen Teil der Spurenmetall-Ionen, für die hier infolge grosser Biomasse ein rund zehnmal grösserer Bedarf herrscht als im Vierwaldstättersee. Durch die Zugabe von NTA oder Eisen kann nun auch bei genügendem Totalgehalt durchaus eine Mangelsituation der betreffenden freien Ionen eintreten, selbst dann, wenn ein grosser Teil der Adsorptions- oder KomplexbildungsKapazität durch $\mathrm{Ca}^{2+}$ bỉockiert wird. Erst durch die allochthone Zufuhr von Spurenmetallen oder durch den Abbau des NTA kann das Wachstum wieder enthemmt werden.

Der Transport von Spurenmetallen aus tieferen Wasserschichten ins Epilimnion ist während der Stagnationszeit weitgehend blockiert. Zudem ist im Falle des Kupfers von den bodennahen Schichten keine Zufuhr zu erwarten, da sich mit dem vorhandenen Sulfid (im Greifensee) schwerlösliche Salze bilden. Bei der beginnenden Zirkulation im Herbst (vgl. Versuch 3, Greifensee) kommen massive Ionenkonzentrationen von Mangan und Zink an die Oberfläche. Schon unterhalb $5 \mathrm{~m}$ Tiefe steigt beispielsweise die Mangankonzentration auf das 10 fache des Oberflächenwertes, und über Grund finden wir 30mal soviel totales Mangan als an der Oberfläche. Das aufsteigende Wasser ist für das Algenwachstum nicht förderlich; durch Zugabe von NTA oder Fe wird das Medium entgiftet, und eine relative Produktionserhöhung gegenüber der Kontrolle ist zu beobachten. Je nach der Zusammensetzung des Planktons werden ferner verschiedene organische Stoffe gebildet (u.a. Toxine). Es ist deshalb möglich, dass die gleiche Art innerhalb eines Jahres im gleichen See verschiedene Wachstumsbedingungen antrifft. Durch die Zugabe von Eisen oder NTA kann der Konkurrenzkampf um die Nährstoffe und Spurenmetalle noch verschärft werden. In allen 7 Versuchen bleibt die Verschiebung der Wachstumskurven der gedüngten Testzellen gegenüber der Kontrolle zeitlich beschränkt. Im Vierwaldstättersee hält die Produktionssteigerung sogar nur einige Tage an und wird dann kompensiert durch eine Wachstumsverminderung. Als Folge davon sinkt die anfänglich erhöhte Biomasse wieder $a b$ und pendelt sich um den Kontrollwert ein. Der zu Beginn der Vierwaldstättersee-Versuche jeweils gemessene Phosphatgehalt reicht nicht aus, um länger anhaltende Produktionssteigerungen zu ermöglichen; der Produktionsabfall ist somit auf die Limitierung durch Nährstoffe zurückzuführen. Alle Zusätze ergeben pro Experiment gleichartige Wachstumsverläufe, einzig im dritten Experiment im Vierwaldstättersee stimmt die Wirkung des Eisens nicht mit der des NTA bzw. der 
kombinierten Düngung überein. Da die adsorptiven Eigenschaften des Eisens mit dem $\mathrm{pH}$ stark variieren und amorphes Eisenhydroxid durch Alterung einen Teil der anfänglichen Adsorptionskapazität verliert, sind bei gleicher Nährstoff- und Spurenmetallsituation innerhalb einer Versuchsserie Schwankungen möglich und zu erwarten. Die zum Teil grossen Streuungen der Produktions- und Biomassewerte der mit Eisen gedüngten Testzellen innerhalb eines Versuchs sind hingegen nicht kausal erklärbar.

\section{Schlussfolgerungen}

Eisen und/oder NTA können im mesotrophen See die Photosyntheseleistung kurzfristig steigern, im eutrophen See hemmen. Nach wenigen Tagen ist diese Reaktion aber wieder abgeklungen. Eine wachstumslimitierende Funktion des Eisens ist äusserst unwahrscheinlich, so dass die Eisendüngung, welche beim dreistufigen Betrieb von Abwasserreinigungsanlagen (mit Fe ${ }^{3+}$-Fällung) infolge des Resteisengehalts des Anlagenabflusses unvermeidlich ist, langfristig gesehen die Planktonproduktion nicht steigern wird.

Da auch eine erhöhte Stickstoffzufuhr weitgehend wirkungslos bleibt [128], ein erhöhtes Phosphatangebot hingegen die Primärproduktion massiv erhöht [40], ist anzunehmen, dass eine Verminderung der Phosphatzufuhr durch Einführung der chemischen (Fällungs-)Stufe der Abwasserreinigung und durch Ersatz der Phosphorkomponenten in den Waschmitteln, z.B. durch NTA, das Pflanzenwachstum und damit die sekundäre Belastung der Seen vermindern wird. Wie gross freilich diese Verminderung im konkreten Fall, z.B. bei den beiden untersuchten Seen, sein wird, kann mit den heutigen Kenntnissen noch nicht genau quantifiziert werden.

Für das Einzugsgebiet des südlichen Teils des Vierwaldstättersees ergibt sich auf Grund einer auf der Bewohnerzahl und der Fläche des landwirtschaftlichen Gebietes basierenden Schätzung bei Annahme eines P-Ausstosses von $3 \mathrm{~g}$ P pro Einwohner und Tag bei mittlerer Wasserführung für die Reuss (= Hauptzufluss) ein mittlerer P-Gehalt von $18 \mu \mathrm{g} / \mathrm{l}$ und für die Muota von $80 \mu \mathrm{g} / \mathrm{l}$. Aus der analytisch ermittelten Tag-Nacht-Schwankung (GÄCHTER, pers. Mitteilung) des P-Gehalts (Trockenwetterabfluss) berechnet, entfällt auf die Reuss in Utbereinstimmung dazu ein mittlerer Anteil von $25 \mu \mathrm{g} / 1$ aus der täglichen Humanaktivität (Siedlungsabwässer, Industrie) und auf die Muota $86 \mu \mathrm{g} / \mathrm{l}$, entsprechend 40-50\% der Gesamtfracht. Wenn vorerst durch Ersatz des Waschmittelphosphors im Laufe der Zeit auch durch konsequente Einführung der 3. Reinigungsstufe in den Kläranlagen des ganzen Einzugsgebiets eine 90 prozentige Elimination des Abwasserphosphors erreicht ist, wird die P-Fracht zum See um mindestens $40 \%$ niedriger sein, wobei anzumerken ist, dass dieser Anteil heute mit einer konstanten Tagessumme mehr oder weniger kontinuierlich zufliesst und im See optimal verwertet wird, während der landwirtschaftliche Anteil schubweise, vor allem während Regenperioden, als Folge der Bodenerosion in den See gelangt.

Der dem Greifensee zufliessende Phosphor stammt zu 90-95\% aus Siedlungsabwässern und Industrie (PLEISCH [101]). Unter solchen Verhältnissen ist die Verminderung des Phosphorgehalts der Zuflüsse bzw. der Zufuhr zum See weitgehend eine Frage der Abwasserbehandlung. Da der Greifensee in einem extremen Mass überdüngt ist, muss zu seiner Sanierung primär die Phosphorbelastung verringert werden, und zwar so weit wie möglich. Dies ist nur mit hohen P-Eliminationsraten 
denkbar. Mit konventioneller, mechanisch-biologisch-chemischer Abwasserreinigung allein wird diese Forderung nicht zu erfüllen sein, und zudem wird auch diese (trotzdem absolut notwendige) Massnahme bis zur vollständigen Realisierung noch längere Zeit beanspruchen. Die Nährstoff-Akkumulation im See und damit die primäre Belastung schreitet in der Zwischenzeit jedoch weiter fort. Mit einem raschen Ersatz der Waschmittelphosphate durch nichtdüngende Produkte könnte diese Entwicklung kurzfristig und wirksam beeinflusst werden. Dass einer solchen Massnahme, d.h. der Einführung von NTA als Substituent, keinerlei limnologische Bedenken im Wege stehen, beweisen die Ergebnisse dieser Arbeit.

\section{E. Zusammenfassung}

1. Es wurde eine In-situ-Methode im technischen Maßstab entwickelt und angewandt, um die Wirkung von NTA (50-9000 $\mu \mathrm{g} / \mathrm{l})$ und/oder Eisen $(30-90 \mu \mathrm{g} / \mathrm{l})$ auf das Wachstum des Phytoplanktons zu studieren.

2. Es wurden 7 Anreicherungsversuche durchgeführt, und zwar 3 im mesotrophen Vierwaldstättersee, 4 im hocheutrophen Greifensee.

3. Das Algenwachstum wurde während jeweils 14 Tagen anhand der Messung der Primärproduktion $\left({ }^{14} \mathrm{C}-M e t h o d e\right)$, des Pigmentgehalts und der Zellendichte bzw. Biomasse der wichtigsten Algenarten verfolgt.

4. Im mesotrophen Vierwaldstättersee bewirkt Eisen und/oder NTA eine Steigerung der Photosyntheserate während der ersten 4 Versuchstage. Die gleichen Algenarten und Varietäten reagieren im Greifensee zum Teil mit einer Wachstumshemmung auf die gleichen Zusätze. Eisen und NTA wirken in allen Experimenten (mit einer Ausnahme) gleichsinnig, entweder fördernd oder hemmend. Die Kombination beider Stoffe erhöht die Einzeleffekte nicht wesentlich.

5. Die anfängliche Produktionserhöhung im Vierwaldstättersee wird durch eine anschliessende Produktionsverminderung praktisch kompensiert. Über 14 Tage gemittelt resultiert eine Biomasse, die von 92 bis $187 \%$ (Kontrolle $=100 \%$ ) variiert. Im Greifensee bleibt die Biomasse während des gleichen Zeitraums zwischen 66 und 102\% der Kontrolle (mit Ausnahme eines einzigen Experiments, das bei beginnender Herbstzirkulation gestartet wurde und bei welchem Eisen und/oder NTA deutlich eine Erhöhung der Biomasse gegenüber der Kontrolle bewirkten.)

6. Die Wirkung der Zusätze hängt ab von der aktuellen chemischen Zusammensetzung des Wassers, insbesondere vom P-Gehalt, von organischen Stoffen und der Spurenmetallsituation, hingegen kaum von der momentanen Artenzusammensetzung des Planktons.

7. Sowohl Eisen (durch Adsorption) als auch NTA (durch Chelierung) verringern das Angebot an freien Ionen verschiedener Metalle, insbesondere von Kupfer. Dieses Angebot wird ferner durch natürliche organische Stoffe beeinflusst. Da die freien Ionen einerseits zum Wachstum benötigt werden, anderseits geringe Mengen $(\mu g / \mathrm{l})$ schon toxisch wirken, kann durch Zufügung von NTA oder Eisen das Medium entgiftet oder das Spurenmetallangebot limitiert werden, mit resultierender Erhöhung bzw. Erniedrigung der Algenproduktion.

8. Im Greifensee steht pro Biomasse-Einheit rund 10mal weniger Totaleisen zur Verfügung als im Vierwaldstättersee. Trotzdem führt Eisendüngung im Greifensee 
zur Wachstumsverminderung des Phytoplanktons. Eine Limitierung des Algenwachstums durch Eisen wird daher ausgeschlossen.

9. Vom limnologischen Gesichtspunkt aus steht der Verwendung von NTA als Ersatz für die kondensierten Phosphate in den Haushaltwaschmitteln nichts im Wege. Mindestens stellt dieser Stoff eine akzeptable Zwischenlösung dar, bis andere, wenn möglich auch $\mathrm{N}$-freie Ersatzprodukte geschaffen sind.

10. Die dritte Reinigungsstufe der Kläranlagen kann auch dort eindeutig befürwortet werden, wo mit Eisensalzen gefällt wird. Die zu erwartende und zudem nur kurzfristige Wachstumssteigerung in mesotrophen Seen beträgt nur 10-30\% der düngenden Wirkung, die der damit eliminierte Phosphor hätte.

\section{SUMMARY}

Phosphorus plays a key rôle in the eutrophication of Swiss lakes. Phosphate precipitation in wastewater treatment and the substitution of phosphates in washing-products with complexing agents such as NTA offers possible ways to eliminate phosphorus. In many in vitro algae tests, however, iron and NTA or EDTA have had a growth-stimulating effect. Seven in situ tests, each of 3 weeks duration were carried out in culture units of 7,000 liters to examine whether 50 to $9,000 \mu \mathrm{g} / 1 \mathrm{NTA}$ and/or 30 to $90 \mu \mathrm{g} / 1$ iron $\left(\mathrm{Fe}^{3+}\right)$ affected phytoplankton growth in natural waters. 3 tests were carried out in mesotrophic Lake Lucerne, 4 in the highly eutrophic Greifensee. Algal reaction to this input was observed for parameters: primary production $\left({ }^{\mathbf{1 4}} \mathrm{C}\right.$-method), pigment content and cell density respectively biomass of the main phytoplankton species; these were then compared with data from a control unit.

Plankton reaction was different for the two lakes: primary production and biomass were temporarily raised by the addition of iron and/or NTA in Lake Lucerne, but the initial 4-day production increase was followed by slackening in production, which practically offset excess growth. The biomass averaged out over 14 days amounted to 92 to 187 percent of the control data.

Both chemicals inhibited photosynthesis in the Greifensee during the summer stagnation period. Only at the beginning of the autumn overturn was an increase in biomass noted in the Greifensee through the addition of iron and/or NTA in relation to the control data. Mean values for the biomass in culture units with chemical input are found to lie between 66 and $102 \%$ of control during the stagnation period.

In keeping with the observation described above, the following pattern was noted for the plankton species common to both lakes: Cryptomonas erosa, Rhodomonas lacustris, Ankistrodesmus falcatus, Scenedesmus quadricauda and other species reacted to the same chemical input with a production increase in Lake Lucerne and a decrease in the Greifensee.

As little as $30 \mu \mathrm{g} / \mathrm{l}$ iron or $50 \mu \mathrm{g} / \mathrm{I}$ NTA causes an unmistakable reaction, which is only slightly heightened by a gradual increase in the iron or NTA concentration. Even a combination of both chemicals hardly enhances the single reaction. The growth-stimulating effect of iron as a nutrient, for although the highly eutrophic Greifensee has about 10 times less iron in relation to the biomass than Lake Lucerne, iron input with or without NTA clearly inhibits primary production. NTA is not capable of keeping $\mathrm{Fe}^{3+}$ entirely in solution. The given chemical composition of the water, $\mathrm{P}$-content, concentration of organic material and trace metals can be seen as the explanation for the divergent behavior patterns of the phytoplankton in both lakes. The composition of plankton species at a given moment is of subordinate importance.

Since iron is - in the form of dispersed $\mathrm{FeOOH}$ and $\mathrm{Fe}(\mathrm{OH})_{3}$ - strongly adsorptive and acts mainly as a cation exchanger in solutions above $\mathrm{pH} 7$ and since NTA ties various metals, especially copper through complex formation, the free ion supply of these metals is reduced. The supply is, however, also influenced by natural complexing agents that represent an unknown portion of the organic material in water. There is a clear correlation between organic material and biomass, which in turn is dependent on the nutrient supply $\left(\mathrm{PO}_{4}-\mathrm{P}\right)$. Assuming that the total supply of 
trace metals is the same, there are less free cations in a eutrophic lake with a correspondingly large mass of organic matter than in an oligotrophic or mesotrophic water body. Because the free ions are both growth-stimulating and toxic even in small quantities $(\mu \mathrm{g} / \mathrm{l})$ the addition of iron and/or NTA can disintoxicate the medium or limit the supply of trace elements with a resulting increase or decrease in algal production. According to a rough estimate the introduction of the tertiary stage of wastewater treatment and the substitution of phosphates in washing-products would lead to a $40 \%$ reduction of the P-loading into Lake Lucerne. Since in this mesotrophic lake iron or NTA input causes only a temporary increase in growth and since the resulting biomass increase during the testing period amounted to only $1 / 3$ to $1 / 10$ of that triggered by the addition of phosphates $(30 \mu \mathrm{g} / \mathrm{l})$, there can be no objection to the use of NTA as a substitute for phosphorus in washing-products and to the precipitation of phosphates with iron.

\section{RÉSUMÉ}

Le phosphore joue le rôle dominant dans l'eutrophisation des lacs suisses. La précipitation des phosphates comme phase supplémentaire de purification dans les stations d'épuration et la réduction des phosphates contenus dans les produits de lessive, voire leur remplacement par des agents complexants, comme le NTA, sont des mesures qui offrent la possibilité de diminuer l'apport du phosphore. Dans beaucoup de tests algologiques in vitro, le fer et le NTA ou l'EDTA cependant, provoquent des augmentations de la croissance, ce qui laisse supposer que de telles matières provoquent également dans les lacs, une production de plancton plus importante. On a cherché, par une méthode in situ à l'échelle technique (unité de culture de 7000 l) en 7 tests d'une durée de trois semaines chacuns, si $50-9000 \mu \mathrm{g} / 1$ NTA et/ou $30-90 \mu \mathrm{g} / 1 \mathrm{Fe}^{3+}$ influence la croissance du phytoplancton dans des eaux naturelles. Trois essais ont été accomplis dans le lac des Quatre-Cantons, mésotrophe, et quatre expériences dans le lac de Greifensee, extrêmement eutrophe. La réaction des algues par rapport à une unité de contrôle traitée de la même façon, non fertilisée, a été observée, sur la base de paramètres mesurés, comme la production primaire (méthode ${ }^{14} \mathrm{C}$ ), le contenu en pigments et la densité des cellules (biomasse) des espèces les plus importantes du phytoplancton.

La réaction du plancton était différente dans les deux lacs. Dans le lac des Quatre-Cantons, la production primaire et la biomasse ont été augmentées temporairement par l'addition de fer et/ou d'NTA. L'augmentation initiale de la production, qui dure à peine 4 jours, est plus ou moins compensée par une diminution consécutive de la production. En prenant la moyenne de 15 jours, il en résulte une biomasse qui est de 92 à $187 \%$ du contrôle non traité.

Dans le lac de Greifensee, les deux substances provoquent pendant la stagnation estivale une inhibition du rendement de la photosynthèse. Au début de la circulation automnale, seulement, on peut observer, dans le lac de Greifensee, une augmentation relative de la biomasse par rapport au contrôle, dû à la fertilisation par le NTA et/ou le fer. Les valeurs de biomasse des unités de culture fertilisées restaient pendant l'époque de stagnation, en moyenne entre 66 et $102 \%$ du contrôle. Le comportement des espèces planctoniques des deux lacs correspond à la constatation si-dessus mentionnée: Cryptomonas erosa, Rhodomonas lacustris, Ankistrodesmus falcatus, Scenedesmus quadricauda et d'autres espèces dans le lac des Quatre-Cantons réagissent sur les mêmes additifs par une augmentation de la croissance et dans le lac de Greifensee, par une inhibition de la photosynthèse.

Déjà $30 \mu \mathrm{g} / 1$ de fer, voire $50 \mu \mathrm{g} / 1$ de NTA sont suivis d'une nette réaction. Celle-ci n'est renforcée qu'en faible mesure si l'on ajoute graduellement du fer ou du NTA. En plus, la combinaison des deux substances n'augmente pas sensiblement les effets de chacunes d'elles. Le fer ne semble pas agir comme facteur limitant la croissance: malgré que le lac de Greifensee, très eutrophe, contienne environ 10 fois moins de fer par rapport à sa biomasse, que le lac des Quatre-Cantons, le fer rajouté, avec ou sans NTA, provoque une nette inhibition de la production primaire.

Par l'addition de NTA le fer n'est pas modifié en une forme mieux utilisable. Les comportements divergents du phytoplancton dans les deux lacs semblent être dûs à la composition chimique actuelle de l'eau, notamment le taux de phosphore, la concentration des matières organiques et la présence des oligo-métaux disponibles. La composition spécifique actuelle du plancton ne joue cependant qu'un rôle subordonné.

Le fer (sous forme de $\mathrm{FeOOH}$ et $\mathrm{FE}(\mathrm{OH})_{3}$ dispersé) agit comme échangeur de cations, particulièrement dans les solutions dont le pH est supérieur à 7. C'est pourquoi les apports de Fe III ou 
de NTA (ou de tous les deux) peuvent provoquer la fixation de certains oligométaux, tel que le cuivre (Fe III par adsorption, NTA par formation de complexe); il en résulte une réduction de la disponibilité de ceux-ci. En plus, les agents complexants naturels, partie intégrante des matières organiques de l'eau, influencement l'utilité des oligo-métaux. Le taux de matières organiques est en corrélation étroite avec la biomasse qui, de son côté, dépend de l'apport de matières nutritives $\left(\mathrm{PO}_{4}-\mathrm{P}\right)$.

A condition que l'offre totale d'oligo-métaux soit la même, dans un lac eutrophe, il y a moins de cations libres que dans une eau oligotrophe ou mésotrophe. Du fait que les ions libres soient d'une part indispensables pour la croissance et soient d'autre part déjà toxiques en petites quantités $(\mu \mathrm{g} / 1)$, on peut, en rajoutant du fer ou du NTA, désintoxiquer le milieu ou limiter l'offre d'oligométaux; il en résulte une augmentation ou une diminution de la production des algues. On peut en conclure, par une estimation grossière, que l'introduction de la troisième phase d'épuration et la substitution des phosphates contenus dans les produits de lessive provoqueront une réduction de $40 \%$ de la charge en phosphore des affluents du lac des Quatre-Cantons. Ces mesures peuvent être recommendées sans réserve, du fait que l'augmentation de croissance observée dans le lac des Quatre-Cantons n'est que de courte durée et n'atteint que 10 à $30 \%$ de l'effet fertilisant qu'aurait provoqué le phosphore s'il n'avait pas été substitué et/ou précipité.

Du point de vue limnologique, il n'y a que peu d'objections à faire contre l'utilisation du NTA comme produit de remplacement dans les lessives.

Herrn Prof. Dr. O. Jaag (Altdirektor der EAWAG) möchte ich danken, dass er mir die notwendige apparative Ausrüstung und einen Arbeitsplatz an der EAWAG in Dübendorf und im Hydrobiologischen Laboratorium der ETH in Kastanienbaum LU zur Verfügung stellte.

Herrn Prof. Dr. W. Stumm (Direktor der EAWAG) danke ich für das grosse Interesse und die vielen wissenschaftlichen Diskussionen, die diese Arbeit entscheidend förderten, ferner besonders für die Überlassung von Resultaten aus der Berechnung von Multiliganden-Systemen.

Den grössten Dank schulde ich Herrn Prof. Dr. H. Ambühl, Leiter der Limnologischen Abteilung der EAWAG, für zahlreiche wissenschaftliche Anregungen, kritische Diskussionen und Hilfestellungen bei den Versuchen sowie für die Durchsicht des Manuskripts und für die stets positive Einstellung zur Arbeit.

Während des arbeitsintensiven praktischen Teils der Arbeit durfte ich manche Hilfeleistung entgegennehmen: So halfen mir in der Werkstatt der technischen Versuchsanlage Tüffenwies die Herren H. Schälchli, E. Schwager und W. Häfliger fachkundig bei der Anfertigung der Kultureinheiten. Herr D. Meierhans und Herr K. Steiner besorgten die ${ }^{14} \mathrm{C}-$ Messungen. Herr dipl. Chem. E. Szabó und Herr B. Ribi waren mit der Evaluation einer verbesserten Eisenanalytik beteiligt. Die Spurenmetallanalysen wurden von Herrn Dr. H. R. Hegi besorgt. Herr dipl. rer. nat. H.P. Riniker bestimmte den TOC. Allen diesen Helfern und Kollegen danke ich herzlich für ihre Hilfsbereitschaft und die sorgfältige Ausführung der Arbeiten.

Die Arbeit wurde mit Unterstützung der Stiftung der Wirtschaft zur Förderung des Gewässerschutzes in der Schweiz ausgeführt.

\section{LITERATURVERZEICHNIS}

[1] Afghan, B. K., und Goulden, P.D., Determination of Trace Quantities of Nitrilotriacetio Acid by Differential Cathode-Ray Polarography, Environ. Sci. Technol. 5, 601 (1971).

[2] АмвӥнL, H., Die praktische Anwendung der elektrochemischen Sauerstoffbestimmung im Wasser, Schweiz. Z. Hydrol. 22, 23-39 (1960).

[3] АмвїнL, Н., und Schmid, M., Die Bestimmung geringster Mengen von Phosphation im Wasser von Binnenseen, Schweiz. Z. Hydrol. 27, 172-183 (1965).

[4] АмвÜнL, H., Der Einfluss chemischer Düngung auf stehende Obevflächengewässer, GWF 107, 357-363 (1966)

[5] Artmann, N.R., Safety Considerations for Detergents, Paper Nr. 11 at the 6th Internat. Wat. Poll. Res. (1972). 
[6] Aubert, M., Gambarotta, J.P., und Laumond, F., Rôle des apports terrigènes dans la multiplication du phytoplancton mavin cas particulier du fer, Rev. Int. Oceanogr. Med. 12, 75 (1968).

[7] Axr, G., Ein Gerät zur kontinuievlichen Messung des ovganischen Kohlenstoffs in Trinkwasser und Abwasserbereichen, Vom Wass. 36, 328-339 (1969).

[8] Barber, R.T., und Ryther, J.H., Organic Chelators: Factors Affecting Primary Production in the Cromwell Current Upwelling, J. exp. mar. Biol. Ecol. 3, 191-199 (1969).

[9] BENNDORF, J., Untersuchungen über Remineralisierung des Phosphors in der Freireasserregion der Saidenbachtalsperve, Int. Rev. ges. Hydrobiol. 53, 635-650 (1968).

[10] Benolt, R. J., Preliminary Observations on Cobalt and Vitamin $B_{12}$ in Fresh Water, Limnol. Oceanogr. 2, 233 (1957).

[11] BerNISCH, J., Einige Beobachtungen und Erfahrungen anf dem Gebiet der praktischen Abroasserbiologie, Z. Fisch. [N. F.] 6, H. 1-7, 157 (1957).

[12] Berth, P., und Fischer, W. K., Waschmittelphosphate und mögliche Austauschstoffe in Beziehung zum Eutrophierungsproblem, Tenside Detergents, 8, 1-9 (1971).

[13] Betzer, P.R., und Pilson, M.E.Q., Concentrations of Particulate Iron in Atlantic OpenOcean Water, J. Mar. Res. 28, Nr. 2 (1970).

[14] Bloesch, J., Sedimentation und Phosphorhaushalt im Vierwaldstättersee (Horwer Bucht) und im Rotsee, Diss. ETHZ (im Druck).

[15] Bouveng, H.W., Davisson, G., und Steinberg, E., NTA in Sequage Treatment, Vatten24, 348-359 (1968).

[16] Bringmann, G., und KüHN, R., Biologische Bestimmung des Begrenzungsfaktors der Trophierung, Ges. Ing. 84, H. 12 (1963).

[17] Bunch, R. L., und Extinger, B., Biodegradability of Potential Org. Substitutes for Phosphates, U. S. Department of the Interior, Fed. Wat. Poll. Control Admin. Ohio (1967).

[18] Chau, Y.K., und Fox, M.E., Gas-Chromatographic Method for the Determination of Nitrilotriacetic Acid in Lake Water, J. chromat. Sci. 9, 271-275 (1971).

[19] Chau, Y.K., und Shiomr, M.T., Complexing Properties of Nitrilotriacetic Acid in the Lake Environment, Water, Air and Soil Poll. 1, 149 (1972).

[20] Christre, A.E., Trisodium Nitrilotriacetate and Algae, Division of Research, Ontario Water Resources Comm. Paper Nr. 2023 (1969).

[21] Colwell, J.D., Phosphatsorption durch Eisen- und Aluminiumoxide, Aust. J. Appl. Sci. 10, 95-103 (1959).

[22] Davies, A.G., Iron Chelation and the Growth of Marine Phytoplancton, J. mar. biol. Ass. U. K. 50, 65-86 (1970).

[23] Deutsche Einheitsverfahven, G-2, 6. Auflage (Verlag Chemie, Weinheim 1971).

[24] Droop, M.R., On Cultivating Skeletonema Costatum: Some Problems. Vortr. Gesamtgeb. Botanik [N. F.] 7, 77-82 (1962).

[25] Dunlap, W. J., Cosby, R.L., McNabb, J.F., Bledsoe, E.E., und Scalf, M. R., Probable Impact of NTA on Ground Water, Ground Water 10, Nr. 1, 107-117 (1972).

[26] Durfie, J.R., Detergents: Nutrient Considerations and Total Assessment, Am. Soc. Limnol. Oceanogr. Spec. Symp. 7, 205-216 (1972).

[27] Duursma, E. K., und Sevenhursen, W., Note on Chelation and Solubility of Certain Metals in Sea Water at Different pH-Values, Netherlands J. Sea Res. 3, 1, 95-106 (1966).

[28] Eden, G. E., Culley, G.E., und Rootham, R.C., Effect of Temperature on the Removal of NTA (Nitrilotviacetic Acid) during Sewage Treatment, Water Res. 6, Nr. 8, 877-883 (1972).

[29] Eidg. Amt für Umweltschutz, Pressemitteilung: Stand der baulichen Abwasserveinigung in der Schweiz (am 1.Januar 1973).

[30] Eidg. Departement des Innern, Schreiben an die Kantonsregierungen vom 13. September 1971.

[31] Eisler, R., Gardner, G.R., Hennexey, R. J., Laroche, G., Walsh, D.F., und Yevich, P.P., Acute Toxicology of Sodium Nitrilotriacetic Acid (NTA) and NTA-Containing Detergents to Marine Organisms, Water Res. 6, 1009-1027 (1972).

[32] Enfors, S. J., und Molin, N., Anaerobic Degradation of Nitrilotriacetate (NTA) by Bacteria, Vatten 27, $162(1971)$.

[33] Epstein, S. S., NTA, Environment 12, Nr. 7 (1970). 
[34] Erickson, S. J., Maloney, T.E., und Gentile, J.H., Effect of Nitrilotriacetic Acid on the Growth and Metabolism of Estuarine Phytoplankton, J. Wat. Poll. Control Fed. 42, Nr. 8, 329-335 (1970).

[35] FogG, G.E., The Importance of Extracellular Products of Algae in Fresh Water, Verh. Int. Ver. Limnol. 12, 219-232 (1953).

[36] FogG, G.E., The Role of Algae in Organic Production in Aquatic Environments, Br. phycol. Bull. 3 (1963).

[37] Forsberg, C., und Lindqvist, G., Experimental Studies on Bacterial Degradation of NTA, Life Sci. 6, 1961-1962 (1967).

[38] Forsberg, C., Jinnerot, D., und Davidsson, L., The Influence of Synthetic Detergents on the Growth of Algae, Vatten 1, 2-16 (1967).

[39] Flannagan, J.F., Toxicity Evaluations of Trisodium Nitrilotriacetate to Selected Aquatic Invertebrates and Amphibians, Manuscript 17th FRB. Tech. Report, Fish. Res. Board Can. (1971).

[40] GÄCHTER, R., Phosphorhaushalt und planktische Primärproduktion im Vierwaldstättersee (Horwer Bucht), Schweiz. Z. Hydrol. 30, 1-66 (1968).

[41] GÄchter, R., Szabó, E., und MAREŠ, A., Die lohale Beeinflussung eines stehenden Gewässers durch eine punktförmige Abwasserbelastung; ein divekter Nachweis der Wachstumsbegrenzenden Wirkung des Phosphors im Vierwaldstättersee, Schweiz. Z. Hydrol. 33, 66-72 (1971).

[42] GÄсHтER, R., Zur Frage der Einleitung von geveinigtem Abwasser in Seen, Schweiz. Z. Hydrol. 33, 73-84 (1971).

[43] GerlofF, G.C., und Skoog, F., Availability of Iron and Manganese in Southern Wisconsin Lakes for the Growth of Microcystis aeruginosa, Ecology 38, 551-555 (1957).

[44] Gessner, F., Hydrobotanik II: Stoffhaushalt (VEB Deutscher Verlag der Wissenschaften, Berlin, DDR, 1959).

[45] Glooschenko, W.A., und Moore, J.E., The Effect of Citrate on Phytoplankton in Lake Ontario, in: Bioassay Techniques and Environmental Chemistry (1973).

[46] Goldberg, E.D., Iron Assimilation by Marine Diatoms, Biol. Bull. (Woods Hole) 102, 243-248 (1952).

[47] Goldman, CH. R., A Method of Studying Nutrient Limiting Factors in-situ in Water Columns Isolated by Polyethylene Film, Limnol. Oceanogr. 7, 99-101 (1962).

[48] Goldman, CH.R., The Role of Minor Nutrients in Limiting the Productivity of Aquatic Ecosystems, Nutrients and Eutrophication, Spec. Symp. 1 (1972).

[49] Goltermann, H.L., Chemical Analysis of Fresh Waters, IBP-Handbook Nr. 8 (1969).

[50] Grant, R.C., Government Report Scores NTA, Soapers Stop Use, Detergents and Specialties (Januar 1971).

[51] Gregor, CH. D., Solubilisation of Lead in Lake and Reservoir Sediments by NTA, Envir. Sci. Technol. 6, Nr. 3 (1972).

[52] Gudernatsch, H., Verhalien von NTA im Kläprozess und im Abrasser, GWF 111, H. 9 $(1970)$.

[53] Guseva, K. A., (1935, 1937, 1939,) zit. in Lund, J. W. G., Ecology of Freshwater Phytoplankton, Biol. Rev, 40, 231-293 (1965).

[54] Haberman, J.P., Polarographic Determination of Traces of Nitrilotriacetate in Water Samples Analyt. Chem. 43, Nr. 1 (1971).

[55] Hamilton, R.D., The Environmental Acceptability of NTA: Curvent Research and Areas of Concern, in: Likens, G.E., Nutrients and Eutrophication: The Limiting-Nutrient Controversy, Am. Soc. Limnol. Oceanogr. Spec. Symp. 1, 217-221 (1972).

[56] HaRvey, H. W., The Supply of Iron to Diatoms, J. Biol. Ass. U. K. 22, 205 (1937).

[57] Harvey, H.W., und Rodhe, W., The Chemistry and Fertility of Sea Waters (Cambridge University Press, London 1955).

[58] Hayward, J., Studies on the Growth of Phaeodactylum tricornutum, J. Mar. Biol. Ass. U. K. 48 und $49(1968,1969)$.

[59] HEAD, P.C., Observations on the Concentration of Iron in Sea Water with Particular Reference to Southhampton Water, J. Mar. Biol. Ass. U. K. 51, 891-903 (1971).

[60] Holm-Hansen, O., Gerloff, G.C., und Skoog, F., Cobalt as an Essential Element for BlueGreen Algae, Physiol. Plant. 7, 665-675 (1954). 
[61] Huber-Pestalozzi, G., Das Phytoplankton des Sïsswassers, in: Die Binnengerüsser 16, Teile 1-6 (Stuttgart 1972).

[62] Hubly, D.W., und CleAsby, J.L., Treatment of Waste Containing NTA in a Trickling Filter, in: Report on NTA (Ed. A.D. Little; Procter \& Gamble 1972).

[63] Hutchinson, G. E., A Treatise on Limnology, Kap. 11 und 15 (New York 1957).

[64] Janicke, W., Úber das biologische Abbauverhalten von Nitrilotriessigsaure, GWF 709,1181 (1968).

[65] Jancovic, M., und MaNn, H., Untersuchungen über die akute toxische Wirkung von NTA, Arch. FischWiss. 20, 178-181 (1969).

[66] Jellinek, H.H.G., und Sangal, S.P., Complexation of Metal Ions with Natural Polyelectrolytes (Removal and Recovery of Metal Ions from Polluted Waters), Water Res. 6, 305 (1972).

[67] Johnston, R., Sea Water, the Natural Medium of Phytoplankton, J. Mar. Biol. Ass. U. K. $43,427-456(1963)$.

[68] JoRdAn, R.A., und Bender, M.E., Stimulation of Phytoplankton Growth by Mixtures of Phosphate, Nitrate and Organic Chelators, Water Res. 7, 189-195 (1973).

[69] Jordan, R.A., und Bender, M.E., An in-situ Evaluation of Nutrient Effects in Lakes, EPA-R3-73-018 (1973).

[70] Kanazawa, T., und Kanazawa, K., Specific Inhibitory Effect of Copper on Cellular Division in Chlovella, Plant. Cell Physiol. 10, 495-502 (1969).

[71] Kliffmüller, R., Der Anstieg des Phosphatphosphors als Ausdruck fortschreitender Eutrophierung im Bodensee (Obersee), Int. Rev. ges. Hydrobiol. Hydrogr. 47, 118-122 (1962).

[72] KolthoFf, J.M., Untersuchungen über Alterung und Adsorption von zweiwertigen Ionen und Mitfällung mit ortho- $\mathrm{Fe}(\mathrm{OH})_{\mathbf{3}}$ in ammoniakalischem Medium, J. Phys. Chem. 43, 767-780 (1939).

[73] LeHN, H., Zur Trophie des Bodensee, Verh. Int. Ver. Limnol. 18, 467-474 (1972).

[74] Lengweiler, H., Buser, W., und Feitknecht, W., Die Ermittlung der Löslichkeit von Eisen (III)- hydroxiden mit ${ }^{\mathbf{5 9}} \mathrm{Fe}$, Helv. Chim. Acta 44, 796 (1961).

[75] LitTle, A.D., Report on NTA: Curvent Status of the Environmental and Human Safety Aspects of Nitrilotriacetic Acid (NTA) (Procter \& Gamble, April 1972).

[76] Longman, G.F., The Determination of Nitrilotriacetic Acid (NTA) in Sewage and Sewage Effluent, Water Res. 5, 1171-1175 (1971).

[77] Lund, J.W.G., The Ecology of the Freshwater Phytoplankton, Biol. Rev. 40, 231-293 (1965).

[78] Lund, J. W. G., Planctonic Algae and the Ecology of Lakes, Sci. Prog. Oxf. 55, 401-419 (1967),

[79] Lund, J. W.G., Preliminary Observations on the Use of Large Experimental Tubes in Lakes. Verh. Int. Ver. Limnol. 18, 71-77 (1972).

[80] McMahon, J.W., The Influence of Light and Acid on the Measurement of Ferrous Iron in Lake Water, Limnol. Oceanogr. 12, 437-442 (1967).

[81] McMahon, J.W., An Acid-Free Bathophenanthroline Method for Measuring Dissolved Ferrous Iron in Lake Water, Water Res. 3, 743-748 (1969).

[82] MefFert, M.-E., und Overbeck, J., Wachstum von Scenedesmus obliquus in Abhängigkeit von der Eisenversorgung, Planta (Berlin) 78, 39-48 (1968).

[83] Menzel, D.W., und Ryther, J.H., Nutrients Limiting the Production of Phytoplankton in the Sargasso Sea, with Special Reference to Iron, Deep-Sea Res. 7, 276-281 (1961).

[84] Menzel, D. W., Hulburt, E. M., und Ryther, J.H., The Effects of Enviching Sargasso Sea Water on the Production and Species Composition of the Phytoplankton, Deep-Sea Res. 10. 209-219 (1963).

[85] Michael, W.R., und Waxim, J.M., Metabolism of Nitrilotriacetic Acid (NTA), Toxicol. Appl. Pharmac. 18, 407-416 (1971).

[86] Mitcheld, L., und Anderson, C., Effect of Gibbevellic Acid in Reducing Fe Chlorosis of Soybeans, Crop. Sci. 6, 111-112 (1966).

[87] Mitscherlich, L., Das Wirkungsgesetz der Wachstumsfaktoren, Z. Pfl.Ernähr. Düng. Bodenk. [A] 1, 49-84 (1922).

[88] Morel, F., und Morgan, J., A Numerical Method for Computing Equilibria in Aqueous Chemical Systems, Envir. Sci. Technol. 6, 58-67 (1972).

[89] Moss, B., Studies on Gull Lake, Michigan, Freshwater Biol. 2, 309-320 (1972). 
[90] Müller, R., und Widemann, O., Die Bestimmung des Nitrations im Wasser, Vom Wass. $22,247-271$ (1955).

[91] Munawar, M., und Vollenweider, R., Effect of Nitrilotriacetic Acid on Natural Phytoplankton Populations of Lake Erie, Ontario and Hamilton Harbour, Canada Center for Inland Waters Burlington, Ontario.

[92] Murray, D., und Povoledo, D., Determination of Nitrilotriacetic Acid in Inland Waters by Gas Chromatography of the Trimethyl Ester, J. Fish. Res. Board Can. 28, 1043-1047 (1971).

[93] Nirsson, R., Removal of Metals by Chemical Treatment of Municipal Waste Water, Water Res. 5, 51-60 (1971).

[94] OHLE, W., Über organische Stoffe in Binnenseen, Verh. Int. Ver. Limnol. 6, 249-262 (1934).

[95] ОнLE, W., Organische Kolloide in ihver Wirkung auf den Stoffhaushalt der Gewässer, Naturwissenschaften 23, 480-484 (1935)

[96] Онце, W., Sulfat als «Katalysator» des limnischen Stoffkveislaufes, Vom Wass. 21 (1954).

[97] OECD, Rapport du groupe d'experts sur les détergents, NR/ENV/72.23 (1972).

[98] Pascher, A., Die Sïsswassevflora, H. 5 und 6 (Verlag Gustav Fischer, Jena 1914/15).

[99] Patton, J., und ReEDER, W., A New Indicator for the Titration of $\mathrm{Ca}^{2+}$ with EDTA, Anal. Chem. 28, 1026 (1956).

[100] Prede, H., und LeE, G.F., Degradation of Nitrilotriacetic Acid in Aerobic Systems, Envir. Sci. Technol. 2, 543-546 (1968).

[101] PLeisch, P., Die Herkunft eutrophievender Stoffe beim Pfäffiker- und Greifensee, Vjschr. naturf. Ges. Zürich 115/2, 129-237 (1970).

[102] Pollard, R.R., Aminoacids Chelating Agents in Detergents Applications, Soap Chem. Spec. 42, 9 (1966).

[103] Praxash, A., und Rashid, M.A., Influence of Humic Substances on the Growth of Marine Phytoplankton: Dinoflagellates, Limnol. Oceanogr. 13, 598 (1968).

[104] RABENHORST, L., Desmidiaceen, in Kryptogamenflora 13 (Akad. Verlagsgesellschaft Leipzig 1937).

[105] Raskina, E.E. (1963), zit. in Lund, J.W.G., Ecology of Freshwater Phytoplankton (vgl. [77]).

[106] RoDHe, W., Environmental Requirements of Fresh-Water Plankton Algae, Symb. bot. upsal. 10 (1), 149 (1948).

[107] Rudd, J.W.M., und Hamilton, R.D., Biodegradation of Trisodium Nitrilotriacetate in a Model Aerated Sewage Lagoon, J. Fish. Res. Board Canada 29, 1203-1208 (1972).

[108] Rudling, L., Determination of Nitrilotriacetic Acid, Water Res. 5, 831-838 (1971).

[109] Sakamoto, M., Chemical Factors Involved in the Control of Phytoplankton in the Experimental Lakes Area, Northwestern Ontario, J. Fish. Res. Board Canada 28, 203 (1971).

[110] SAUBERER, F., Empfehlungen für die Durchführung von Strahlungsmessungen an und in Gewässern, Mitt. int. Ver. Limnol. 11, 1-77 (1962).

[111] Schateperclaus, W., Fischkvankheiten (Akademie-Verlag, Berlin 1954).

[112] ScharpF, C.G., und Ramos, F. J., Influence of NTA on the Toxicity, Excretion and Distribution of Cadmium in Female Rats, Toxicol. Appl. Pharmac. (1971).

[113] SchegG, E., Produktion und Destruktion in der trophogenen Schicht, Schweiz. Z. Hydrol. 33, 425-532 (1971)

[114] SснміD, M., und АмвӥнL, H., Bestimmung geringster Mengen von Gesamtphosphor im Wasser von Binnenseen, Schweiz. Z. Hydrol. 27, 183-192 (1965).

[115] Schmid, M., Die Bestimmung kleiner Mengen von organischem Stickstoff im Wasser von Binnenseen, Schweiz. Z. Hydrol. 30, 244-266 (1968).

[116]. Schwarzenbach, G., und Flaschka, H., Die komplexometrische Titration (Enke-Verlag, Stuttgart 1955).

[117] Schweiz. Bundesrat, Verordnung über die Abbaubarkeit von Wasch-Spïl-und Reinigungsmitteln vom 19. Juni 1972.

[118] Schwörbel, J., Methoden der Hydrobiologie (Kosmos-Verlag, Stuttgart 1966).

119] Seth, P.N., Venkataraman, R., und Maheshwari, S.C., Studies on the Growth and Flowering of a Short-Day Plant, Wolffia microscopica, Planta (Berlin) 90, 349-359 (1970).

[120] Shapiro, J., Iron Available to Algae, in: Chemical Environment in the Aquatic Habitat, IBP. Symp. Amsterdam, Okt. 1966, S. 219-228 (1967). 
[121] Shapiro, J., The Relation of Humic Color to Iron in Natural Waters, Verh. Int. Ver. Limnol. $16,477-484(1966)$.

[122] Shumate, K.S., Thompson, J.E., Brookhart, J.D., und Dean, C.L., NTA-Removal by Activated Sludge, Field Study, J. Water Poll. Control Fed. 42, 631-640 (1970).

[123] Singer, PH.C., The Effects of NTA on Metal Ion Release from Eutrophic Lake Sediments, University of Notre-Dame, Indiana.

[124] Singer, Ph.C., und Stumm, W., The Solubility of Ferrous Iron in Carbonalebearing Waters, JAWWA 62, 198-202 (1970).

[125] Skuja, H., Taxonomie des Phytoplanktons einiger Seen in Uppland, Schweden, Symb. bot. upsal. $g$ (3), 399 (1948).

[126] Smith, M. J., und Manahan, S.E., Studies of the Effect of Cupric Ion Activity on Algal Growth. The Use of the Cupric Ion Selective Electrode in Natural Aquatic Systems, Paper presented at the 162nd National Meeting, Am. Chem. Soc. 17 (1971).

127] Sprague, J.B., Chelating Agent NTA Protects Fish from Copper and Zinc, Nature 220, 1345 (1968).

[128] Stadelmann, P., Stickstoffkreislauf und Primärproduktion im mesotrophen Vievwaldstättersee (Hower Bucht) und im eutrophen Rotsee, mit besondever Berïcksichtigung des Nitrats als limitierenden Faktors, Schweiz. Z. Hydrol. 33, 1-65 (1971).

[129] Steemann-Nielsen, E., und Wium-Andersen, S., Copper Ions as Poison in the Sea and in Freshwater, Mar. Biol. 6, 93-97 (1970).

[130] Steemann-Nielsen, E., The Use of Radioactive Carbon ${ }^{\mathbf{1 4}} \mathrm{C}$ for Measuring of Organio Production in the Sea, J. Cons. 18, 117 (1952).

[131] StengeI, E., Zustandsänderungen verschiedener Eisenverbindungen in Nährlösungen für Algen, Arch. Hydrobiol. Suppl. 38/1 und 2, 151-169 (1970).

[132] Strickland, J.D.H., und Terhune, L.D.B., The Study of in-situ Marine Photosynthesis Using a Large Plastic Bag, Limnol. Oceanogr. 6, 93-96 (1961).

[133] Strickland, J.D.H., und Parson, T.R., A Practical Handbook of Seawater Analysis, Bull. Fish. Res. Board Canada 767, (1968).

[134] Sтuмm, W., Die Rolle der Komplexbildung in natürlichen Gewässern und allfälige Beziehungen zur Eutrophierung, Gewässerschutz-Wasser-Abwasser, H. 8, 57-87 (1972).

[135] Stumm, W., und LEE, G.F., The Chemistry of Aqueons Iron, Schwciz. Z. Hydrol. 22, 295 (1960).

[136] Stumm, W., und Morgan, J.J., Aquatic Chemistry, Kap. 6 (Wiley-Interscience, New York 1970).

[137] Swisher, R.D., Crutchfield, M.M., und Caldwell, D.W., Biodegradation of Nitvilotriacetate in Activated Sludge, Envir. Sci. Technol. 1 820-827, (1967).

138] Tamrya, H., et. al. in: Burlew, J. S., Algal Cultuve Carnegie Inst. Publ. 600, 204-232, (1953).

139] Tarantelli, T., Adsorption und Mitfällung zweiwerliger Kationen mit Eisenhydroxid, Atti. Accad. Sci. Torino Classe Sci. Fis. Mat. Nat. 92, 576 (1957).

[140] Thom, N.S., Nitvilotriacetic Acid: A Litevatuve Survey, Water Res. 5, $391-399$ (1971).

[141] Thomas, E.A., Empirische und experimentelle Untersuchungen zur Kenntnis der Minimumstoffe in 46 Seen der Schweiz und angrenzender Gebiete, Monatsbull. Schweiz. Ver. Gas- und Wasserfachmänner 2, 3 (1953).

[142] Thompson, J.E., und DuthiE, J.R., The Biodegradabitity and Treatability of NTA, J. Wat. Poll. Control Fed. 40, 306-319 (1968).

[143] Uehlinger, V., Etude statistique des méthodes de dénombrement planctonique, Thèse Nr. 1363, Université de Genève (1964).

[144] UtermöhL, H., Zur Vevollkommnung der quantitativen Phytoplankton-Methodik, Mitt. Int. Ver. Limnol. 2, 1-38 (1958).

[145] VollenweIder, R.A., Eutrophication of Water by Phosphorus, Riv. ital. Sost. grasse 45, 99-107 (1968).

[146] WaLteR, G., Ökologische Untersuchungen über die Wirkung Fe(II)-haltiger Braunkohlegruben-Abwässer auf Vorflutorganismen, Wiss. Z. Karl-Marx-Univ. Leipzig 15, Math.-Nat. Reihe 1, 247-269 (1966).

[147] Warken, C.B., und Malec, E. J., Biodegradation of Nitvilotriacetic Acid and Related Imino and Amino Acids in River Water, Science 176, 277-279 (1972). 
[148] Weinstein, L.H., Merss, A.N., und UhLer, R.L., Growth-Promoting Effects of Ethylenediamine Tetra-Acetic Acid, Nature 178, 1188 (1956).

[149] Welz, B., und Wiedeking, E., Einsatz der flammenlosen Atomabsorption zur Bestimmung von Spurenmetallen in Wasser und Abwasser, Z. Anal. Chem. 264, 110-118 (1973).

[150] Whitton, B. A., Studies on the Growth of Riverain Cladophora in Culture, Arch. Microbiol. 58, 21-29 (1967).

[151] WiEsSNer, W., Inorganic Micronutrients, in: Physiology and Biochemistry of Algae (Ed. R. A. Lewin, New York 1962).

[152] Winkler, L.W., Die Bestimmung des im Wasser gelösten Sauerstoffs und die Löslichkeit des Sanerstoffs im Wasser, Chem. Ber. 21, 2843-2855 (1888).

[153] Williams, P.M., The Association of Copper with Dissolved Organic Matter in Seawater, Limnol. Oceanogr. 14, 156-158 (1969).

[154] Yentsch, C.S., Primary Production, in: Oceanography and Marine Biology, S. 157-176 (Ed. H. Barnes, London 1963).

Adresse des Autors:

Dr. rer. nat. H. R. Bürgi, EAWAG, Uberlandstrasse 133, CH-8600 Dübendorf. 